\title{
ENERGY CAPTURE IMPROVEMENT OF A SOLAR PV SYSTEM USING A MULTILEVEL INVERTER
}

\author{
A Thesis \\ Presented to \\ The Graduate Faculty of The University of Akron \\ In Partial Fulfillment \\ of the Requirements for the Degree \\ Master of Science
}

Nayeem Mahmud

August, 2011 


\title{
ENERGY CAPTURE IMPROVEMENT OF A SOLAR PV SYSTEM USING A MULTILEVEL INVERTER
}

\author{
Nayeem Mahmud
}

Thesis

Approved:

Advisor

Dr. Yilmaz Sozer

Co-Advisor

Dr. Iqbal Husain

Committee Member

Dr. Tom Hartley
Accepted:

Department Chair

Dr. Jose A. De Abreu-Garcia

Dean of the College

Dr. George K. Haritos

Dean of the Graduate School

Dr. George R. Newkome 


\begin{abstract}
The challenges with solar energy extraction are addressed in the proposed approach through development and demonstration of multilevel inverter architecture and the associated control algorithms. The proposed multilevel inverter topology along with the control algorithms for solar photovoltaic (PV) systems increase the overall energy capture from the sun. Multilevel inverters are mostly used in medium and high power applications because of their robustness and reliability. It offers higher efficiency and operates at low frequency. Numerous multilevel inverter topologies have been introduced over the years. In this proposed approach, cascaded multilevel inverter topology has been used. The proposed system suggests how to achieve maximum power point tracking (MPPT) from individual panels rather than from a centralized structure. A centralized controller coordinates the power flow from the individual cells which then feeds into a multilevel inverter to achieve overall MPPT and to deliver compatible AC energy to the utility system. The resulting output AC voltage of the inverter swings with nine levels and forms a staircase waveform which is nearly sinusoidal. To interface the inverter with the grid, a zero crossing detector is used.
\end{abstract}

A 9-level inverter with a total capacity of 800 watts was successfully implemented and tested. A new current control algorithm was developed for the proposed multilevel inverter. The simulation and experimental results show that the current drawn 
from the individual PV arrays using the developed algorithm are very close to the commanded inputs so that the arrays can operate at their MPPT points. The overall system minimizes the shading effect and improves the per panel efficiency as well as increase the overall energy harvest.

Keywords: Renewable Energy, Solar PV, Multilevel Inverter 


\section{ACKNOWLEDGEMENTS}

I wish to express my deepest gratitude to my advisor Dr. Yilmaz Sozer for his valuable supervision, encouragement and support throughout the whole work. I also wish to express my sincere appreciation and gratitude to my co-advisor Dr. Iqbal Husain for his support and valuable suggestions during the course of this research. I am grateful to my advisory committee members for their support to make this research a success and most of all for giving me the chance to work with them.

I would like to express my gratitude to all my colleagues of Power Electronics lab for their friendship, encouragement and support to complete this study. In Particular, I would like to thank Gregory Pasquesoone and Rajib Mikail for their support, assistance and encouragement during the whole course of this research.

In special, I would like to thank Mr. Erik Rinaldo and Mr. Gregory Lewis for their help during the implementation of the experimental setup.

I would also like to thank my parents, my brothers and my fiancée for their love, encouragement and continuous support over the years. 


\section{TABLE OF CONTENTS}

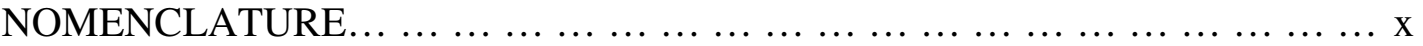

\section{CHAPTER}

I. INTRODUCTION $\ldots \ldots \ldots \ldots \ldots \ldots \ldots \ldots \ldots \ldots \ldots \ldots \ldots \ldots \ldots \ldots \ldots$

$1.1 \quad$ Renewable Energy Systems $\ldots \ldots \ldots \ldots \ldots \ldots \ldots \ldots \ldots \ldots \ldots$

$1.2 \quad$ Research Motivation $\ldots \ldots \ldots \ldots \ldots \ldots \ldots \ldots \ldots \ldots \ldots$

$1.3 \quad$ Research Objectives $\ldots \ldots \ldots \ldots \ldots \ldots \ldots \ldots \ldots \ldots \ldots$

1.4 Thesis Organization $\ldots \ldots \ldots \ldots \ldots \ldots \ldots \ldots \ldots \ldots \ldots$

II. UTILITY INTERACTIVE SOLAR PV SYSTEMS ... ... . . . . . . . . 5

$2.0 \quad$ Introduction $\ldots \ldots \ldots \ldots \ldots \ldots \ldots \ldots$

2.1 Solar Photovoltaic System $\ldots \ldots \ldots \ldots \ldots \ldots \ldots \ldots \ldots \ldots$

2.2 Array Configuration $\ldots \ldots \ldots \ldots \ldots \ldots \ldots \ldots \ldots \ldots \ldots \ldots 7$

$2.3 \quad$ Basic Inverter Topology $\ldots \ldots \ldots \ldots \ldots \ldots \ldots \ldots \ldots \ldots \ldots \ldots$

$2.4 \quad$ Multilevel Inverters $\quad \ldots \ldots \ldots \ldots \ldots \ldots \ldots \ldots$

2.4.1 Diode-Camped Inverter... $\ldots \ldots \ldots \ldots \ldots \ldots \ldots \ldots \ldots$

2.4.2 Capacitor-Clamped Inverter $\ldots \ldots \ldots \ldots \ldots \ldots \ldots \ldots \ldots 11$

2.5 Grid Interactive Solar PV Array Configurations $\ldots \ldots \ldots \ldots \ldots$

$2.6 \quad$ Maximum Power Extraction $\ldots \ldots \ldots \ldots \ldots \ldots \ldots \ldots$ 
2.7 Panel Mismatches in Solar PV Systems ... . . . . . . . . . . . . 16

$2.8 \quad$ Module Integrated Converters $\ldots \ldots \ldots \ldots \ldots \ldots \ldots \ldots \ldots \ldots$

$2.9 \quad$ Proposed Multilevel Inverter Topology $\ldots \ldots \ldots \ldots \ldots \ldots \ldots$

2.10 Battery Charging Operation of the Multilevel Inverter $\ldots \ldots \ldots \ldots 23$

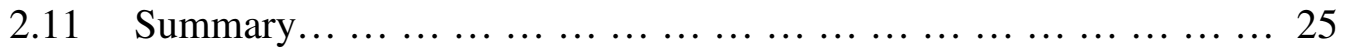

III. MULTILEVEL INVERTER CONTROL ALGORITHM ... ... . . . . . . . 26

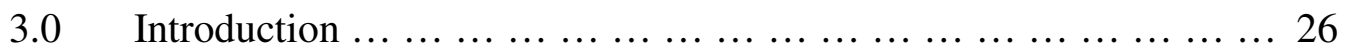

$3.1 \quad$ Switching Angles $(\alpha ' s) \ldots \ldots \ldots \ldots \ldots \ldots \ldots \ldots \ldots \ldots \ldots \ldots \ldots$

$3.2 \quad \operatorname{Alpha}(\alpha) \operatorname{Scheduler} \ldots \ldots \ldots \ldots \ldots \ldots \ldots \ldots \ldots$

Zero Crossing Detection $\ldots \ldots \ldots \ldots \ldots \ldots \ldots \ldots \ldots$

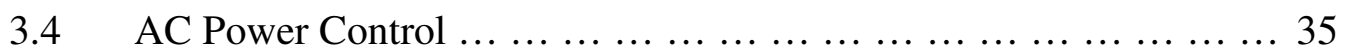

$3.5 \quad$ Summary $\ldots \ldots \ldots \ldots \ldots \ldots \ldots \ldots$

IV. $\quad$ SIMULATION RESULTS $\ldots \ldots \ldots \ldots \ldots \ldots \ldots \ldots \ldots \ldots$

$4.0 \quad$ Introduction $\ldots \ldots \ldots \ldots \ldots \ldots \ldots \ldots \ldots \ldots$

$4.1 \quad$ Solar PV Model Development $\ldots \ldots \ldots \ldots \ldots \ldots \ldots \ldots$

4.2 Cascaded Multilevel Inverter with Fixed Switching Angles ... . . . . 41

4.3 Cascaded Multilevel Inverter with Grid Connection ... . . . . . . . . 44

4.4 Multilevel Inverter with Control Algorithm ... .............. 46

$4.5 \quad$ Summary $\ldots \ldots \ldots \ldots \ldots \ldots \ldots \ldots$

V. PROTOTYPE DESIGN AND IMPLEMENTATION $\ldots \ldots \ldots \ldots \ldots \ldots \ldots$

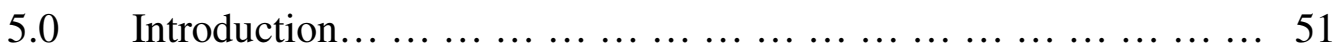

$5.1 \quad$ Hardware Implementation $\ldots \ldots \ldots \ldots \ldots \ldots \ldots \ldots \ldots \ldots \ldots \ldots$ 
5.1 .1 MOSFET Driver Circuit...................... 52

$5.1 .2 \quad$ H-Bridge module... $\ldots \ldots \ldots \ldots$
$\ldots$

5.1.3 Fault Detection and Protection Circuitry............ 53

5.1 .4 Current Sensor Circuit $\ldots \ldots \ldots \ldots \ldots \ldots \ldots \ldots \ldots$

5.1 .5 Grid Voltage Sensing Circuit ... . . . . . . . . . . . . . . 54

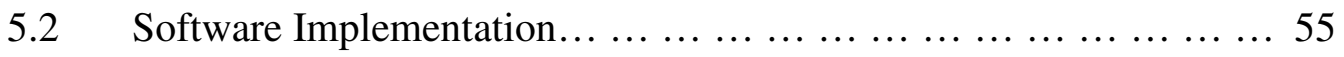

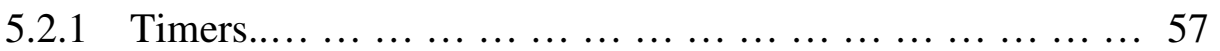

5.2 .2
PWM Generator $\ldots \ldots \ldots \ldots \ldots$$\ldots \ldots \ldots \ldots$

5.2.3 Analog to Digital Converter....................61 61

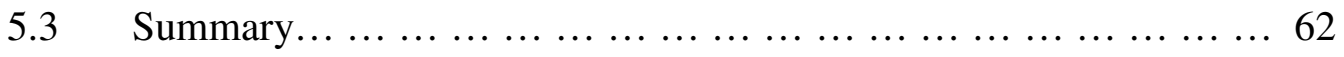

VI. EXPERIMENTAL RESULTS ... . . . . . . . . . . . . . . . . . . . . . . . . . . 63

$6.0 \quad$ Introduction $\ldots \ldots \ldots \ldots \ldots \ldots \ldots$

$6.1 \quad$ Experimental Setup... $\ldots \ldots \ldots \ldots \ldots \ldots \ldots \ldots \ldots \ldots \ldots \ldots$

$6.2 \quad$ Inverter Output Voltage Analysis $\ldots \ldots \ldots \ldots \ldots \ldots \ldots$

$6.3 \quad$ Switching Waveforms Analysis.................... 67

6.4 Standalone Multilevel Inverter with Resistive Load............. 68

$6.5 \quad$ Multilevel Inverter with Grid interfacing................ 71

6.6 Battery Charging Operation of the Multilevel Inverter.......... 75

$6.7 \quad$ Inverter Efficiency Analysis... . . . . . . . . . . . . . . . 80

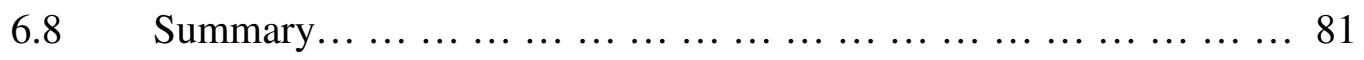

VII. CONCLUSIONS AND FUTURE WORKS $\ldots \ldots \ldots \ldots \ldots \ldots \ldots \ldots \ldots$

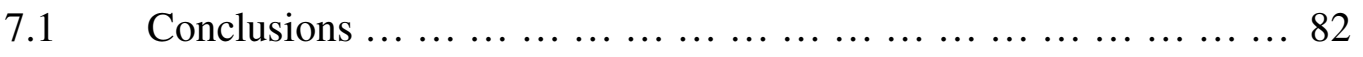




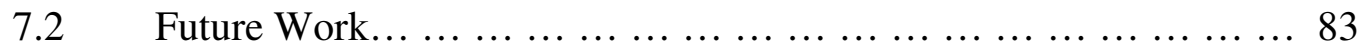

7.2.1 Diode-Clamped Multilevel Inverter... .................. 83

7.2.2 System Design $\ldots \ldots \ldots \ldots \ldots \ldots \ldots \ldots \ldots \ldots \ldots \ldots \ldots \ldots$

REFERENCES $\ldots \ldots \ldots \ldots \ldots \ldots \ldots$

APPENDICES $\ldots \ldots \ldots \ldots \ldots \ldots \ldots \ldots \ldots \ldots \ldots$

APPENDIX A. SIMULINK DIAGRAMS $\ldots \ldots \ldots \ldots \ldots \ldots \ldots \ldots \ldots \ldots \ldots$

APPENDIX B. SCHEMATICS \& PCB LAYOUTS..................... . . 93 


\section{NOMENCLATURE}

\begin{tabular}{|c|c|c|}
\hline Symbol/Acronym & Unit & Description \\
\hline Iph & A & Photo-generated current \\
\hline$I_{0}$ & A & Diode saturation current \\
\hline$q$ & $\mathrm{C}$ & Electron charge \\
\hline$K$ & $\mathrm{~m}^{2} \mathrm{kgs}^{-2} \mathrm{~K}^{-1}$ & Boltzmann constant \\
\hline$T$ & ${ }^{\circ} \mathrm{C}$ & Absolute temperature \\
\hline Voc & $\mathrm{V}$ & Open tircuit voltage \\
\hline$V_{O P}$ & $\mathrm{~V}$ & Operating voltage \\
\hline $\mathrm{P}_{\max }$ & Watt & Maximum power \\
\hline $\mathrm{n}$ & - & No. of inverter modules \\
\hline Varray_rms & $\mathrm{V}$ & RMS of the array voltage \\
\hline$I_{\text {array_rms }}$ & A & RMS of the array current \\
\hline$I_{\text {array }}(n)$ & A & Array current at any instant \\
\hline$V_{\text {array }}(n)$ & $\mathrm{V}$ & Array voltage at any instant \\
\hline $\mathrm{P}(\mathrm{n})$ & Watt & Panel power at any instant \\
\hline$P(n-1)$ & Watt & Panel power of previous instant \\
\hline$I_{d c_{-} C M D}$ & A & Current command \\
\hline$\Delta \mathrm{i}$ & A & Current increment \\
\hline
\end{tabular}




\begin{tabular}{|c|c|c|}
\hline$\lambda$ & $\mathrm{kW} / \mathrm{m}^{2}$ & Solar irradiation factor \\
\hline$I_{S T R I N G}$ & A & String current \\
\hline$V_{\text {grid }}$ & $\mathrm{V}$ & Grid voltage \\
\hline$i_{\text {grid }}$ & A & Grid current \\
\hline Power $_{\text {out }}$ & Watt & Grid power \\
\hline Power $_{\text {in }}$ & Watt & Input power from the grid \\
\hline$D_{x}$ & $\%$ & $\begin{array}{l}\text { Percentage of the current drawn } \\
\text { by the individual solar panels }\end{array}$ \\
\hline$\alpha$ & Radian & Switching angle \\
\hline$I_{d c_{-} C M D_{-} P U}$ & A & Per unit command current \\
\hline$I_{C_{-} \alpha \_e s t} P U$ & A & Estimated Per Unit currents \\
\hline$E(n)$ & A & $\begin{array}{l}\text { Error for the i-th switching } \\
\text { Angle combination }\end{array}$ \\
\hline$E_{T}$ & A & Total error \\
\hline $\mathrm{V}_{\text {old }}$ & $\mathrm{V}$ & Grid voltage at previous instant \\
\hline $\mathrm{V}_{\text {inv }}$ & $\mathrm{V}$ & Inverter output voltage \\
\hline $\mathrm{R}_{\mathrm{s}}$ & $\Omega$ & Series resistance \\
\hline $\mathrm{R}_{\mathrm{sh}}$ & $\Omega$ & Shunt resistance \\
\hline$\Delta$ & Radian & Power angle \\
\hline
\end{tabular}




\section{CHAPTER I}

\section{INTRODUCTION}

\subsection{Renewable Energy Systems}

Electricity is the most commonly used type of energy on which modern civilization is highly dependent on. However, the conventional generating systems, especially the thermo-electric power plants that use radioactive materials or fossil fuels have a significant environmental impact causing widespread pollution. Additionally, the cost of fossil fuel keeps increasing since the fossil fuel reserves are limited. In this circumstance, alternative energy sources continue to gain in popularity beyond the reasons of reducing environmental pollution. The new technological developments in renewable energy systems make them commercially viable alternatives.

Renewable energy systems typically do not have a constant and stable source of energy. In solar photovoltaic (PV) systems, sun irradiance might change quite a lot during the day. A stable grid interface is desired to filter the fluctuation in the renewable energy source to provide reliable power to the user. As such, most of the solar PV systems interface to the grid [1]-[4]. Therefore, a stable grid interface is required to feed the grid without any fluctuation. Solar PV cells provide DC voltage. The DC electric energy is converted into AC electric energy by using an inverter. The control objective on the DC side is to capture maximum energy and deliver it to the utility grid. The energy 
captured by the system drives the system payback. Increasing the energy capture can have a substantial positive impact [5]-[7]; a more productive system is able to pay for itself more quickly.

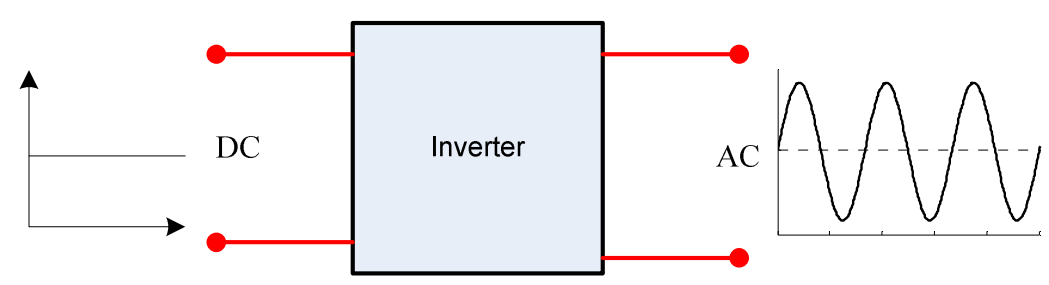

Figure 1.1: General inverter operation.

The device that converts the direct current (DC) into the alternating current (AC) is called the inverter. Figure 1.1 shows the general inverter functionality. There are several inverter topologies for renewable energy systems proposed in the literature. Many different inverter circuit topologies are possible. Similarly, there are also numerous techniques available for the control of these inverters.

Pulse Width Modulated (PWM) inverters are considered as the state-of-the-art technology for DC to AC power conversion. Inverters can be operated in two or more levels of DC voltages depending on the circuit topology. Due to the numerous advantages over conventional two level inverters, multilevel inverters became very popular for the renewable energy systems in recent years. It is possible to run the power devices at lower frequencies using multilevel inverter topologies; the lower frequency operation yields better power conversion efficiency. 


\subsection{Research Motivation}

The research motivation for this thesis comes from the necessity of individual maximum power point tracking (MPPT) for the solar PV panels, which is lacking in the available solar PV systems. The available PV systems employ a centralized structure for maximum power point tracking. The centralized control structure of MPPT tracks the maximum power point for the overall system instead of individual solar panels. Therefore, it does not resolve the problem associated with partial shading, which causes the poor performance of the overall solar PV system. This is the motivation to build a solar PV inverter system which is capable of tracking individual maximum power point of the solar panels and ensures the maximum capture of energy on DC side.

\subsection{Research Objectives}

In this thesis, a cascaded multilevel inverter topology for solar PV systems along with an algorithm for each inverter cell to achieve individual panel MPPT is presented. The developed system would also be applicable to battery charging stations.

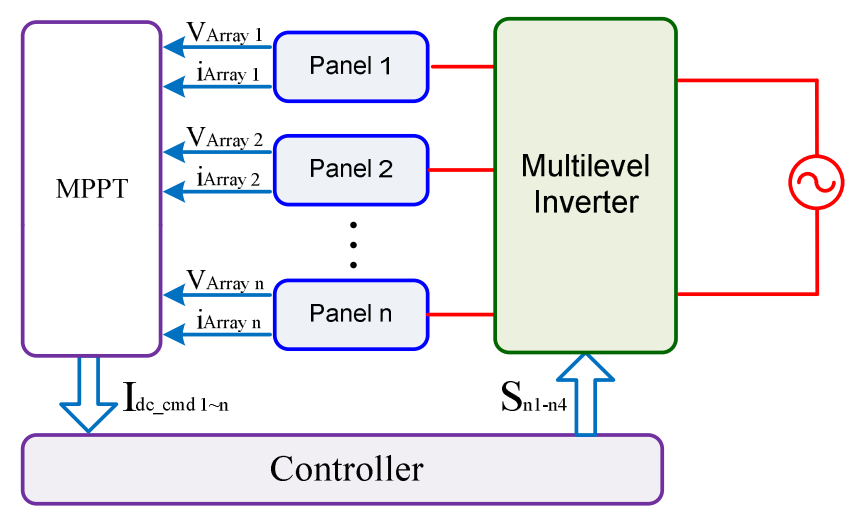

Figure 1.2: An overview of the overall system. 
The main objectives of this thesis are to study, design, simulate and implement a cascaded multilevel inverter using state of the art components. And to develop an algorithm which can perform individual maximum power point tracking for the solar panels and maximize the energy capture on the DC side and avoid the shading effect substantially. Finally, the objective is to test this algorithm on the developed multilevel inverter for both solar panels and battery operation. Figure 1.2 shows the block diagram of the proposed system.

\subsection{Thesis Organization}

A brief overview of the subsequent chapters is given in this section. In Chapter 2, different array configurations, maximum power point tracking algorithms and their necessity in solar PV systems, different multilevel inverter topologies along with the proposed topology are discussed. In Chapter 3, the proposed multilevel control algorithm is presented. Chapter 4 presents the simulation results of the proposed algorithm. In Chapter 5, hardware and software implementations of the proposed system are presented. Chapter 6 consists of the performance analysis and experimental results, which validate the developed control algorithm. Finally, conclusions and future work are presented in Chapter 7.

The MATLAB/Simulink software, schematics, PCB layouts of the prototype and the digital signal processor (DSP) programming code are provided in the Appendix. 


\section{CHAPTER II}

\section{UTILITY INTERACTIVE SOLAR PV SYSTEMS}

\subsection{Introduction}

The challenges with power extraction from the solar PV systems are addressed in this chapter. Different array configurations, inverter topologies and control algorithms are also discussed. A multilevel inverter system is proposed for the capture of maximum energy from individual panels.

\subsection{Solar Photovoltaic System}

Photovoltaic energy conversion in solar cells has two essential steps. First one is the absorption of light which generates an electron-hole pair. The electron and hole are separated by the structure of the device. The electrons go to the negative terminal and the holes go to the positive terminal. The electric potential is generated based on the separation of the holes and the electrons.

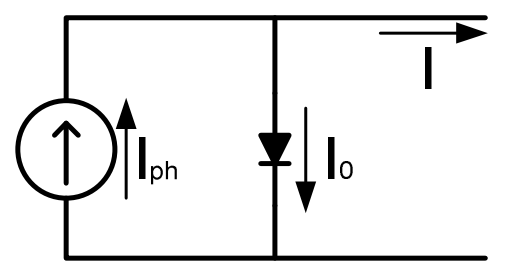

Figure 2.1: The equivalent circuit of an ideal solar cell. 
A typical solar cell can be represented by a current source connected with a diode in parallel. Figure 2.1 shows the equivalent circuit of an ideal solar cell. The CurrentVoltage (I-V) characteristic can be described by the Shockley solar cell equation given as

$$
I=I p h-I_{0}\left(e^{\frac{q V}{K T}}-1\right)
$$

where $q$ is the electron charge, $V$ is the voltage at the terminal, $K$ is the Boltzmann constant, $T$ is the absolute temperature, $I_{0}$ is the diode saturation current and $I p h$ is the photo-generated current. The I-V characteristic of an ideal solar cell is shown in Figure 2.2. In the ideal case, the short circuit current $I_{s c}$ is equal to the photo-generated current $I p h$, and the open circuit voltage $V o c$ is given by

$$
V o c=\left(\frac{K T}{q}\right) \ln \left(1+\frac{I p h}{I_{0}}\right)
$$

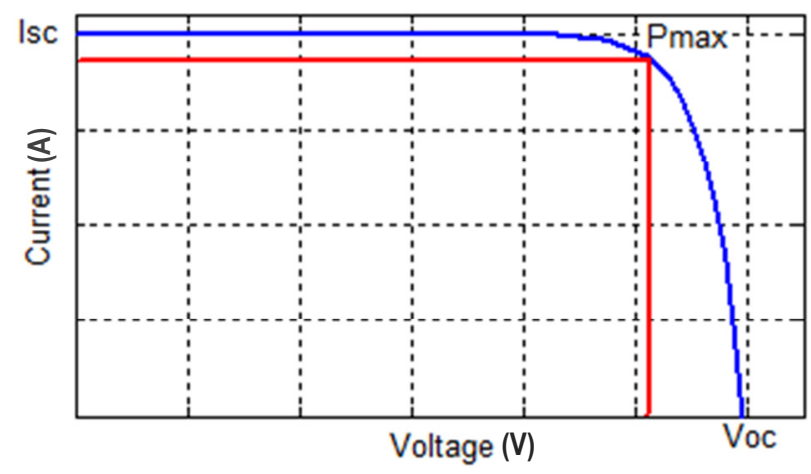

Figure 2.2: The current-voltage (I-V) curve of an ideal solar cell.

The power produced by the cell is shown in Figure 2.3, where $\mathrm{P}_{\max }$ is the maximum power produced by the solar cell. 


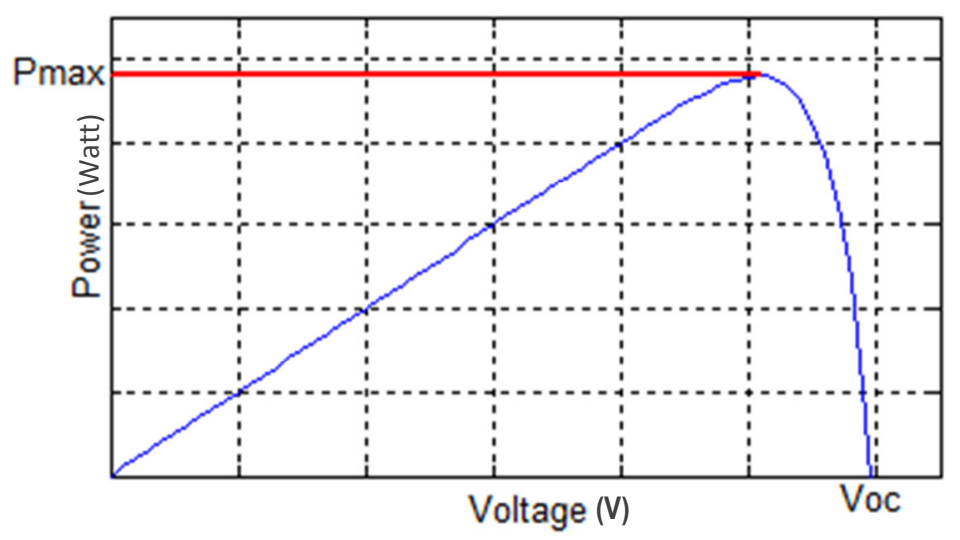

Figure 2.3: Power-voltage curve of an ideal solar cell.

\subsection{Array Configuration}

Solar photovoltaic arrays are configured either in parallel, series or the combination of series and parallel to set the desired terminal voltage and current. In the case of series string configuration, a higher voltage level can be achieved but the current ratings are limited by the individual panel rating. On the other hand, higher current ratings can be achieved for the parallel configuration, but individual panel voltages limit the total voltage output. Therefore, in most cases, a series-parallel configuration is used, where both voltage and current level can be increased and a desired power level can be achieved. Figure 2.4 shows the series connection and the series-parallel connection of solar PV array configurations. 


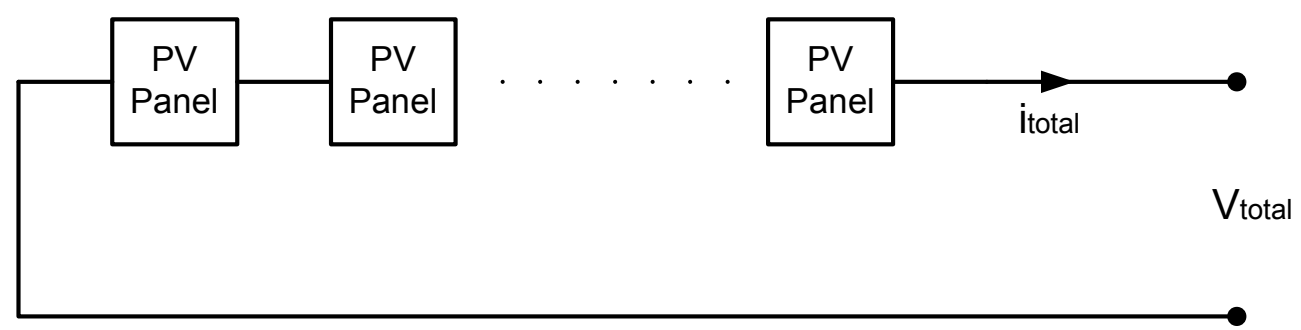

(a)

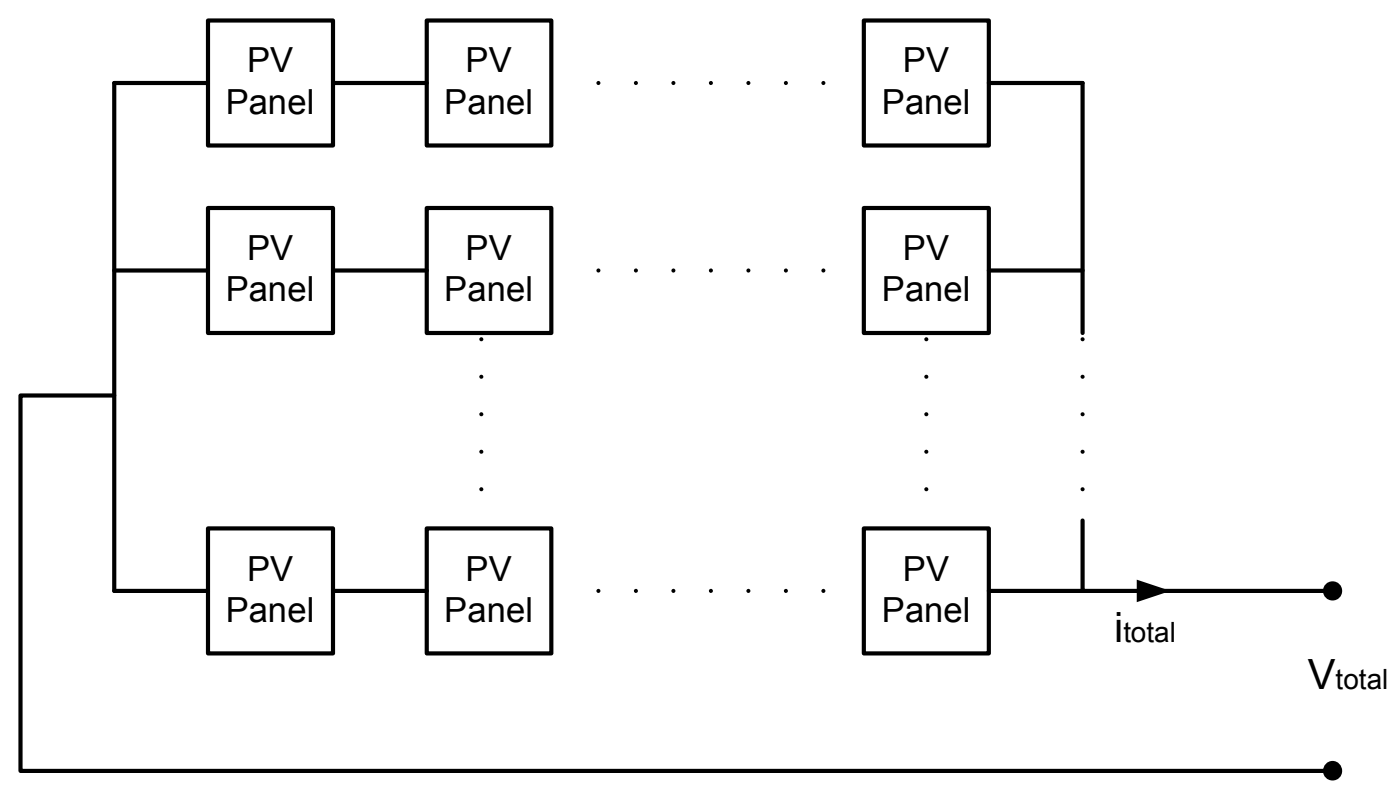

(b)

Figure 2.4: (a) Series string and (b) Series/Parallel array configurations.

\subsection{Basic Inverter Topology}

The main objective of an inverter is to produce AC output power from the DC input power. The inverter has power devices and associated controllers. Figure 2.5 shows the circuit topology of a single phase, two-level power inverter and its AC output. 


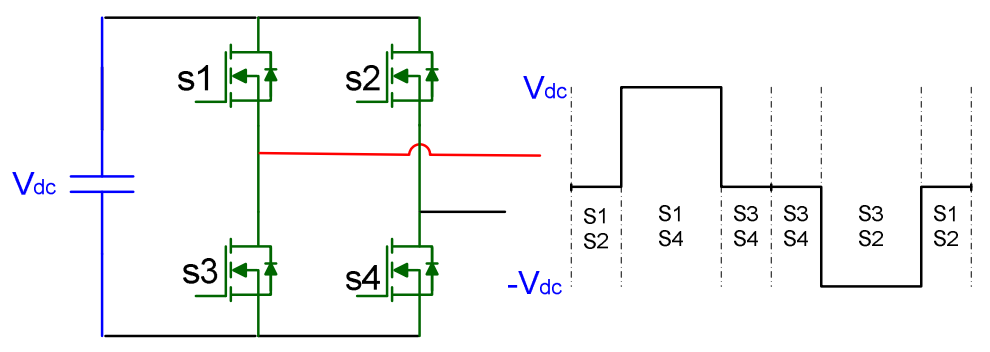

Figure 2.5: Basic inverter topology and its output.

The output is produced by controlling the four switches for the single phase inverter. Switches $\mathrm{S} 1$ and $\mathrm{S} 4$ are turned $\mathrm{ON}$ to obtain $+\mathrm{V}_{\mathrm{dc}}$, whereas $-\mathrm{V}_{\mathrm{dc}}$ can be obtained by turning ON switches S2 and S3. When (S1 and S2) or (S3 and S4) are ON, the output voltage is 0 . The frequency of the resulting output voltage can be controlled by controlling the duration of the ON time of the switches.

\subsection{Multilevel Inverters}

The multilevel inverter topologies have become popular as a very important alternative in the area of high-power medium-voltage applications. In recent years, numerous industrial applications have been requiring the higher power equipments. Multilevel inverters have been introduced as an alternative solution for high power and medium voltage levels [8]-[12].

The multilevel inverter includes an array of power semiconductor switches with several lower DC voltage sources. The commutation of the power switches allows the addition of the lower level DC voltage sources to generate the high voltage at the output, 
where the rating of the DC voltage sources determines the rating of the power semiconductor switches.

The multilevel inverters have a good number of advantages over conventional two-level converters, where high frequency PWM switching is used. The major advantages are good quality of the stepped waveforms (lower dv/dt), smaller commonmode voltage, and low distortion in the input current [11]. The multilevel inverters can also be operated at both fundamental switching frequency and high switching frequency PWM, which assures lower switching loss and higher efficiency. Although multilevel inverter requires a great number of semiconductor switches and each switch requires an appropriate gate driver circuit, switches with lower voltage ratings can be used to minimize the expense.

Due to several advantages over high power inverter, numerous multilevel inverter topologies have been introduced over the years. However, three different structures for the multilevel inverter have been found in literature, which are more popular in recent days. They are: diode-clamped (neutral-clamped) [12], capacitor-clamped (flying capacitors) [8], [13]-[14] and cascaded multi-cell with separate dc sources [8], [24]-[26]. In addition, several modulation and control techniques have been developed for the multilevel inverters on this occasion.

\subsubsection{Diode-Camped Inverter}

Diode-clamped topology is proposed by Nabae et al [12]. Figure 2.6 shows a three level diode-camped inverter, where the DC bus voltage is divided into three levels by two bulk capacitors connected in series. The output voltage has three states: $\frac{V d c}{2}, 0$, 
$-\frac{V d c}{2}$. The diodes D1 and D1' provide a path for the currents at the voltage increments. Diode-clamped inverters are mostly limited to the original three-level structure due to the capacitor voltage balancing issues.

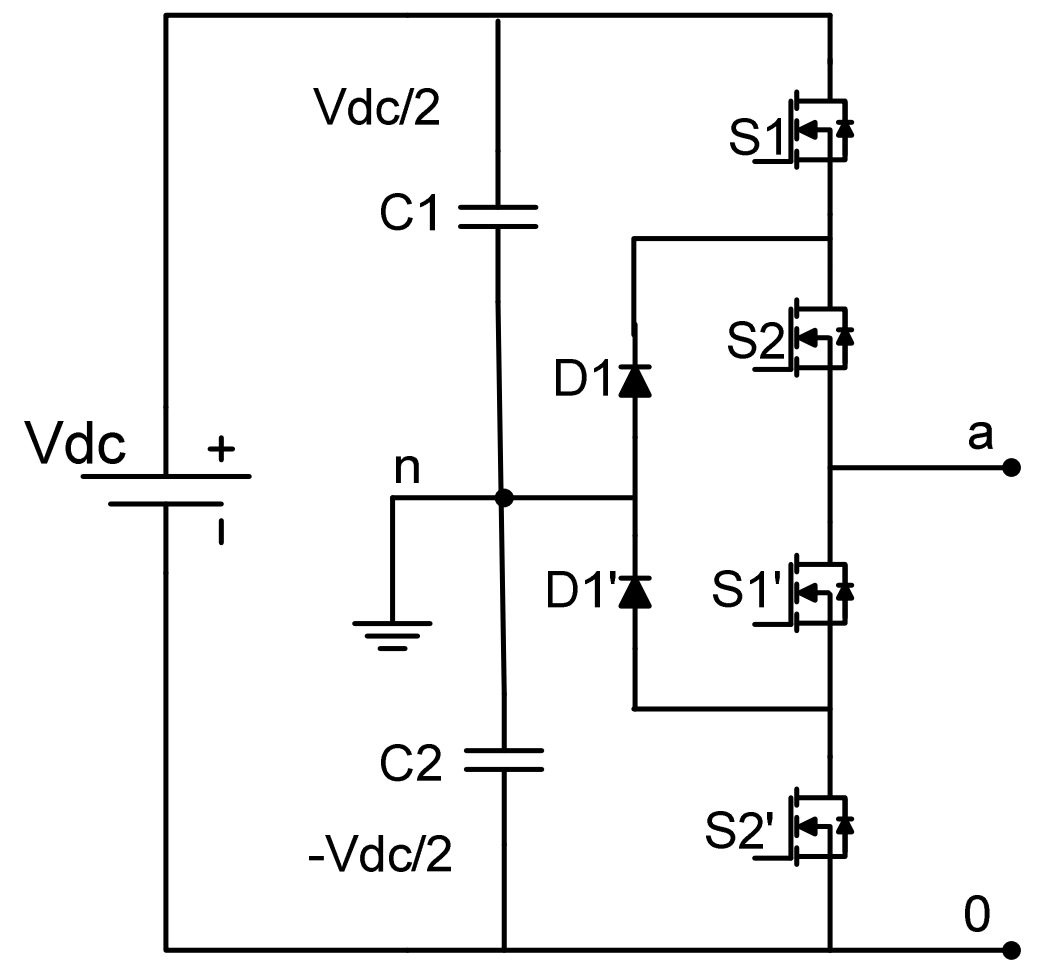

Figure 2.6: Diode-clamped multilevel inverter.

\subsubsection{Capacitor-Clamped Inverter}

Another popular topology is capacitor-clamped inverter. A three level capacitorclamped inverter is shown in Figure 2.7. The circuit is also known as flying capacitor inverter [8], [13]-[14]. The inverter has three output voltage states: $\frac{V d c}{2}, 0,-\frac{V d c}{2}$. This circuit does not need any additional clamping diodes and also provides redundant switching states which can be used for controlling the capacitor charging. However, 
larger structure of the inverter requires high number of capacitors and additional circuitry to initialize the capacitor charging.

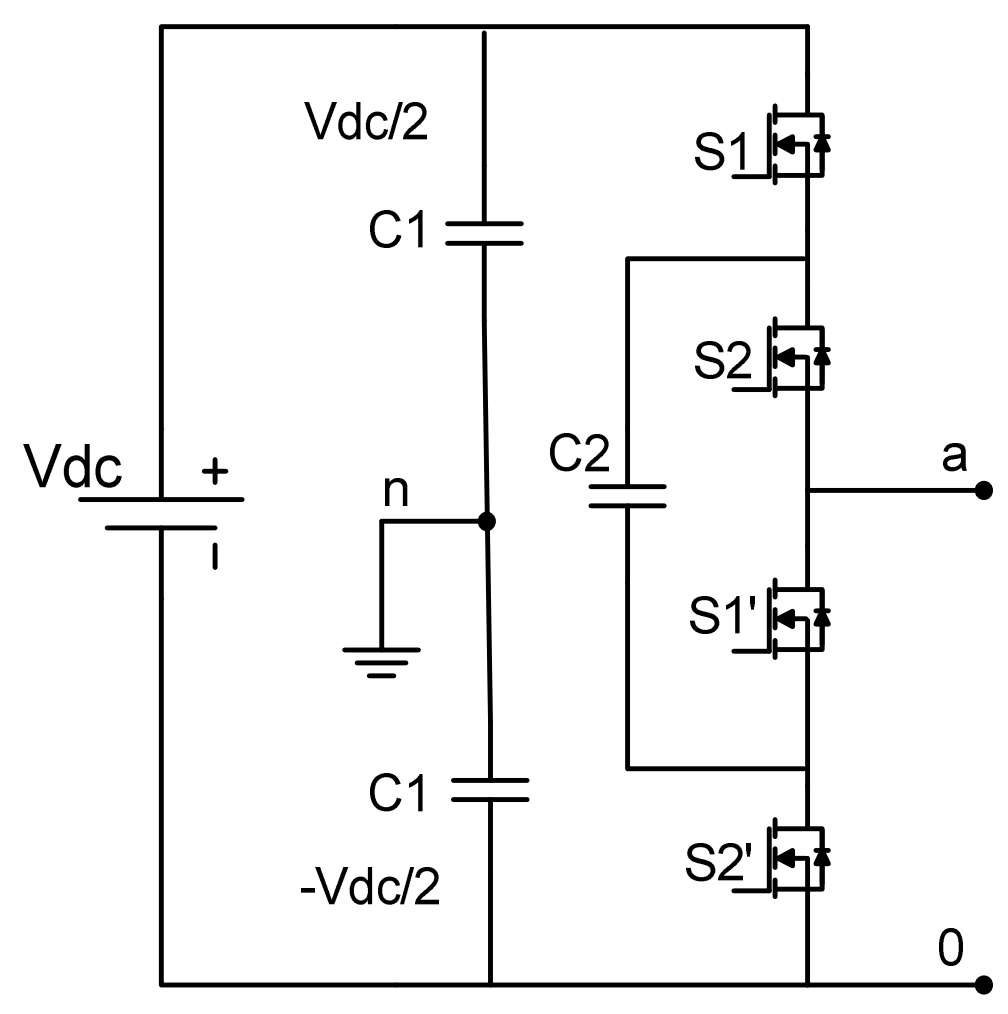

Figure 2.7: Capacitor-clamped multilevel inverter.

\subsection{Grid Interactive Solar PV Array Configurations}

Parallel or series-parallel configured arrays are matched to the low voltage inverters in the range of $48 \mathrm{~V}$ to $110 \mathrm{~V}$. Series configured arrays are connected to string inverter input voltage ranging from $250 \mathrm{~V}$ to $600 \mathrm{~V}$ [15]-[16]. Figure 2.8 shows the typical grid interactive solar PV systems with the series/parallel and series string array configurations. 


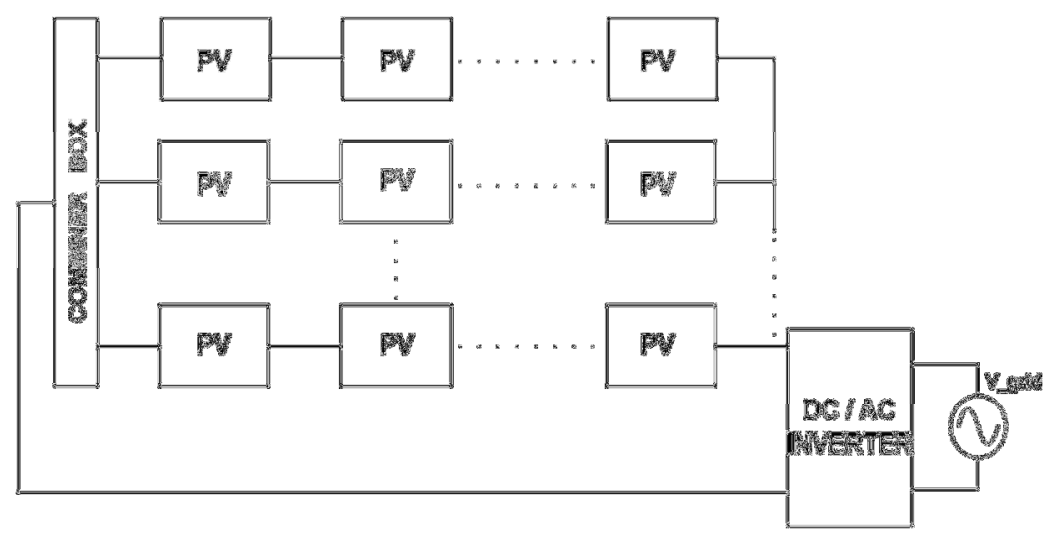

(a)

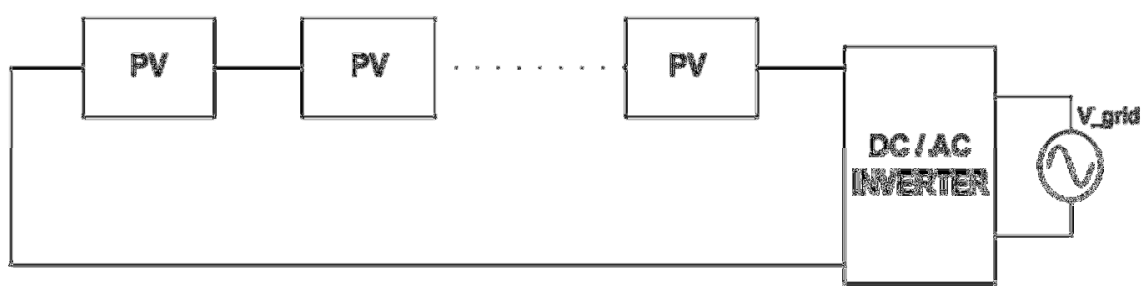

(b)

Figure 2.8: Grid interactive solar PV systems: (a) Series/parallel and (b) Series string array configurations.

In the case of series string inverter configuration, several panels are connected in series. The inverter sees only the strings of panels and is not capable of controlling individual panels. However, the amount of power extraction is adversely affected; if all the cells are not equally illuminated (partially shaded). The power extraction is dictated by the weakest panel in the string as all the panels need to carry the same current. The shaded cells produce less current but these cells are also forced to carry the same string current as the other fully illuminated cells. The shaded cells may act as loads by getting reverse biased and draining power from fully illuminated cells. Also in several cases, the system can be irreversibly damaged by the hot-spot problem, if it is not appropriately protected [17]-[18]. 


\subsection{Maximum Power Extraction}

The available energy from the solar panels varies nonlinearly. The amount of solar energy available is subject to change and is difficult to estimate without the measurement of sun radiance and panel temperature. Even with the sensing elements, estimation is not accurate. Shadings can happen quite frequently and affect the performance of the arrays. Also the performance of the array degrades as the time passes. Inverter needs to automatically adjust the power output to draw maximum available power at any time.

Maximum Power Point Tracking (MPPT) is an essential part of a solar PV system. Many tracking methods have been developed and implemented, and can be found in the literature. Among them, hill-climbing or perturb and observe $(\mathrm{P} / \mathrm{O})$ algorithm is the most commonly used MPPT method. According to this method, perturbing the duty ratio of the power converter, which is connected to the PV array, perturbs the array current which would perturb the output power. If there is an increase in power, the subsequent perturbation should be kept in the same direction to reach the MPP, and if there is a decrease in power, the perturbation should be reversed [19]. This algorithm is summarized in Table 2.1. The process is repeated periodically until the system reach MPP. The system then oscillates about the MPP. The oscillation can be minimized by reducing the step size of the perturbation. However, a smaller perturbation size increases the time to reach the MPPT; a variable perturbation size that gets smaller towards the MPP can solve this problem. 
Table 2.1: Summary of hill-climbing and P/O algorithm.

\begin{tabular}{|c|c|c|}
\hline Perturbation & Change in Power & Next Perturbation \\
\hline Positive & Positive & Positive \\
\hline Positive & Negative & Negative \\
\hline Negative & Positive & Negative \\
\hline Negative & Negative & Positive \\
\hline
\end{tabular}

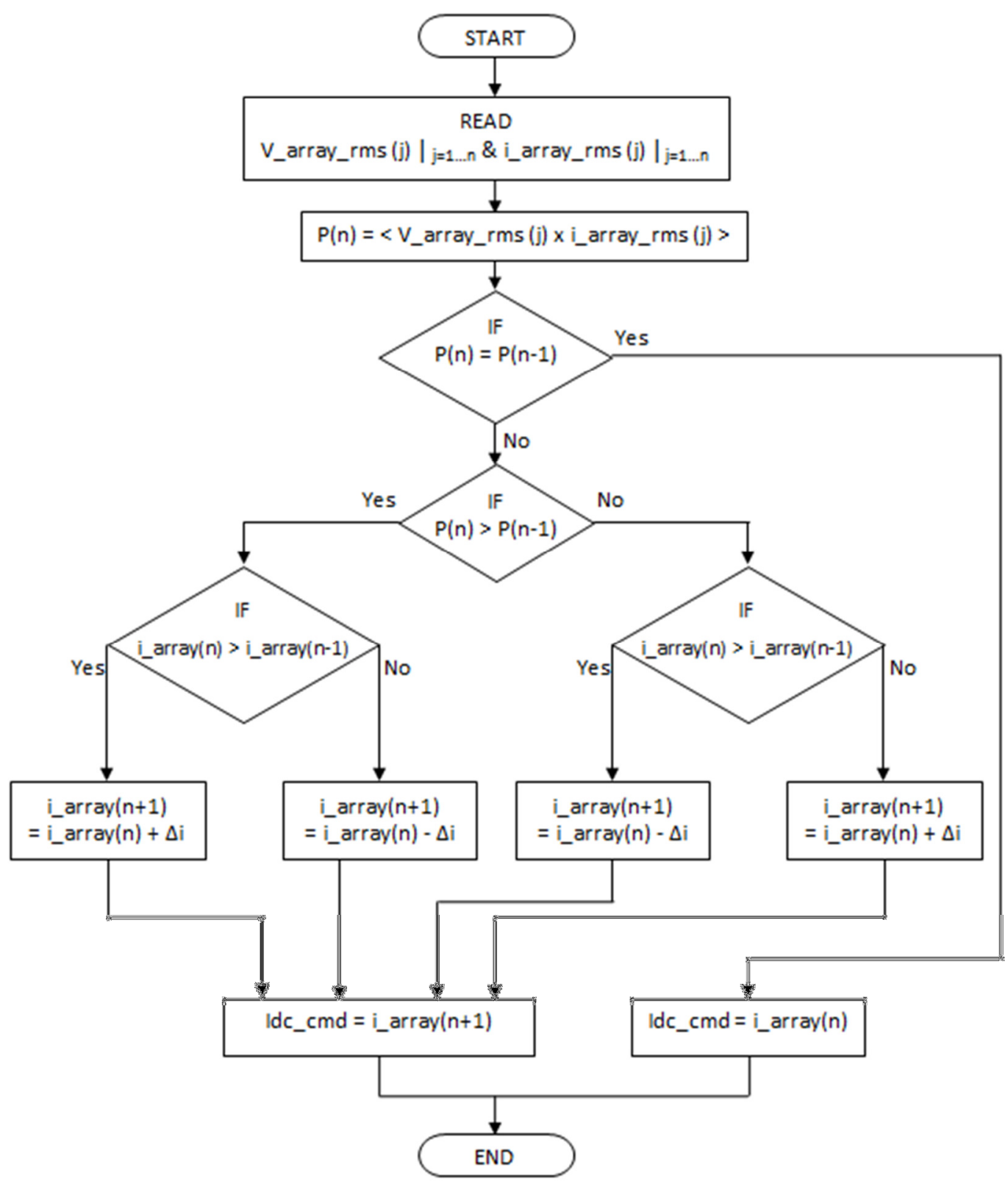

Figure 2.9: MPPT algorithm. 
Figure 2.9 shows the flow chart of the MPPT algorithm which is used in this research. As seen from this figure, the current and voltage sensors measure the current and voltage to calculate the power. The power at any instant of time is compared to the power of the previous instant to make a decision in the following step.

\subsection{Panel Mismatches in Solar PV Systems}

The shading of the panels is an undesired phenomenon in the solar PV system that adversely affects the output power level. Due to the sun irradiance received differently in different solar PV panels connected together, the total power extraction from the panels is affected severely.

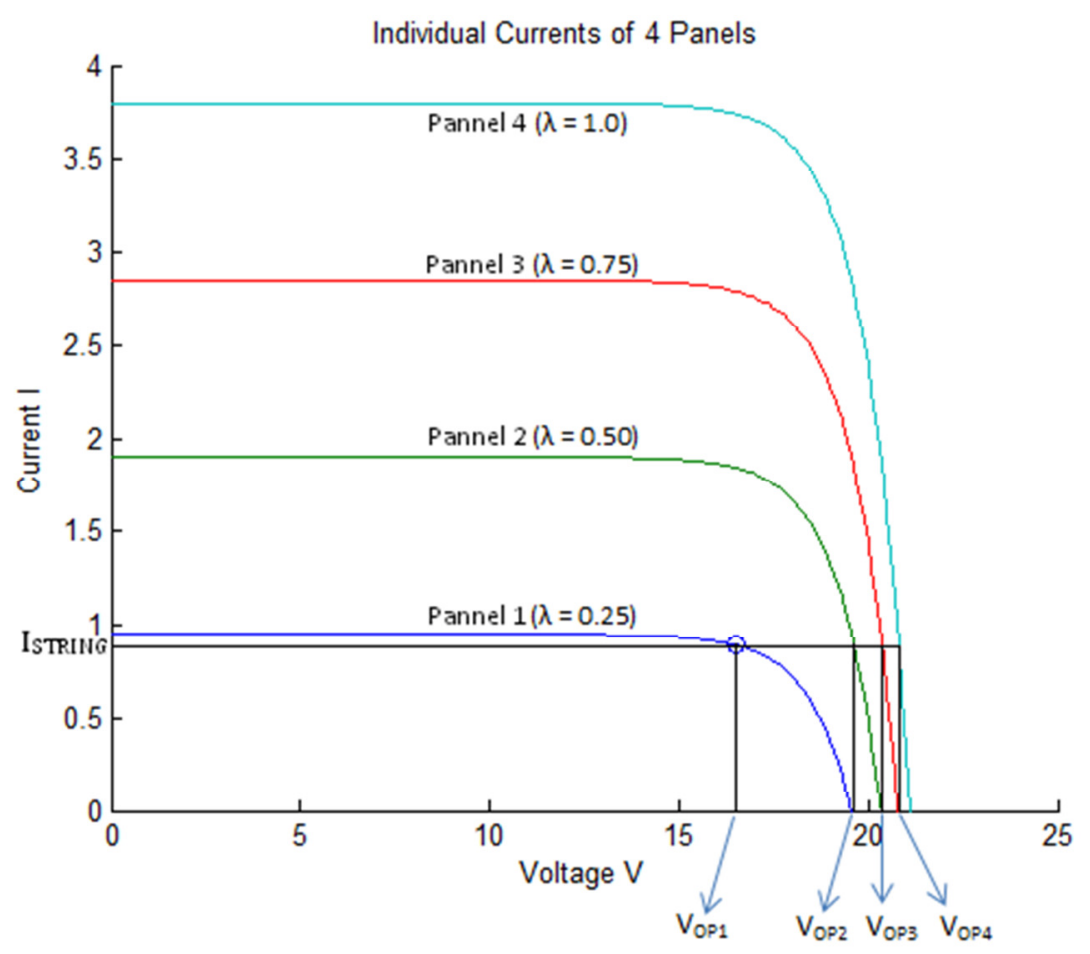

Figure 2.10: I-V curves of the four panels with different irradiation $\lambda$. 


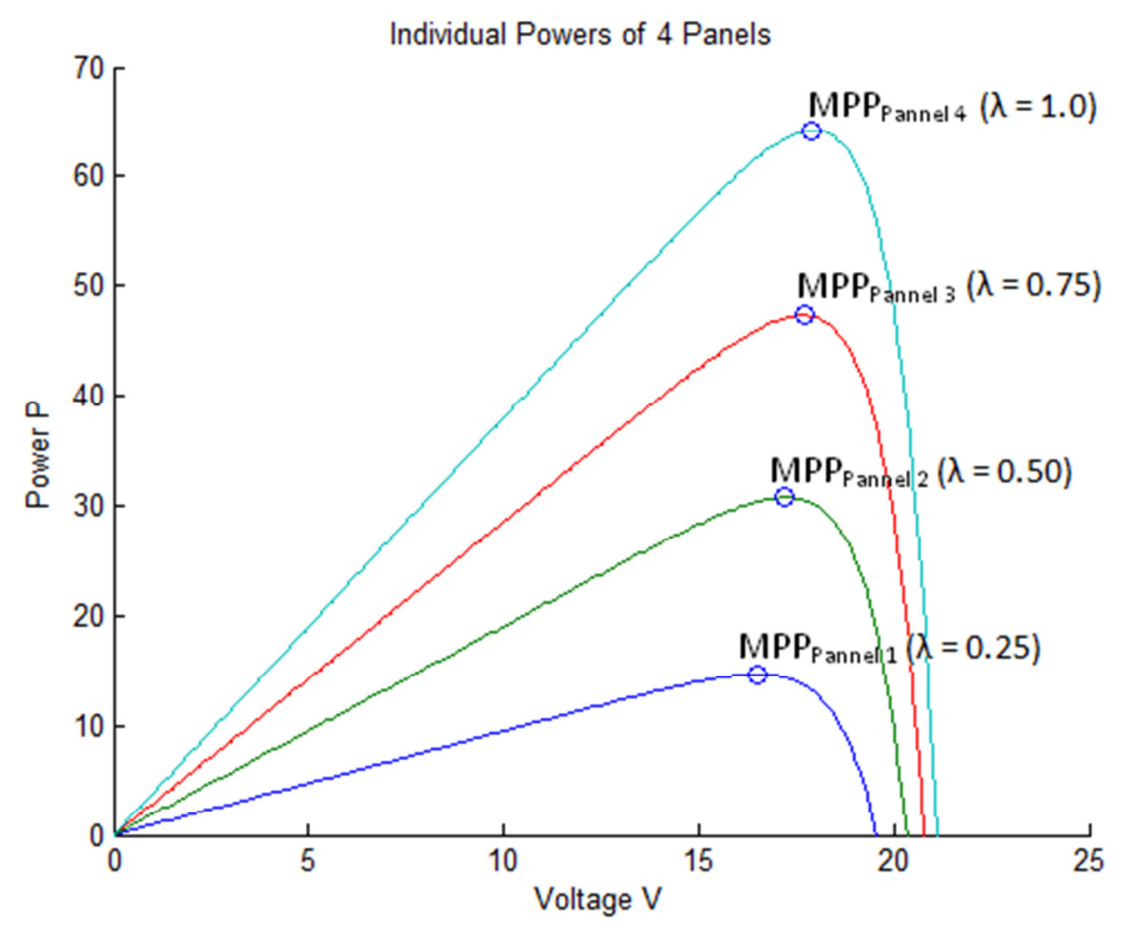

Figure 2.11: P-V curves of the four panels with different irradiation factor $\lambda$.

Figures 2.10 and 2.11 show the $\mathrm{I}-\mathrm{V}$ and $\mathrm{P}-\mathrm{V}$ curves of a series string configured four panels with each panel having 36 cells connected in series. Each panel has a different irradiation factor $\lambda$ from the sun; panel 1 has $\lambda=0.25 \mathrm{~kW} / \mathrm{m}^{2}$, panel 2 has $\lambda=$ $0.50 \mathrm{~kW} / \mathrm{m}^{2}$, panel 3 has $\lambda=0.75 \mathrm{~kW} / \mathrm{m}^{2}$ and panel 4 has $\lambda=1.0 \mathrm{~kW} / \mathrm{m}^{2}$. As shown in Figure 2.10, MPPT for panel 1 occurs at $0.8897 \mathrm{~A}$ and $16.5 \mathrm{~V}$. The circuit current $\mathrm{I}_{\text {STRING }}$ becomes the current where MPPT occurs in the panel that has minimum irradiance.

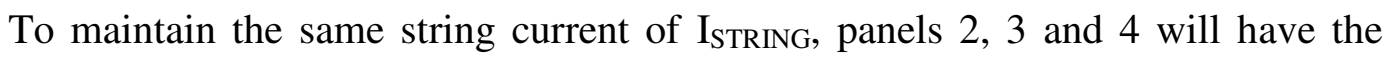
corresponding operating voltages as $V_{O P 2}=19.6 \mathrm{~V}, V_{O P 3}=20.3 \mathrm{~V}, V_{O P 4}=20.8 \mathrm{~V}$. Therefore, the total power extracted from the four panels will be 


$$
\begin{gathered}
P_{\text {TOTAL }}=I_{\text {STRING }} x\left(V_{O P 1}+V_{O P 2}+V_{O P 3}+V_{O P 4}\right) W \\
=0.8897 x(16.5+19.6+20.3+20.8) W=68.6821 \mathrm{~W} .
\end{gathered}
$$

However, Figure 2.11 shows that the MPPs for the individual panels are $14.7 \mathrm{~W}$, 30.7 W, 47.3 $\mathrm{W}$ and $64.20 \mathrm{~W}$ respectively due to the different irradiance factor $\lambda$ 's. The total maximum output power, $P_{M A X}$ would be

$$
P_{M A X}=14.7+30.7+47.3+64.20 W=159.9 W
$$

This higher value of $P_{M A X}$, which is more than double of $P_{\text {TOTAL }}$, is achieved by individual panel MPPT, rather than a centralized MPPT structure which affects the overall system by maintaining I $_{\text {STRING }}$ even though different panels may have different irradiance values.

\subsection{Module Integrated Converters (MICs)}

In order to eliminate the adverse effects of shading, an alternative approach suggested in the literature and being developed in the industry is the autonomous control for tracking the maximum power of solar panels locally [20]-[22]. Module integrated converters (MICs) provide better energy capture. MICs are configured as either DC/DC converters or DC/AC converters provide MPPT for the individual inverters. 


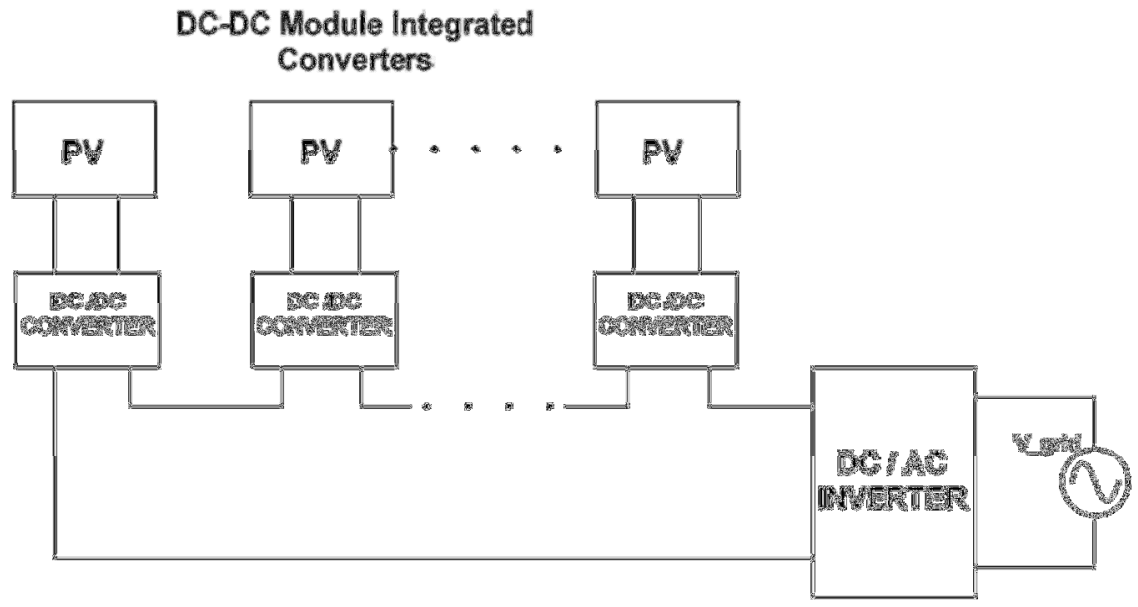

(a)

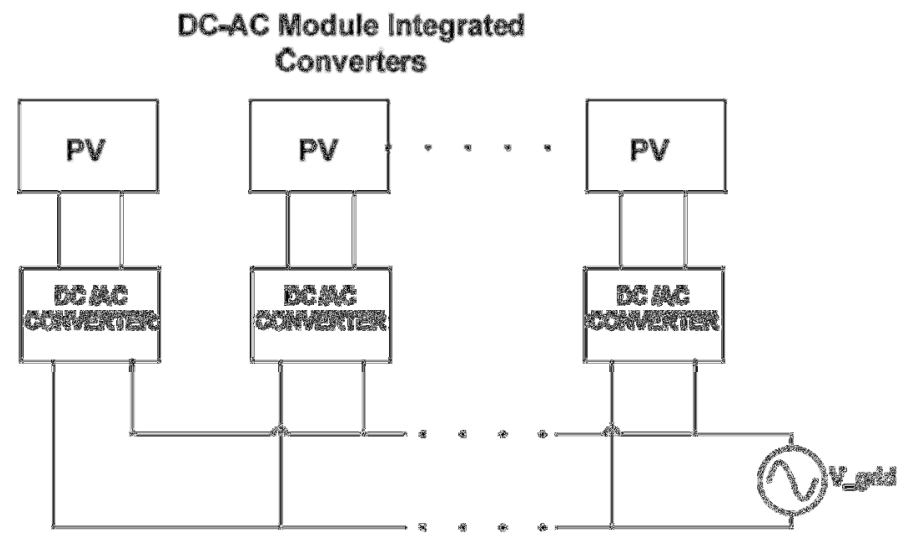

(b)

Figure 2.12: (a) DC/DC and (b) DC/AC module integrated converters.

Figure 2.12 shows the configuration of the solar PV systems through the MICs. In the first approach, individual DC/DC converters work as a buck-boost converter and process the power at MPP of the individual arrays. The second approach is to use DC/AC 
inverters for each panel. Both approaches provide better energy capture, but increase the total inverter cost of the system significantly.

\subsection{Proposed Multilevel Inverter Topology}

A single-phase structure of an m-level cascaded multilevel inverter is the proposed topology where the individual PV panels or series-parallel connected portion of the PV panels are fed into single-phase H-bridge inverter modules. Each single-phase full-bridge inverter module generates three voltage levels at the output: $+\mathrm{V}_{\mathrm{DC}}, 0$ and $\mathrm{V}_{\mathrm{DC}}$. The resulting phase voltage is synthesized by the addition of the voltage generated by different inverter cells. This is made possible by connecting the DC voltage sources to the AC output by different combinations of the four power switches, S1, S2, S3 and S4. The number of output voltage levels, $m$ in a cascaded inverter is defined by $m=2 n+1$, where $\mathrm{n}$ is the number of $\mathrm{H}$-bridge inverter modules.

The output of the each cell is connected in series to feed the AC utility grid. It is possible to run the individual cells at the utility frequency. By adjusting the duty ratio of the individual cells, the amount of power extracted by the individual cell of the inverter can be controlled. Although the amounts of current output from the individual cells are same, the input currents drawn from the arrays can be different. Using this approach, maximum power extraction from the individual panels is possible. The individual cell controllers and the centralized controller share the responsibility of the power conversion.

Figure 2.13 shows the proposed bi-directional multilevel inverter topology for the solar PV arrays. The total input power from the DC sources in the proposed topology is: 


$$
\text { Power }_{\text {in }}=V_{\text {array } 1} i_{\text {array } 1}+V_{\text {array } 2} i_{\text {array } 2}+\ldots \ldots \ldots+V_{\text {array } n} i_{\text {array } n}
$$

where $V_{\text {array } n}$ and $i_{\text {array } n}$ are the individual cell input voltages and the currents from the arrays. The power fed into the utility is

$$
\text { Power }_{\text {out }}=V_{\text {grid }} i_{\text {grid }}
$$

where $V_{\text {grid }}$ and $i_{\text {grid }}$ are the utility voltage and the current.

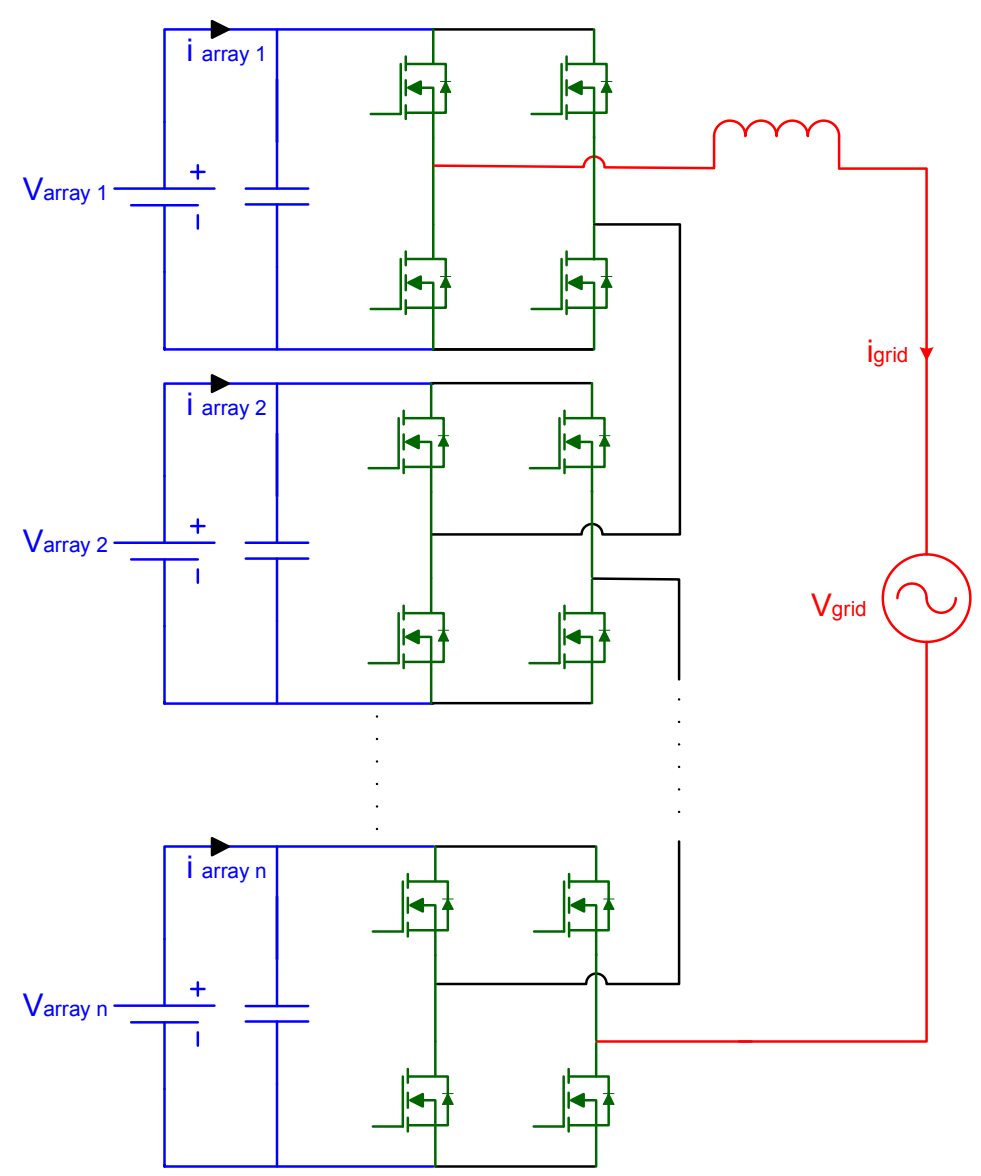

Figure 2.13: Proposed multilevel inverter topology.

Figure 2.14 shows the output voltage waveforms from the individual cells and inverter output voltage. 

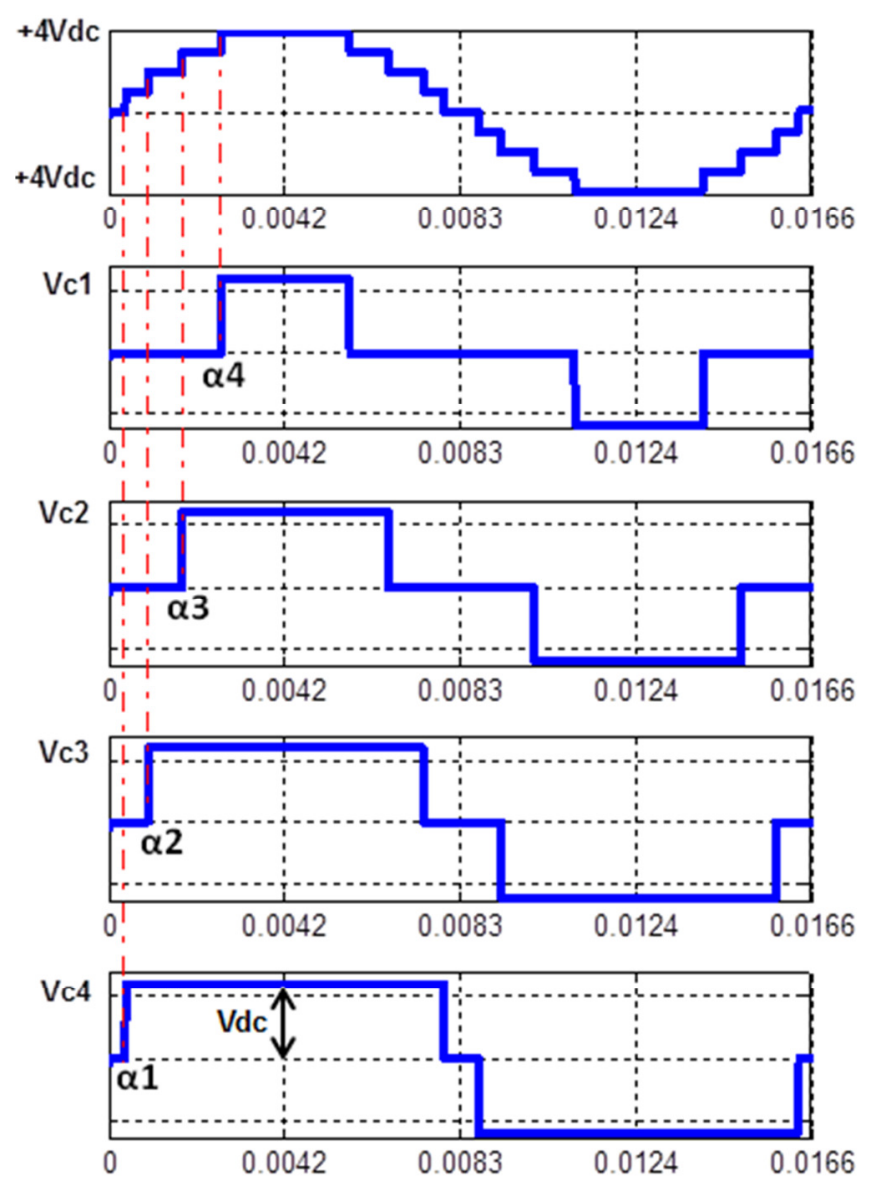

Figure 2.14: Inverter stepped-voltage waveform and individual cells' output voltages.

By changing the direction of power flow, this inverter system can also be used as a battery charger, which can charge different state of charge batteries separately by delivering different charging currents and achieve the charge level balancing at the same time. The inverter takes power from the grid and distributes the power to the different batteries depending on their state of charge. In the next section, battery charging station using the proposed inverter topology is discussed. 


\subsection{Battery Charging Station Using Proposed Inverter Topology}

A battery charger takes electrical power from a source and delivers it to the battery units in a suitable form. Battery pack takes DC power, while most of the electrical power system delivers power at AC voltages. Therefore, battery charger converts AC energy to DC energy and determines the manner in which the power is delivered to the battery. Therefore, the main parts of a battery charger system are the power processing unit and the battery management unit to ensure that the power is delivered in the right manner and is of the right form [23].

The power processing unit consists of an AC-to-DC converter and the associated control circuit. The battery management system consists of sensors and microcontroller and it controls the charging process for optimum charging. The sensors provide information about the currents, voltages and temperatures of the battery unit. The microcontroller receives this information from the sensors and sends commands to the power processing unit to deliver the required charging current to the individual battery units.

Figure 2.15 shows the battery charging operation of the proposed multilevel inverter from the grid. By adjusting the duty ratio of the individual modules, the amount of power delivered by the individual module can be controlled and the delivered currents to the batteries can be different. 


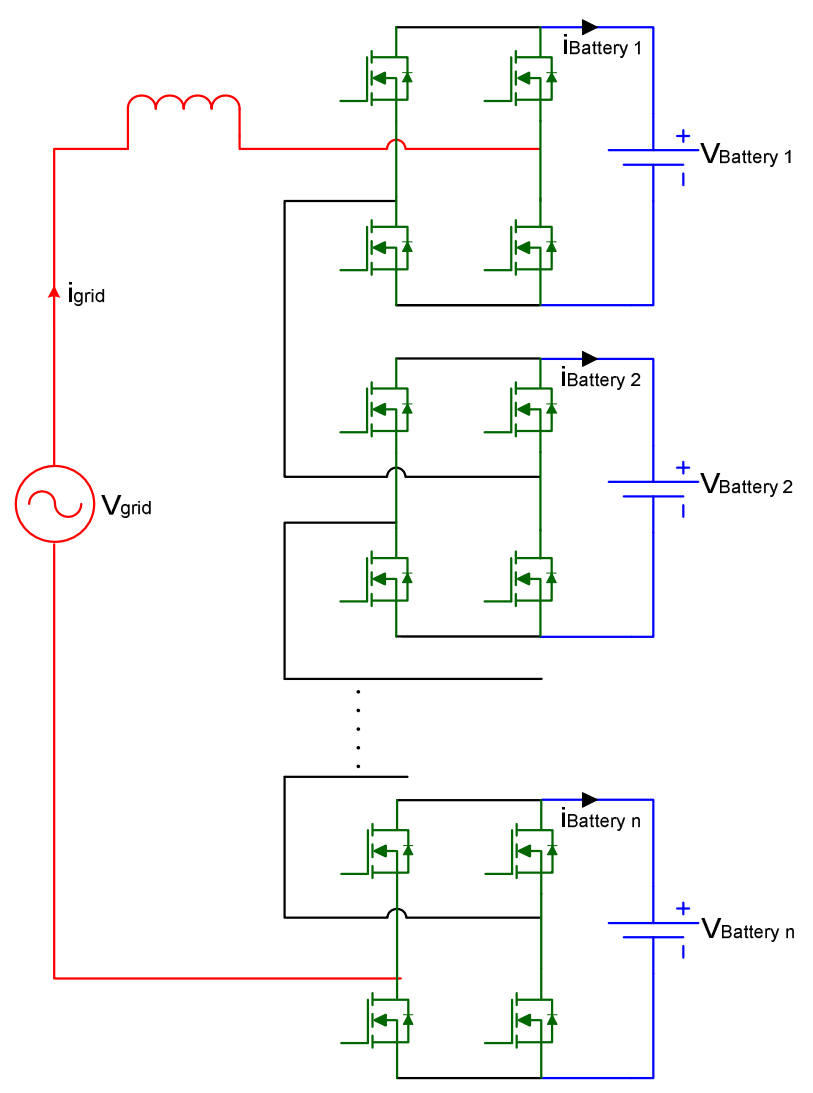

Figure 2.15: Battery charging from the grid using the proposed inverter.

Using this approach, different batteries can be charged by the different charging currents. The total input power from the utility grid is

$$
\text { Power }_{\text {in }}=V_{\text {grid }} i_{\text {grid }}
$$

where $V_{\text {grid }}$ and $i_{\text {grid }}$ are the utility voltage and the current. The power delivered to the batteries is

Power $_{\text {out }}=V_{\text {Battery } 1} i_{\text {Battery } 1}+V_{\text {Battery } 2} i_{\text {Battery } 2}+\ldots \ldots \ldots+V_{\text {Battery } n} i_{\text {Battery } n}$ where $V_{\text {Battery } n}$ and $i_{\text {Battery } n}$ are the individual battery charging voltages and the charging currents from the grid. 


\subsection{Summary}

A cascaded multilevel inverter topology is proposed to solve the problem associated with the series string inverters during MPPT operation. The advantage of this inverter is its cascaded structure, where different solar panels can be operated at their maximum power points individually. The individual solar panels can be operated efficiently using this single stage inverter. The proposed system also reduces the cost compared to the available module integrated converters, where the number of inverters increases with the number of solar panels.

Finally, it is also indicated that the proposed inverter topology can be used as a battery charger from the grid, where different charging currents can be delivered to the individual batteries with different state of charge. In the next chapter, the overall control algorithm for this multilevel inverter is presented. 


\section{CHAPTER III}

\section{MULTILEVEL INVERTER CONTROL ALGORITHM}

\subsection{Introduction}

The multilevel solar PV inverter system has individual inverters for individual panels, but is centrally controlled in a coordinated way using a novel control algorithm. The overall system consists of a multilevel inverter with n-number of modules, n-number of solar panels, maximum power point tracking, switching angle generator and distributor among the modules, PWM generator and a grid voltage sensing circuit. The current and voltage sensors measure the panel currents and panel voltages from each panel. Another current sensor measures the grid current. The flow diagram of the overall system is illustrated in Figure 3.1.

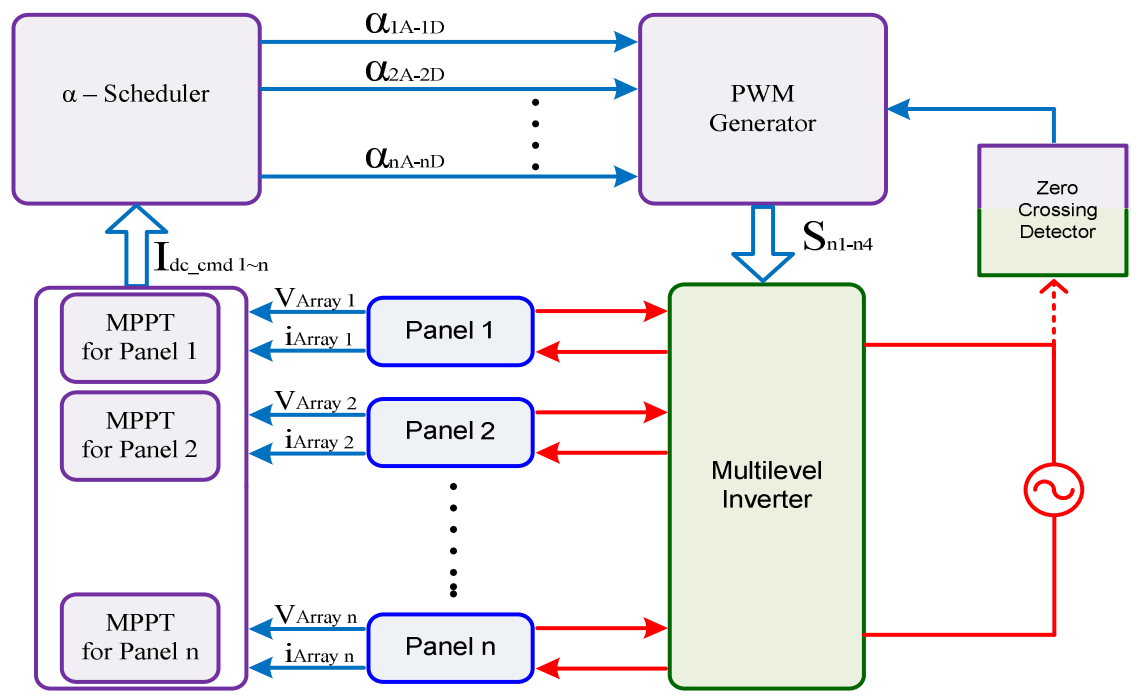

Figure 3.1: Flow diagram of the overall system. 
The individual cell controllers and the centralized controller share the responsibility of the power conversion. The control objective is to deliver the power to the grid cumulatively from the solar panels. The total input power from the solar panels is

$$
\text { Power }_{\text {in }}=V_{\text {array } 1} i_{\text {array } 1}+V_{\text {array } 2} i_{\text {array } 2}+\ldots \ldots \ldots+V_{\text {array } n} i_{\text {array } n}
$$

where $V_{\text {arrayn }}$ and $i_{\text {arrayn } n}$ are the individual cell input voltages and the currents from the arrays. The power fed into the utility is

$$
\text { Power }_{\text {out }}=V_{\text {grid }} i_{\text {grid }}
$$

where $V_{\text {grid }}$ and $i_{\text {grid }}$ are the utility voltage and the current.

Let the variable $D_{x}$ be the percentage of the current being drawn by the individual solar panels for a specified period. The centralized controller produces the individual $D_{x}$ 's to produce Power out $_{\text {that }}$ matches the desired Power out $_{\text {. The }} D_{x}$ time can be as much as the utility grid period and as low as the lowest PWM period that can be achieved by the converter. The resulting AC output has to be compatible with the AC utility system.

The realization of the $D_{x}$ can be done through proper switching configuration of the switches on the cell inverters. The magnitude of the turn-on and turn-off angles would dictate the $D_{x}$ for the inverter cell. In the developed control algorithm, the turn-on and turn-off angles are symmetrically positioned within one half electrical cycle; hence, the control algorithm has to generate one switching angle, denoted as " $\alpha$ " for each module. In one utility cycle, $\alpha$ could be changed four times to regulate the amount of currents drawn from the solar panels. The individual cell $\alpha$ angles should be coordinated with other cells to synthesize sine wave utility current. For a set of four panels and four individual 
inverters, there will be four single phase output voltages. The individual output voltages will synthesize into an overall nine-level output voltage as shown in Figure 3.2.
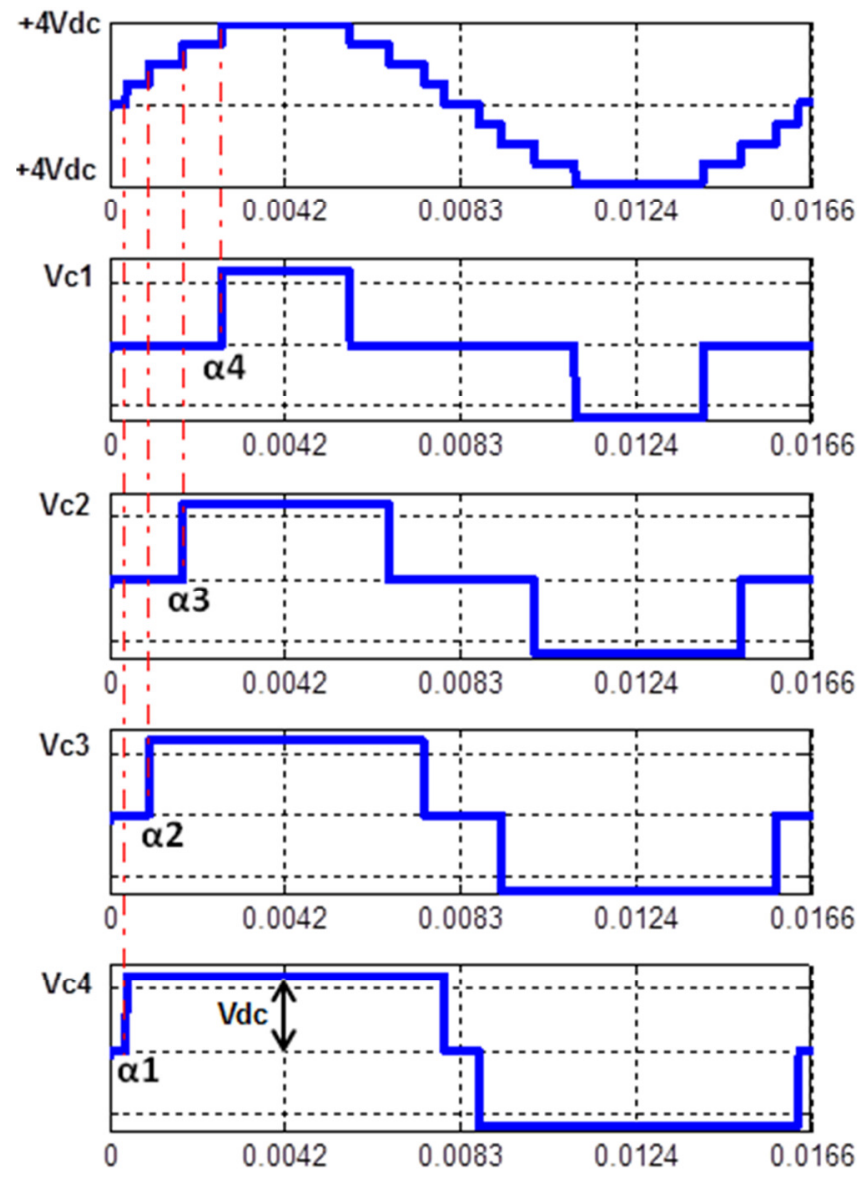

Figure 3.2: Inverter stepped-voltage waveform and individual cells' output voltages.

\subsection{Switching Angles ( $\alpha$ ‘s)}

The switching angles are calculated using selective harmonic elimination method.

Figure 3.3 shows a quarter-wave symmetric stepped voltage waveform synthesized by a $(2 m+1)$-level inverter. The waveform has no even harmonics. The amplitude of any odd harmonic of this stepped-waveform can be expressed as follows: 


$$
h_{n}=\frac{4 V_{d c}}{n \pi}\left[\cos \left(n \alpha_{1}\right)+\cos \left(n \alpha_{2}\right)+\ldots \ldots \ldots+\cos \left(n \alpha_{m}\right)\right]
$$

where $V_{d c}$ is the battery voltage, $n$ is the odd harmonic order and $\alpha$ 's are the switching angles.

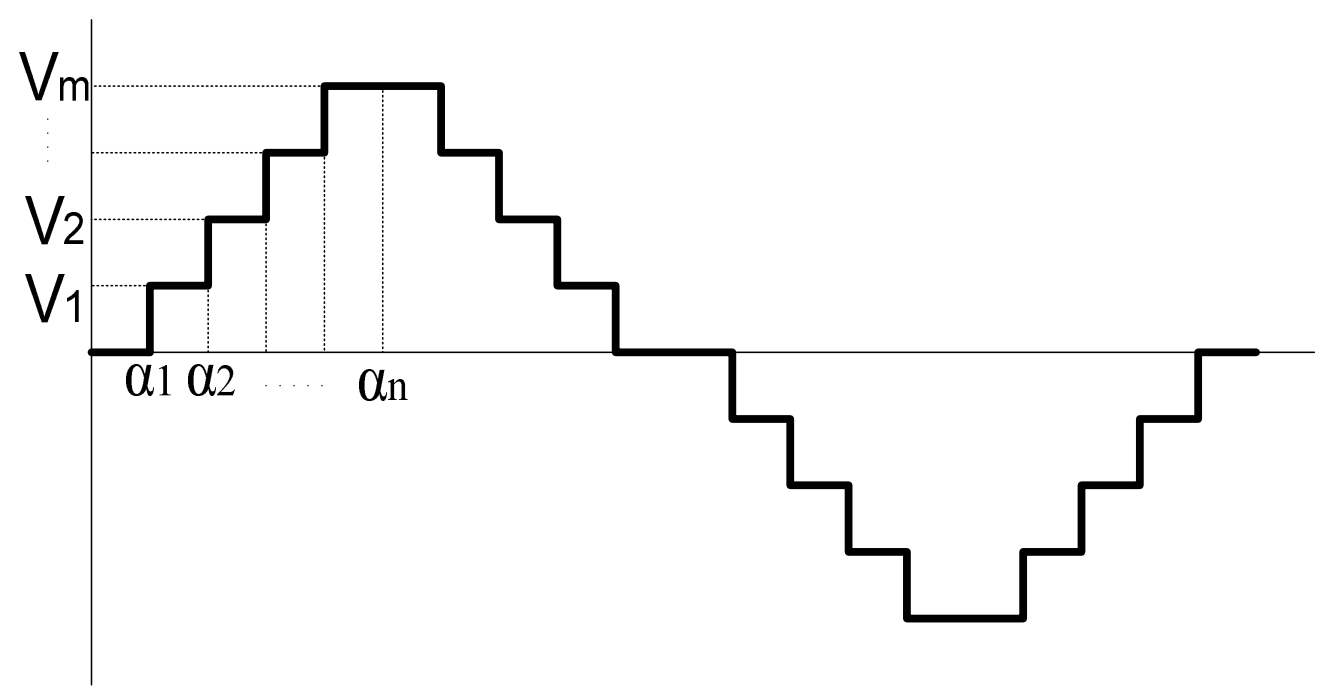

Figure 3.3: Generalized stepped-voltage waveform.

It follows from Figure 3.3 that the switching angles must satisfy the following condition:

$$
\alpha 1<\alpha 2<\alpha 3<\cdots \cdots \cdots<\alpha m<\frac{\pi}{2} .
$$

To minimize the total harmonic distortion, the most significant low frequency harmonic components will be eliminated from the voltage waveform. The high frequency harmonic components can then be readily removed by using additional filter circuits. Therefore, the $3^{\text {rd }}, 5^{\text {th }}$ and $7^{\text {th }}$ harmonics are chosen to be eliminated from the voltage waveform [24]. Because of the symmetric characteristic, no even harmonic components exist in this waveform. Therefore, the set of nonlinear equations for a nine-level inverter is as follows: 


$$
\begin{aligned}
& \cos \left(\alpha_{1}\right)+\cos \left(\alpha_{2}\right)+\cos \left(\alpha_{3}\right)+\cos \left(\alpha_{4}\right)=\pi \\
& \cos \left(3 \alpha_{1}\right)+\cos \left(3 \alpha_{2}\right)+\cos \left(3 \alpha_{3}\right)+\cos \left(3 \alpha_{4}\right)=0 \\
& \cos \left(5 \alpha_{1}\right)+\cos \left(5 \alpha_{2}\right)+\cos \left(5 \alpha_{3}\right)+\cos \left(5 \alpha_{4}\right)=0 \\
& \cos \left(7 \alpha_{1}\right)+\cos \left(7 \alpha_{2}\right)+\cos \left(7 \alpha_{3}\right)+\cos \left(7 \alpha_{4}\right)=0
\end{aligned}
$$

Solving the above set of nonlinear equations using Newton-Raphson method, the switching angles were calculated, which correspond to the minimum total harmonic distortion (THD) of $8.5 \%$ for a nine-level inverter. Table 3.1 shows the calculated switching angles for a nine-level cascaded multilevel inverter. Figure 3.4 shows a sine wave and the generated stepped-waveform superimposed on each other using the above switching angles.

Table 3.1: Switching angles calculated for a nine-level inverter

\begin{tabular}{|c|c|c|c|c|}
\hline Switching Angles & $\alpha_{1}$ & $\alpha_{2}$ & $\alpha_{3}$ & $\alpha_{4}$ \\
\hline Angles (radian) & 0.15 & 0.35 & 0.65 & 1 \\
\hline
\end{tabular}

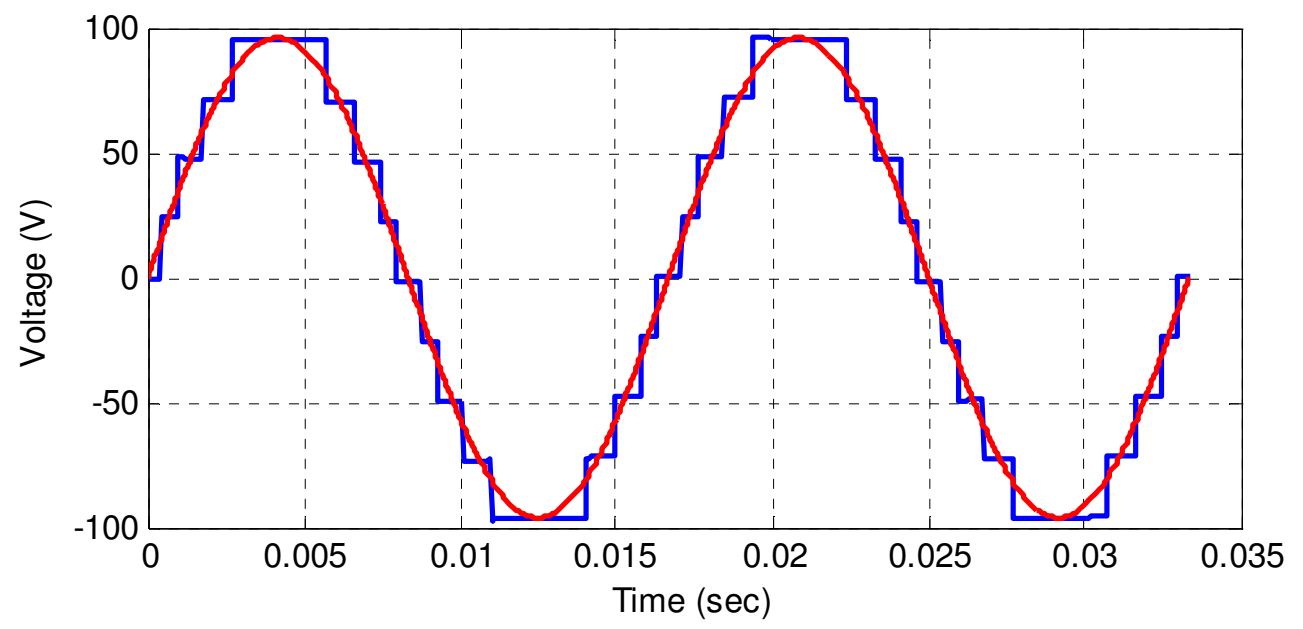

Figure 3.4: Super imposing of a pure sine wave and generated stepped waveform. 


\section{2 $\operatorname{Alpha}(\alpha)$ Scheduler}

The control algorithm is implemented in the $\alpha$-Scheduler block. The main function of the $\alpha-$ Scheduler block is to determine the optimum set of switching angles and distribute them among the modules. Figure 3.5 shows the outputs of the n-number of individual modules. The switching angles ( $\alpha$ 's) are interchanged four times per utility cycle. For each quarter cycle, n-number of $\alpha$ 's are distributed among the n-number of panels.

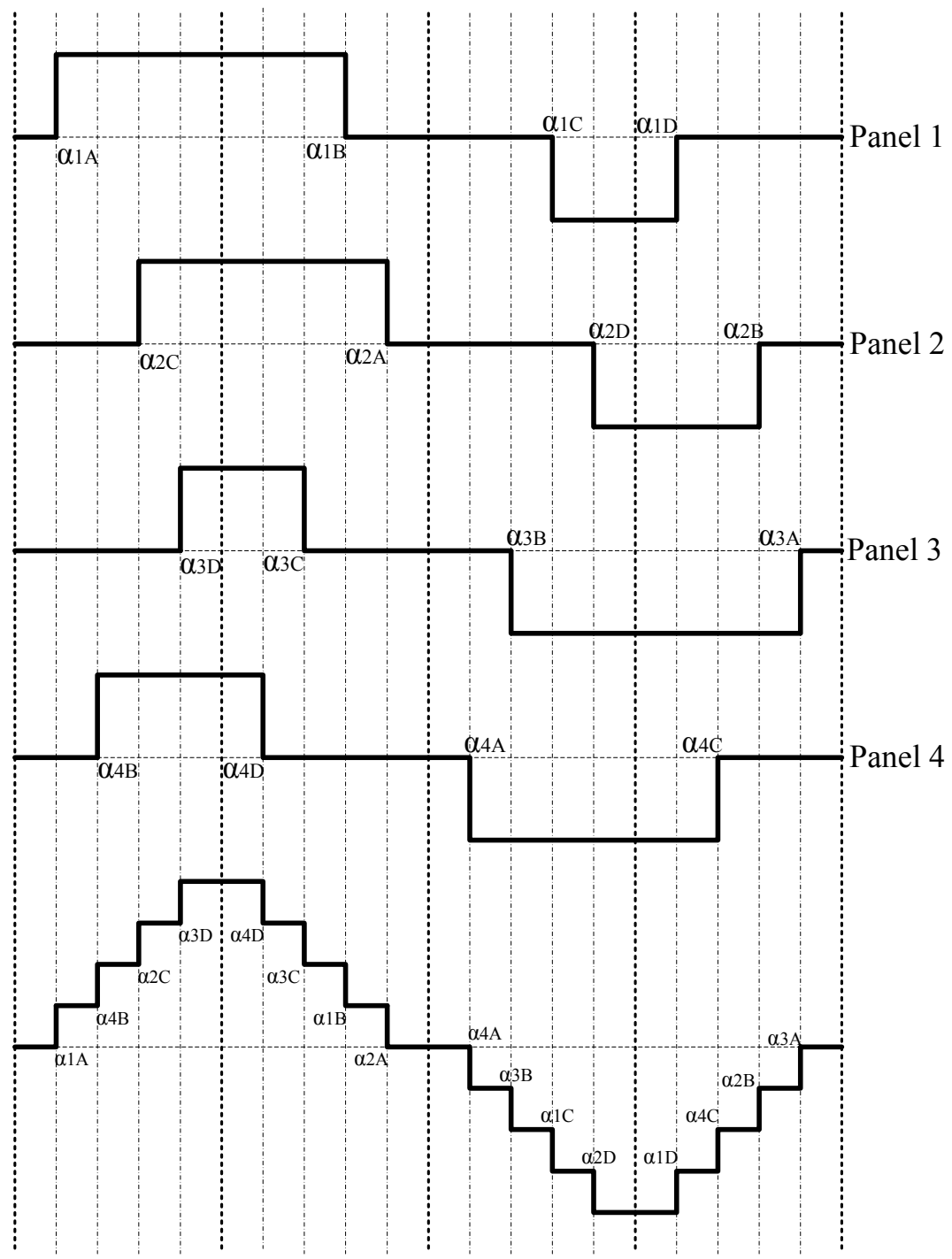

Figure 3.5: Switching angles are interchanged among n-number of modules. 
The $\alpha$-Scheduler block receives the current commands $\left(I_{d c_{-} C M D}\right.$ 's) from the MPPT algorithm and determines the corresponding set of switching angles. To develop a generic algorithm, individual array current commands are normalized to the amount of the grid current as follows:

$$
I_{d c_{-} C M D_{-} P U}=\frac{I_{d c_{-} C M D}(j)}{i_{\text {grid }}} .
$$

The difference between the per unit commanded currents and the estimated per unit currents gives the error $\mathrm{E}(\mathrm{n})$ for the individual solar panels as

$$
E(n)=I_{d c_{-} C M D_{-} P U}(n)-I_{c_{-} \alpha_{-} e s t P U}(i)
$$

The objective is to minimize the total error given as

$$
E_{T}(i)=\frac{E(1)+E(2)+\cdots+E(n)}{n}
$$

The algorithm iterates to minimize $E_{T}$ and finds the corresponding set of four switching angles $\left(\alpha_{\text {A-D }}\right.$ 's) for each inverter module per utility cycle. The $\alpha-$ Scheduler algorithm cycles the individual duties around the modules of the multilevel inverter, where the switching angle $\alpha$ 's are interchanged between the solar panels during a single utility cycle. The amount of average currents drawn from the individual solar panel is controlled by adjusting the duty cycles. The inverter thus allows all the panels to operate at their individual maximum power points throughout the operation. The switching angles are changed four times per utility cycle. The resultant waveform is synthesized by adding four waveforms. An algorithm was developed to produce the different combinations of the switching angles, $\alpha$ 's and recorded in a tabular form. The combinations satisfy the condition that all four switching angles are distributed in each quarter cycle to produce a 
resultant sinusoidal waveform. Figure 3.6 shows the flow chart of the $\alpha$-Scheduler algorithm.

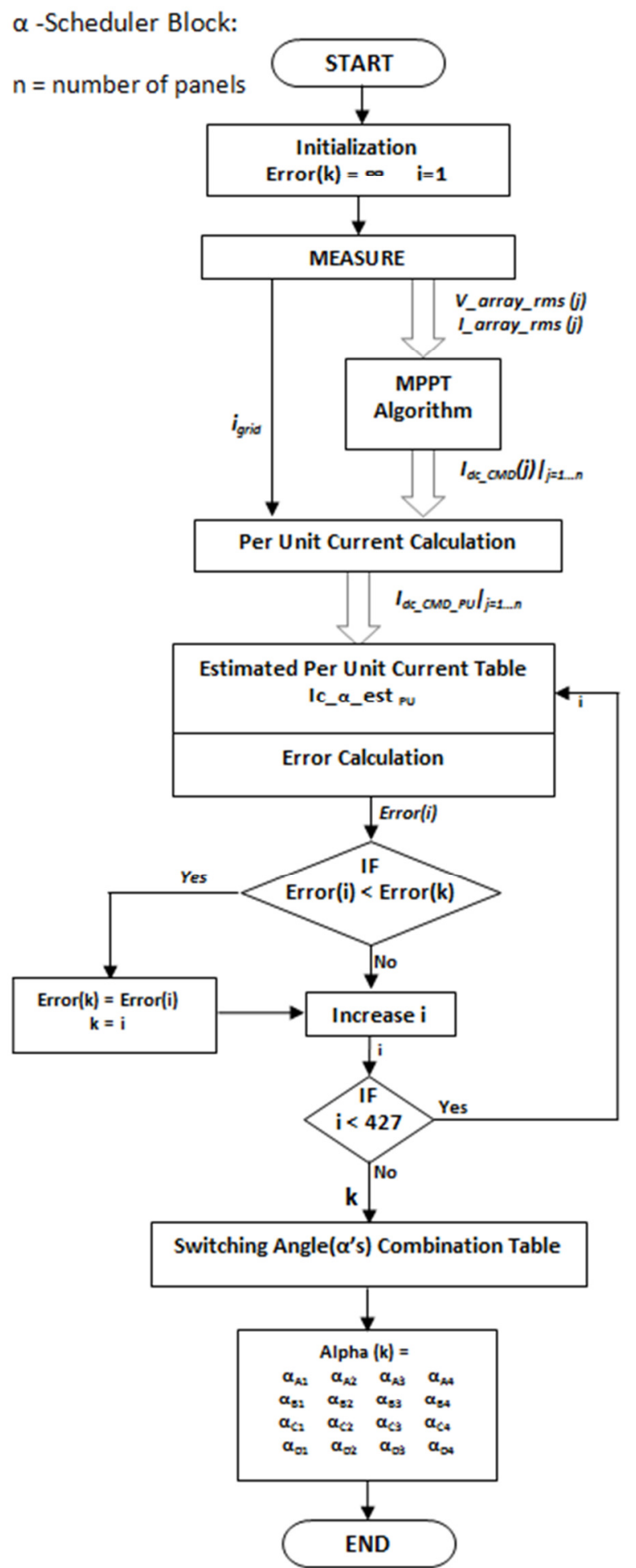

Figure 3.6: Alpha scheduler algorithm. 


\subsection{Zero Crossing Detection}

The solar PV inverter unit needs to be synchronized with the grid for energy transfer from the panels to the utility grid. The grid synchronization requires the same phase angle, frequency and amplitude between the inverter and the grid. The phase detection system is one of the important parts of the grid tied inverter control system. The harmonic content of the inverter output current as well as the power factor control are affected by the phase detection techniques. The ideal phase detection technique should be fast enough to respond to the changes in the grid phase as well as it should cancel the noise and higher harmonics in the grid voltage. There are several techniques have been proposed in the literature [25]-[28]. The simplest method is based on zero crossing detection of the grid voltage, which is used in this paper. The inverter output voltage is synchronized to the grid voltage at every positive zero crossing of the grid voltage.

The zero crossing detection algorithm has been implemented in the DSP. The grid voltage sensor circuit measures the grid voltage and converts it to a 0 to $3.3 \mathrm{~V}$ signal and sends this signal to the DSP which swings from $0 \mathrm{~V}$ to $+3.3 \mathrm{~V}$ with $1.67 \mathrm{~V}$ mid-point. The implemented zero crossing detection algorithm detects only the positive zero crossing of the grid voltage and very robust in the presence of the noise. Figure 3.7 shows the algorithm used for implementing the zero crossing detector. 


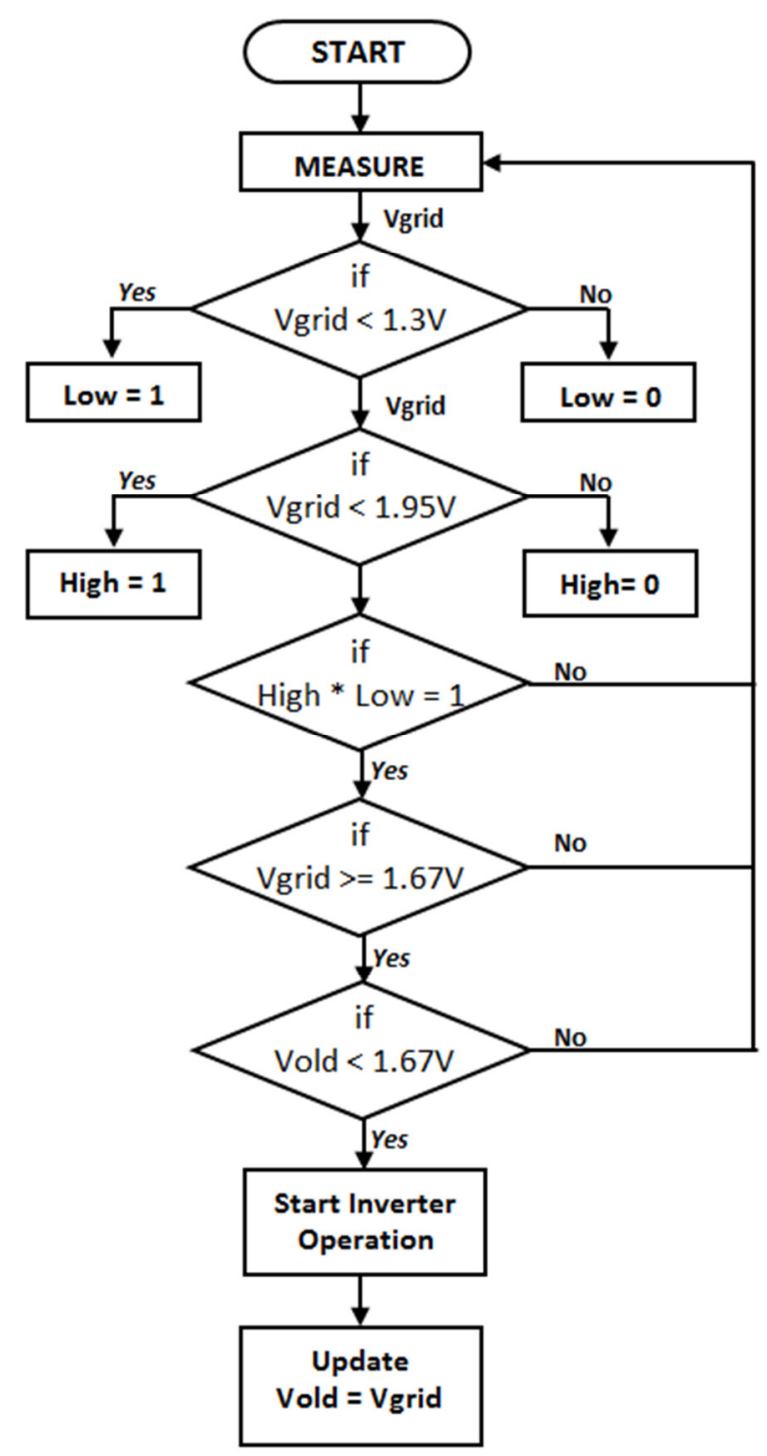

Figure 3.7: Zero crossing detection algorithm.

\subsection{AC Power Control}

The amount of power flow between the DC side and the grid is controlled by varying the value of the phase angle $(\delta)$ between the inverter and the grid voltages. By changing the sign of the the power angle, power can flow in both directions. In case of solar panels, inverter voltage leads the grid voltage to let the power flow from the inverter to the grid. On the other hand, grid voltage leads the inverter voltage during battery 
charging operation to let the power flow from the grid to the batteries. The power flow equation is as follows:

$$
P=\frac{\left(V_{i n v} V_{g r i d}\right)}{X_{L}} \sin (\delta)
$$

where $V_{\text {inv }}$ and $V_{\text {grid }}$ are the inverter voltage and grid voltage, respectively.

It is also possible to control the amount of reactive power by changing the power angle. The equation for the reactive power $\mathrm{Q}$ is as follows:

$$
Q=V_{r m s} I_{r m s} \sin (\theta)
$$

where $\theta$ is the phase angle between voltage and current.

\subsection{Summary}

In this chapter, the overall control algorithm is presented. The main objective of the control algorithm, addressed in the $\alpha$-Scheduler block, is to determine the optimum set of switching angles and distribute them to the different modules by generating PWM signals accordingly. The flow chart for this overall operation is also presented. The generations of the per unit current look-up table and switching angle combination look-up table are also discussed in this chapter. Finally, the objective and the operation of the zero crossing detection are discussed.

In the next chapter, the simulation results are provided with the control algorithm implemented in a MATLAB/Simulink environment. The validity of the algorithm has been analyzed through computer simulation prior to experimental verification. 


\section{CHAPTER IV}

\section{SIMULATION RESULTS}

\subsection{Introduction}

Simulation of the proposed inverter was done in MATLAB/Simulink environment. The generalized PV model, MPPT for individual PV panels, cascaded multilevel inverter with different loads were all integrated in a system simulation model. The control algorithm was developed using Embedded MATLAB function and simulated with the system model. The solar PV model was developed based on the Kyocera KD135GX-LPU photovoltaic module. Figure 4.1 shows the general block diagram of the overall system and the control architecture.

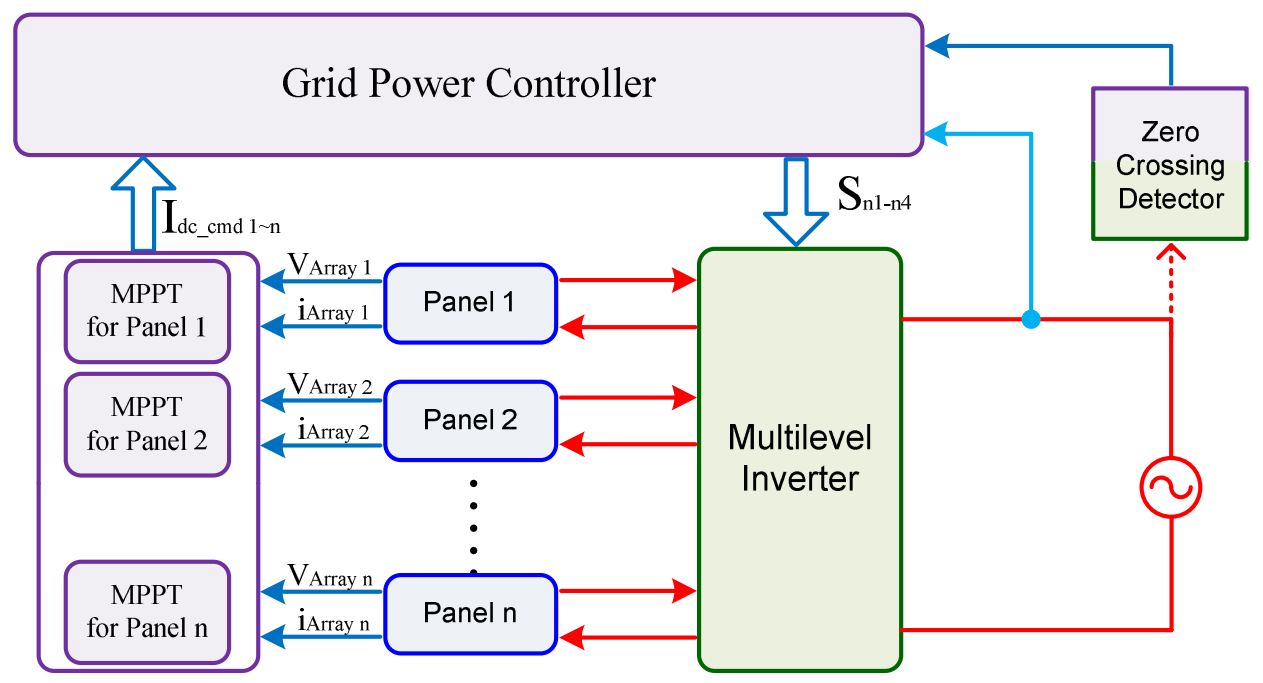

Figure 4.1: General block diagram of the overall system along with the control architecture. 


\subsection{Solar PV Model Development}

The solar PV simulation model is developed based on the the panel I-V and P-V characteristics given by the equations described in section 2.1. Figure 4.2 shows the generalized PV model implemented in MATLAB/Simulink environment. The model produces power and current based on the sun irradiance, cell temperature and the cell current.

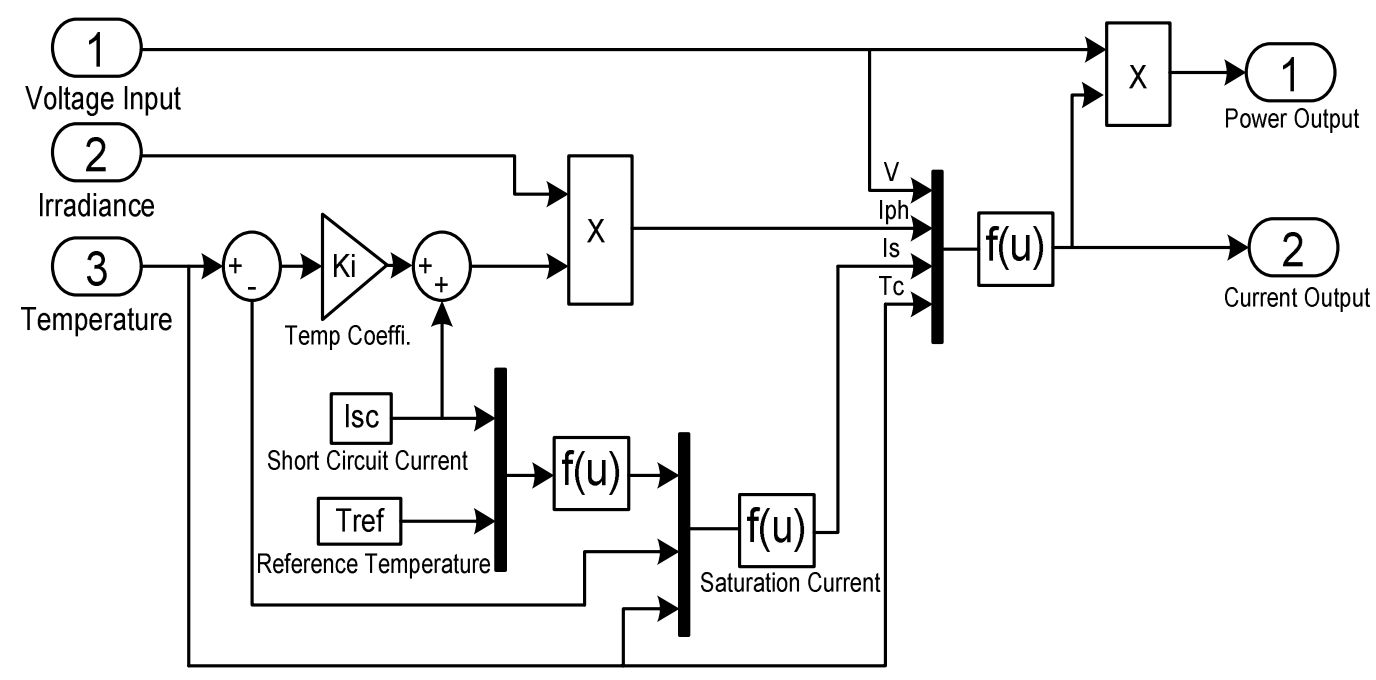

Figure 4.2: Generalized PV model.

The MPPT algorithm given in Section 2.6 is implemented for the individual PV panels. The irradiance value is varied such that it actually varies with time during the day, and the current, voltage and power curves were analyzed. The block diagram of this simulation is shown in Figure 4.3. The parameters are used for the PV module are given in Table 4.1. 
Table 4.1: Parameters used to develop the PV module

\begin{tabular}{|l|c|}
\hline \multicolumn{1}{|c|}{ Parameters } & Values \\
\hline Open Circuit Voltage, $\mathrm{V}_{\mathrm{oc}}$ & $22.1 \mathrm{~V}$ \\
\hline Short Circuit Current, $\mathrm{I}_{\mathrm{SC}}$ & $3.8 \mathrm{~A}$ \\
\hline Temperature & $25 \mathrm{C}$ \\
\hline $\mathrm{R}_{\mathrm{s}}$ & 0 \\
\hline $\mathrm{R}_{\mathrm{sh}}$ & inf \\
\hline Irradiance & $0 \sim 1$ \\
\hline
\end{tabular}

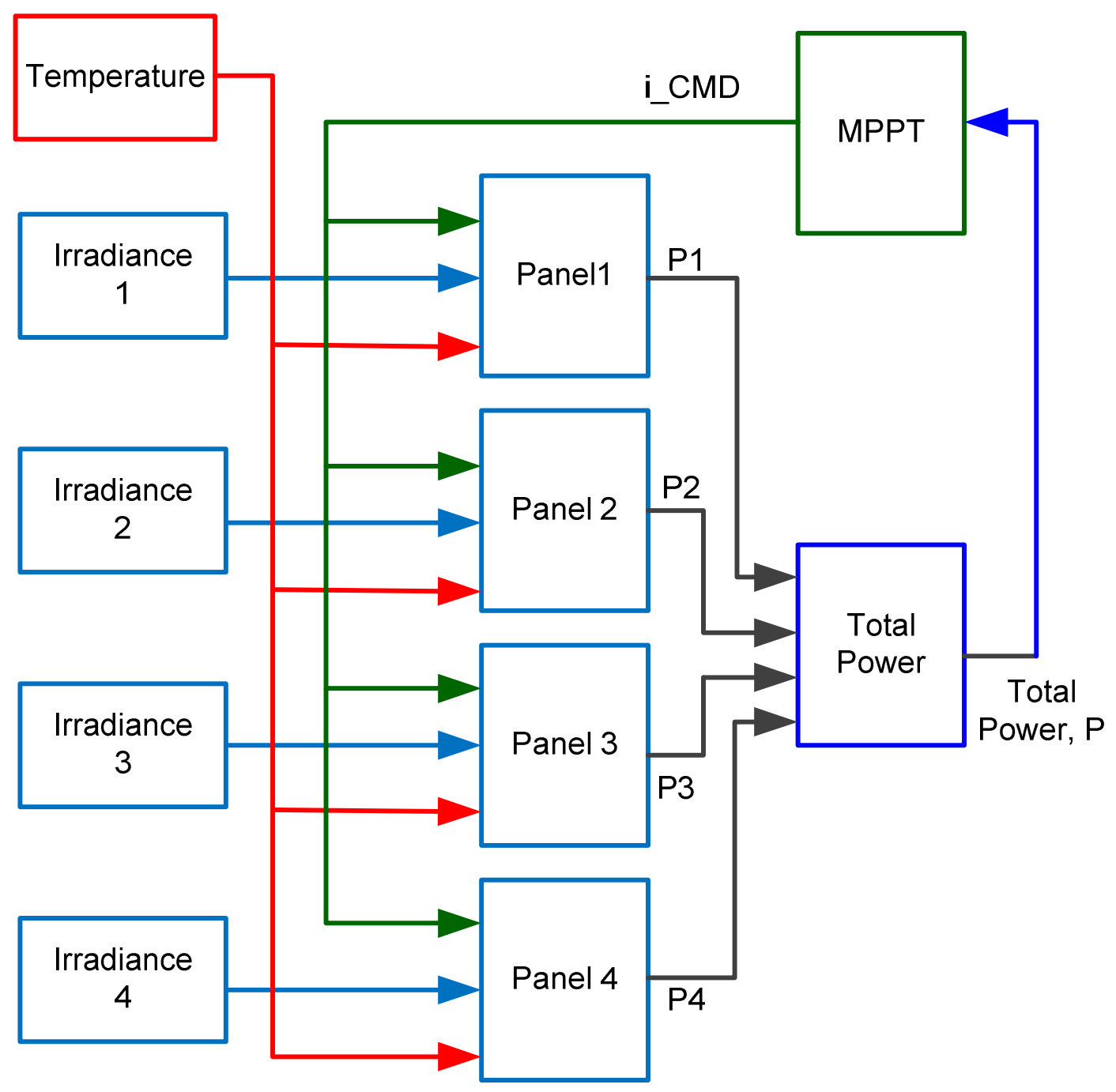

Figure 4.3: Block diagram of the MPPT operation for four panels. 
For a given irradiance change and the output current for all four panels shown in Figures 4.4(a) and 4.4(b), the change in the panel voltage and power is presented in Figures 4.4(c) and 4.4(d).

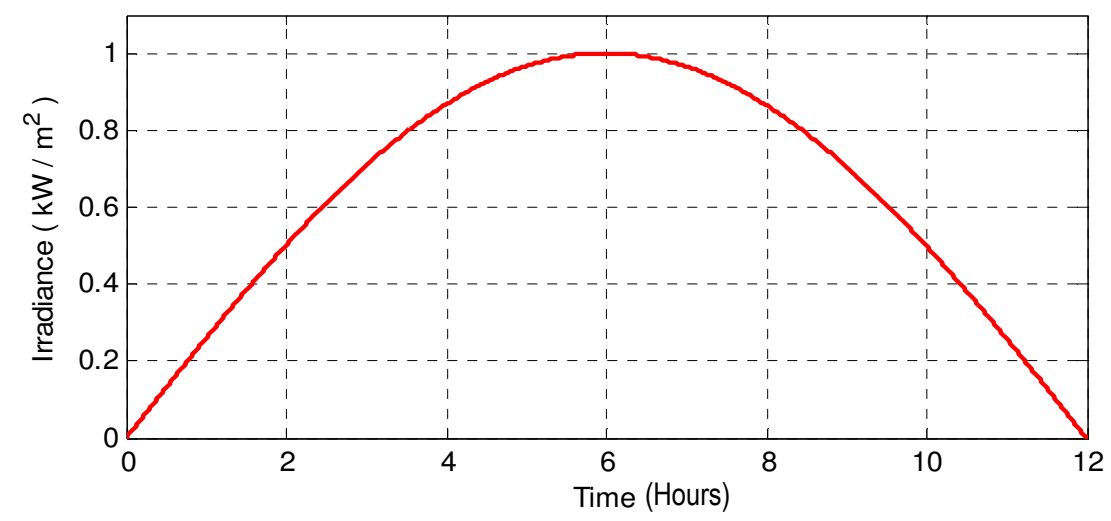

(a)

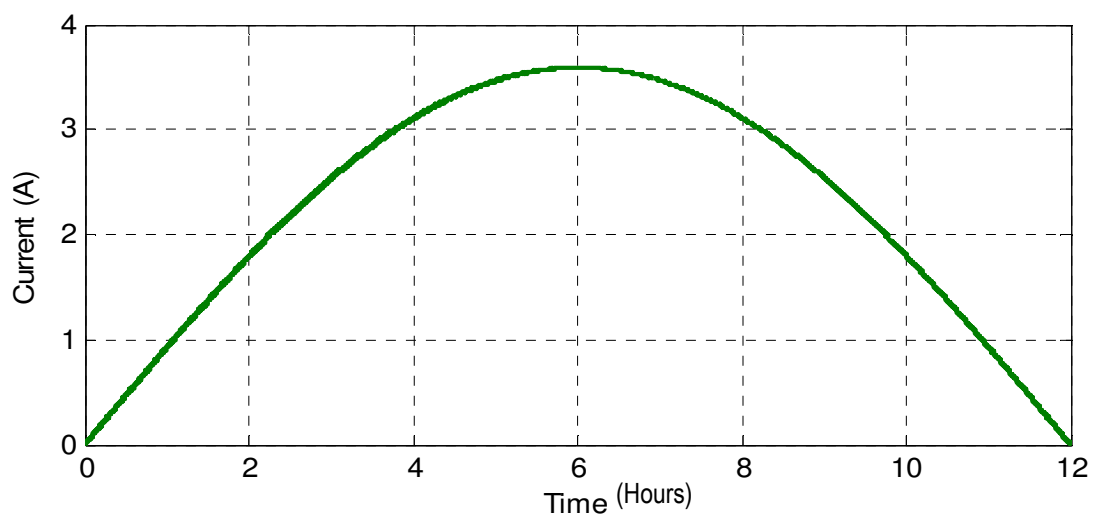

(b)

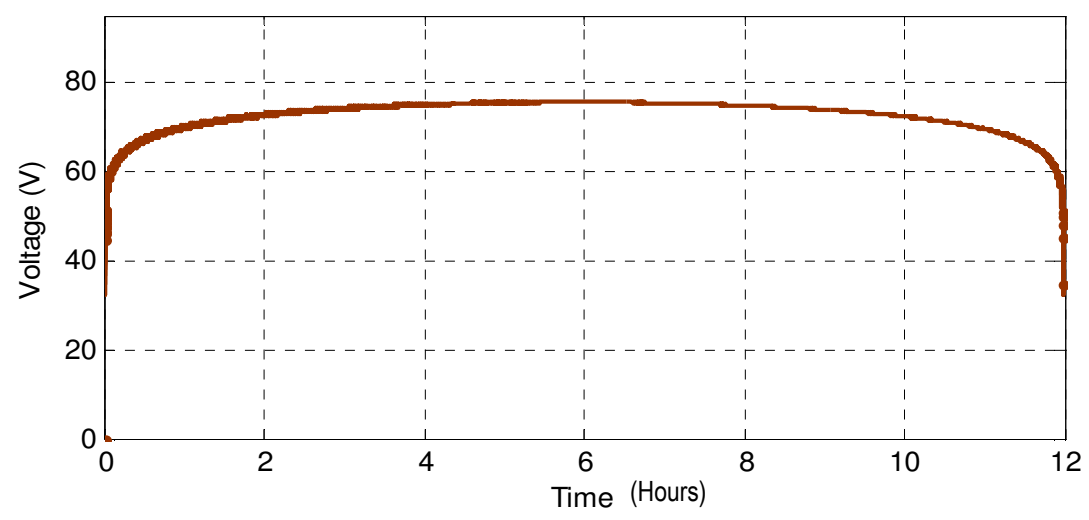

(c) 


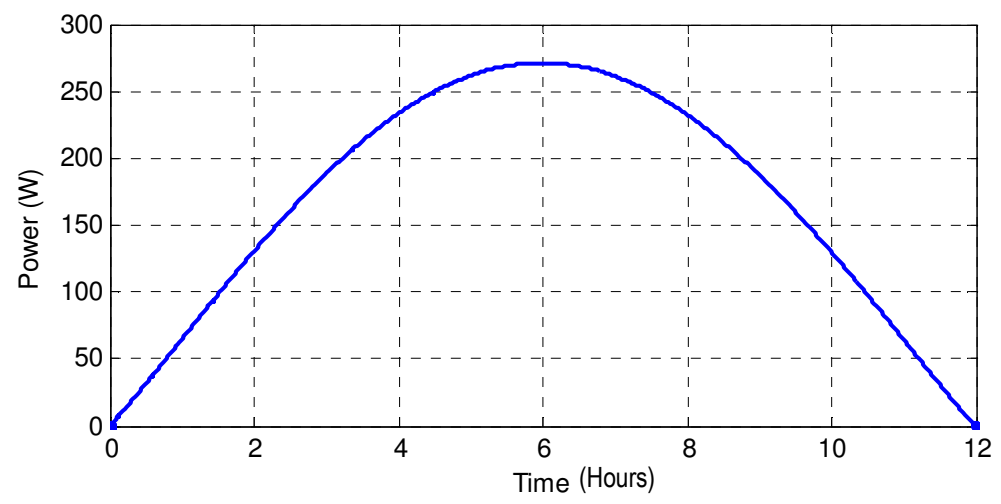

(d)

Figure 4.4: (a) Variable irradiance applied to the four panels, (b) Commanded current curve due to variable irradiance, (c) Total voltage output and (d) Output power curve due to variable irradiance.

\subsection{Cascaded Multilevel Inverter with Fixed Switching Angles}

A nine-level (with 4 H-bridges) cascaded multilevel inverter with fixed switching angles for different modules is considered. Each multilevel inverter cell is powered by 48V array for the simulation studies. Initial simulations are done for the stand alone systems.

Figure 4.5 shows the output voltage and current waveform, with a $10 \Omega$ output load. Both the voltage and current waveforms are staircase waveforms. Figures 4.6 and 4.7 show the inverter output voltage and output current with a $2.5 \mathrm{mH}$ inductive load. As shown from these figures, the voltage is a staircase waveform and the current is a $90^{\circ}$ phase shifted sinusoidal current. The overall simulation block diagram is shown in Figure 4.9 . 


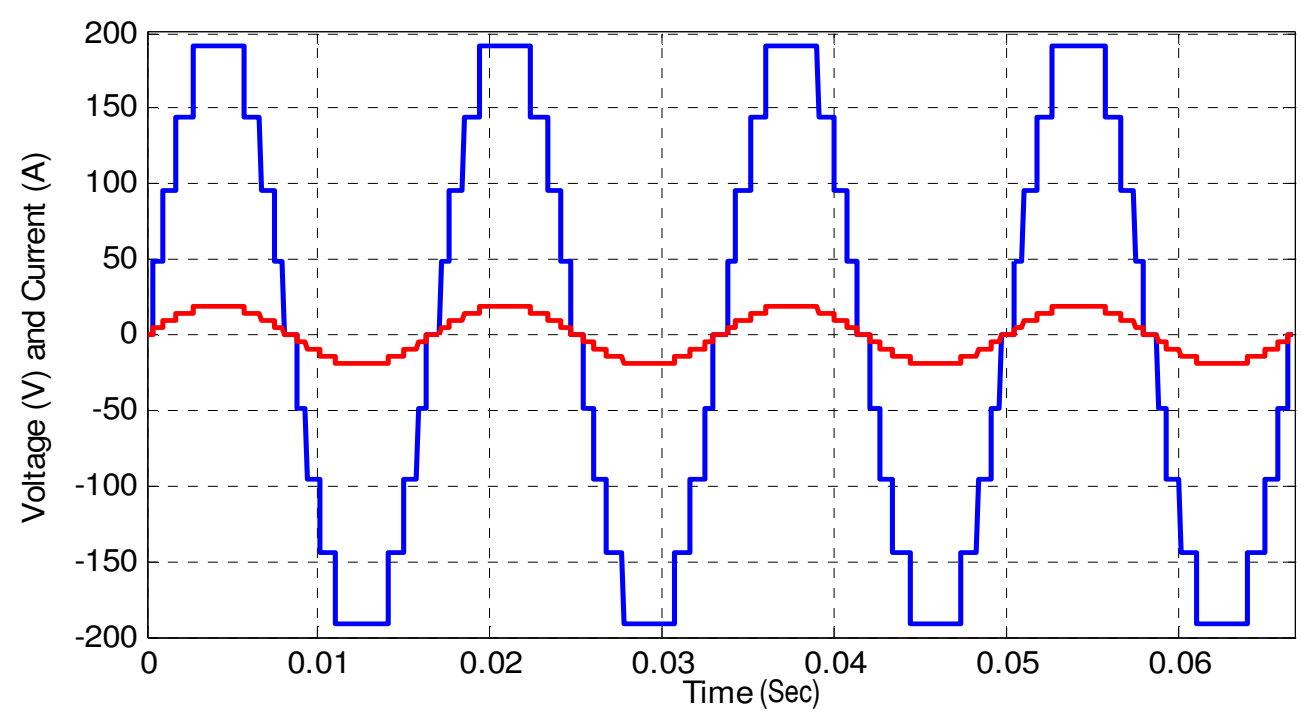

Figure 4.5: Inverter output voltage and current with a $10 \Omega$ resistive load.

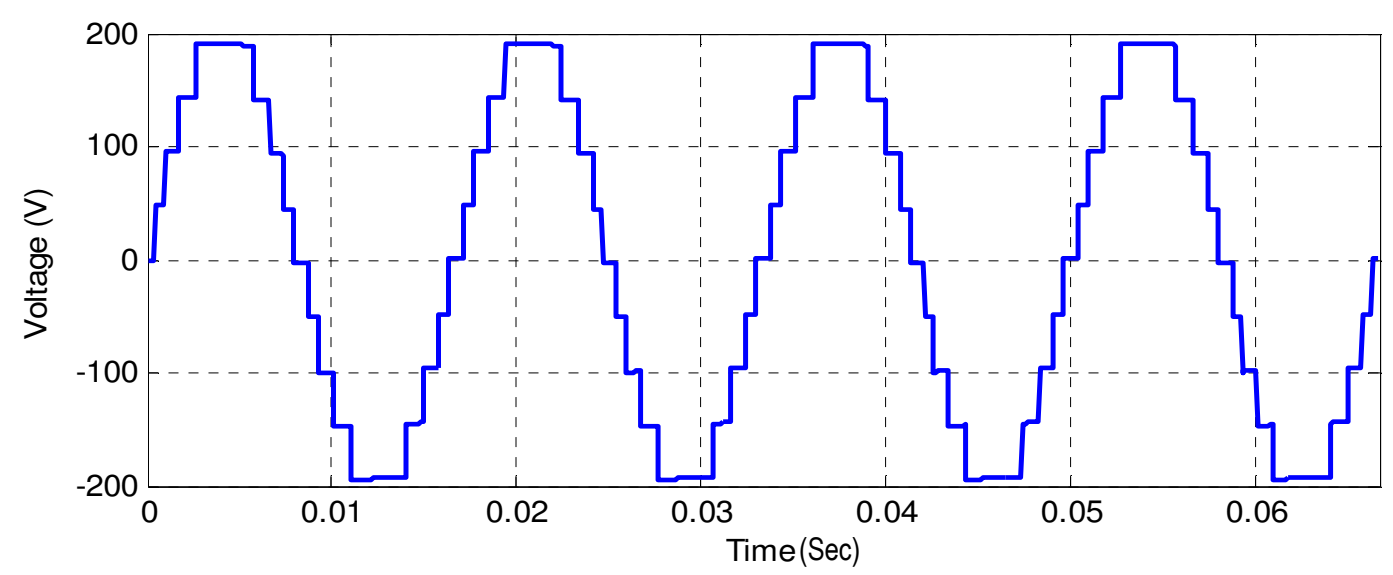

Figure 4.6: Inverter output voltage with a $2.5 \mathrm{mH}$ inductive load.

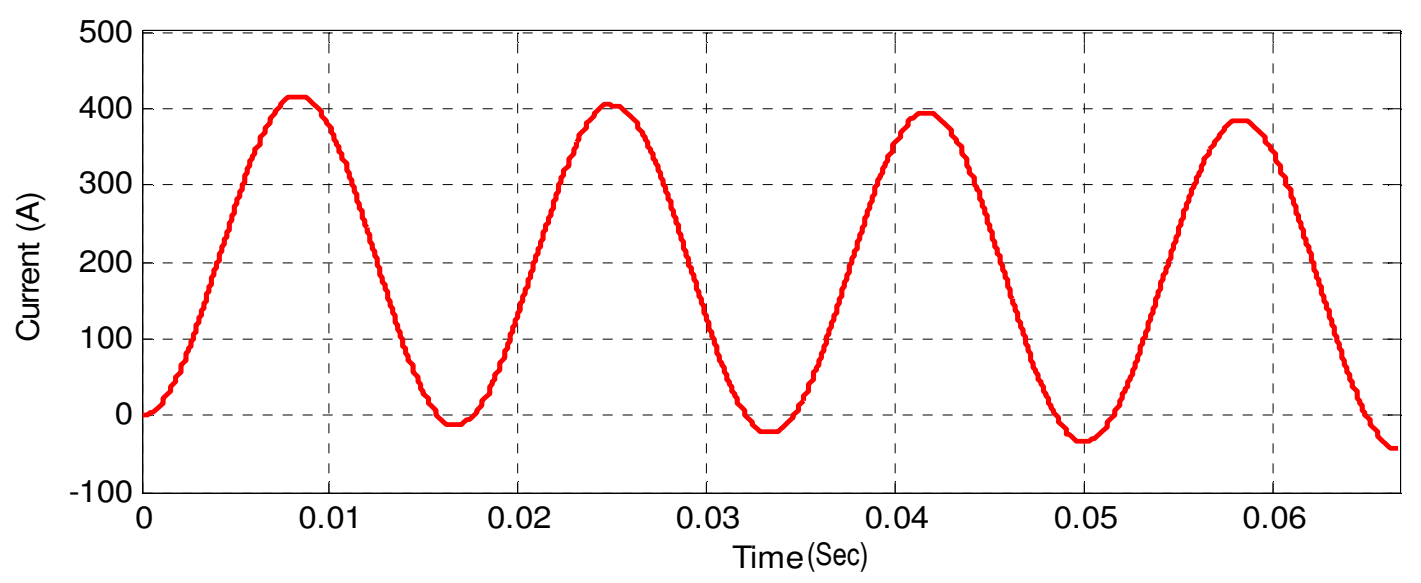

Figure 4.7: Inverter output current with a $2.5 \mathrm{mH}$ inductive load. 
Figure 4.8 shows the inverter output voltage and the current through a resistorinductor load, where $\mathrm{R}=10 \Omega$ and $\mathrm{L}=2.5 \mathrm{mH}$. The voltage waveform is staircase and the current is sinusoidal and phase shifted from the voltage $\left(<90^{\circ}\right)$.

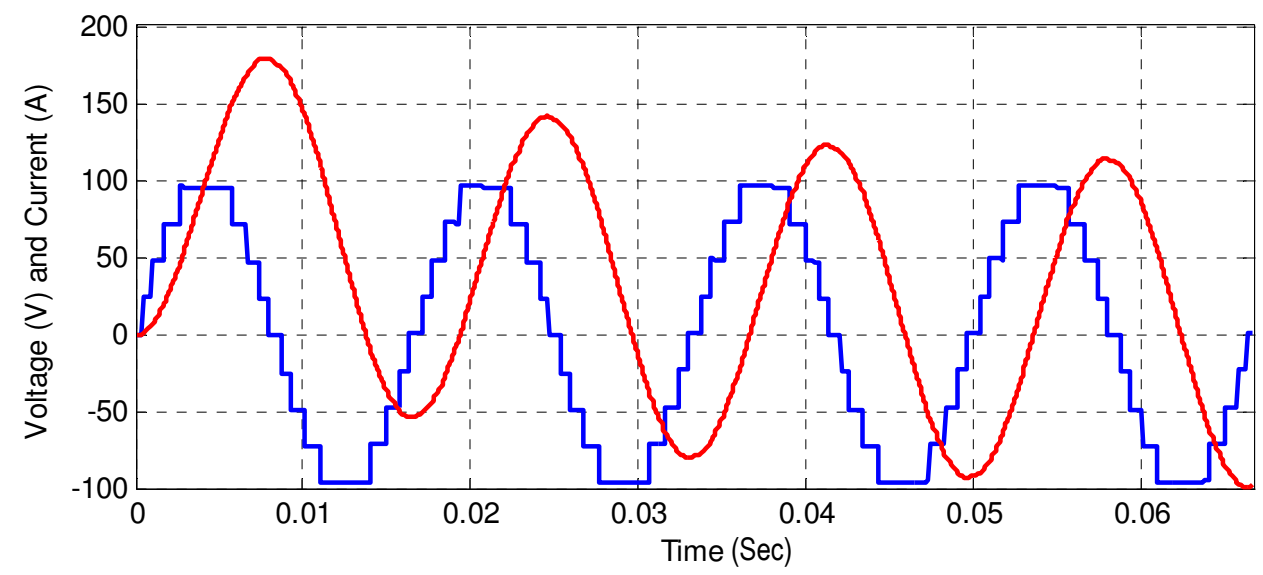

Figure 4.8: Inverter output voltage and current with a RL load.

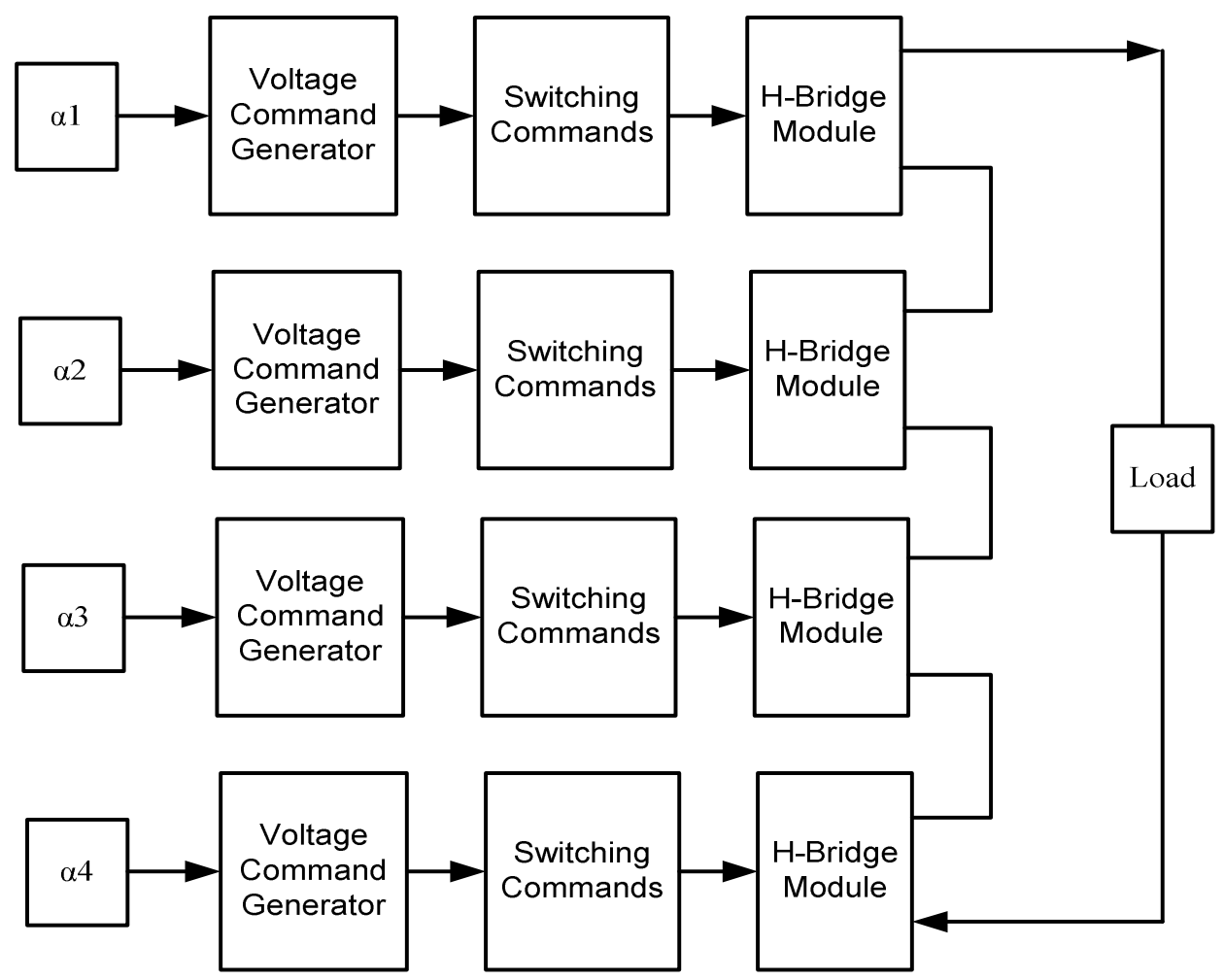

Figure 4.9: Block diagram of a cascaded multilevel inverter with fixed switching angles. 


\subsection{Cascaded Multilevel Inverter with Grid Connection}

The developed simulation model of the multilevel inverter is interfaced to the AC. A line inductor of $2.5 \mathrm{mH}$ is used to interface the inverter to the grid. Figure 4.10 shows the block diagram of this simulation.

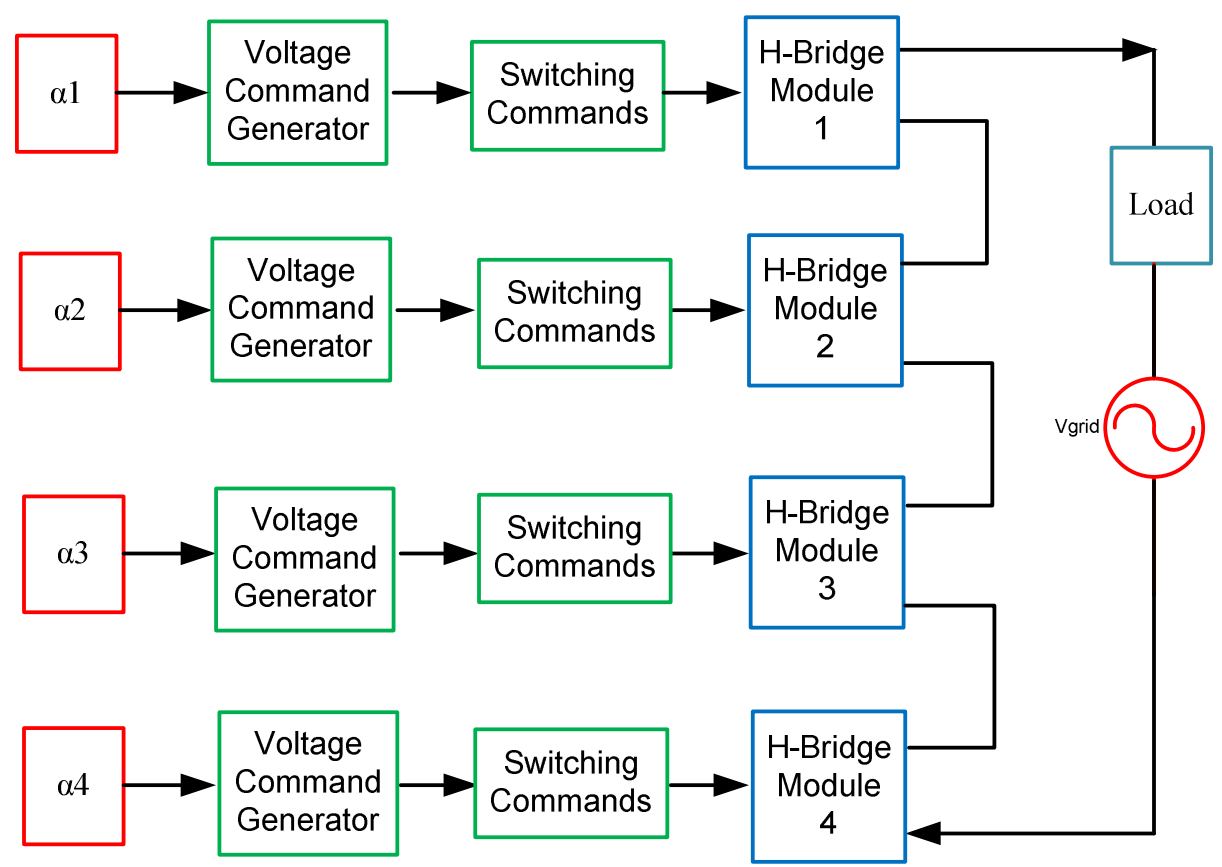

Figure 4.10: Block diagram of a cascaded multilevel inverter with the grid connection.

The power flow from the DC side to the grid is controlled by controlling the phase angle $(\delta)$ between the inverter and the grid voltages. The parameters used in the Simulink tool box for the above simulation are given in Table 4.2.

Table 4.2: Parameters used in the Simulink tool box

\begin{tabular}{|l|c|}
\hline \multicolumn{1}{|c|}{ Parameter } & Value \\
\hline $\mathrm{V}_{\text {inv }}$ Peak & $96 \mathrm{~V}$ \\
\hline $\mathrm{V}_{\text {grid }}$ Peak & $96 \mathrm{~V}$ \\
\hline $\mathrm{V}_{\text {grid }}$ Phase & $-10^{\circ}$ \\
\hline $\mathrm{V}_{\text {grid }}$ Frequency & $60 \mathrm{~Hz}$ \\
\hline $\mathrm{X}_{\mathrm{L}}$ & $0.942 \mathrm{mho}$ \\
\hline
\end{tabular}


Figure 4.11 shows the inverter output voltage and current and Figure 4.12 shows the grid voltage and line current.

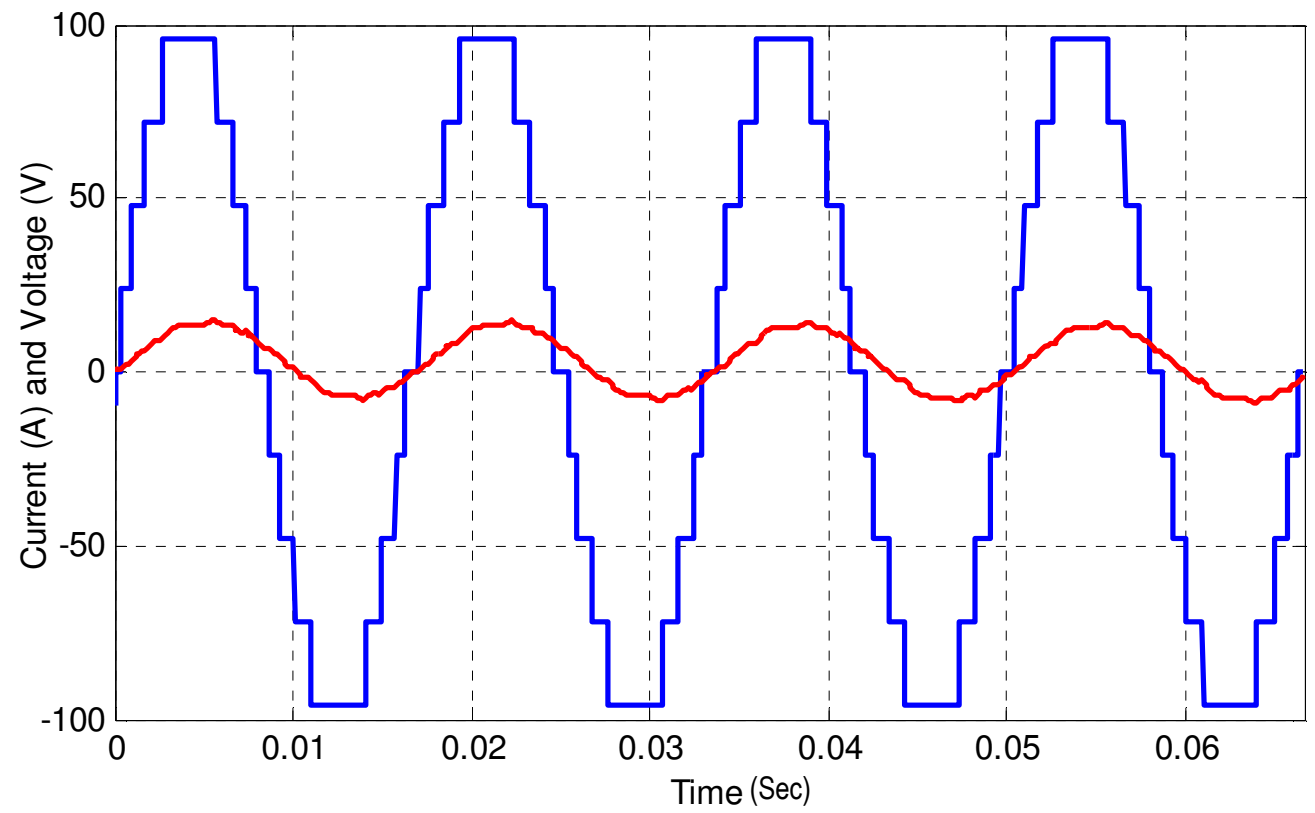

Figure 4.11: Inverter output voltage and current with grid connection.

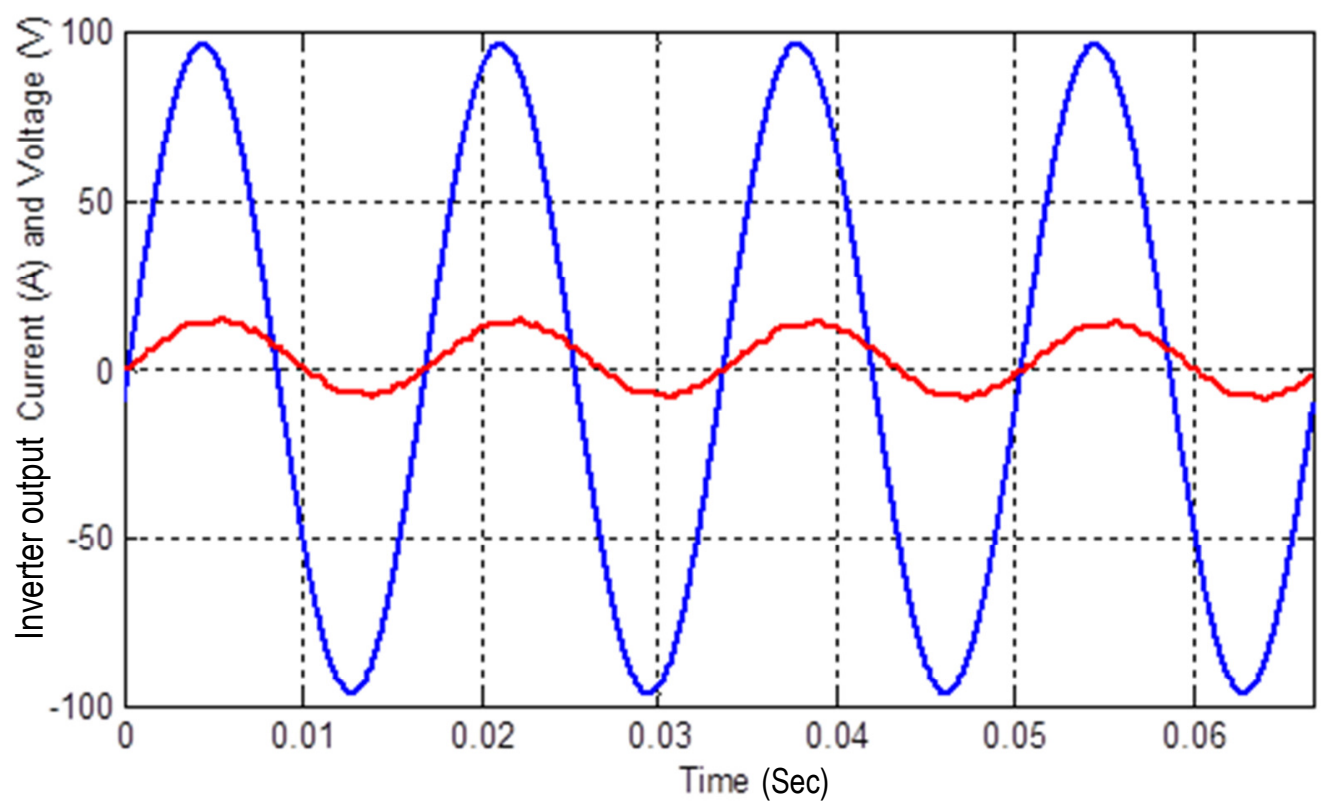

Figure 4.12: Grid voltage and line current. 


\subsection{Multilevel Inverter with Control Algorithm}

The control algorithm is implemented in the embedded MATLAB function and simulated in Simulink and Simpower toolbox. The control algorithm takes the current commands as the input and gives voltage commands as an output. The voltage commands are translated into switching commands for the H-bridge module. The output stage is connected to the grid by a line inductance in series. A $2.5 \mathrm{mH}$ inductor is used as the line inductor for the interfacing. The detailed Simulink blocks are given in Appendix A. The block diagram of this operation is shown in Figure 4.13.

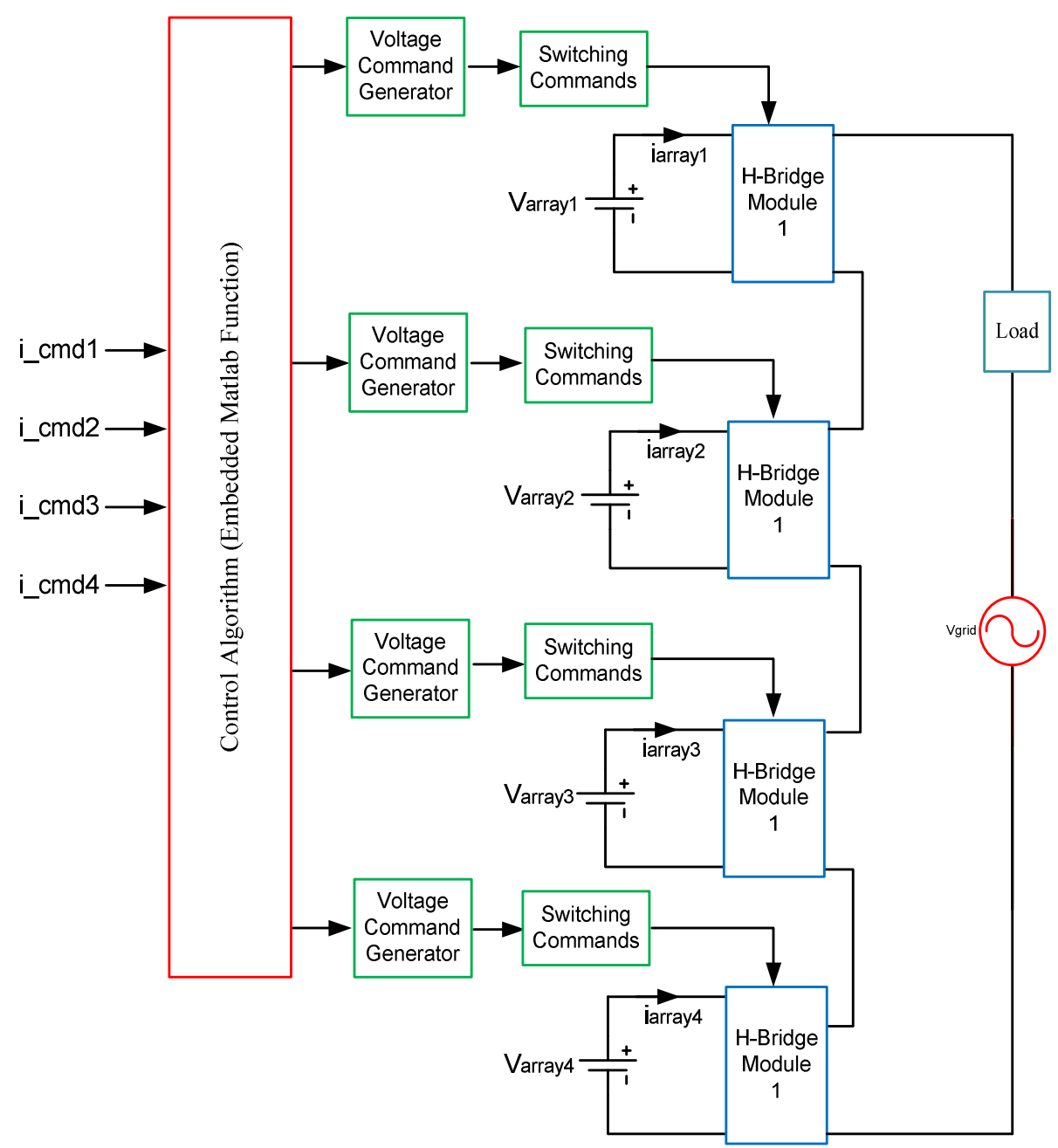

Figure 4.13: Block diagram of the multilevel inverter with the control algorithm. 
Figure 4.14 shows the simulation results where the switching angle $\alpha$ 's are interchanged between the panels during single utility cycle to draw currents as close as the commanded ones from the solar panels.
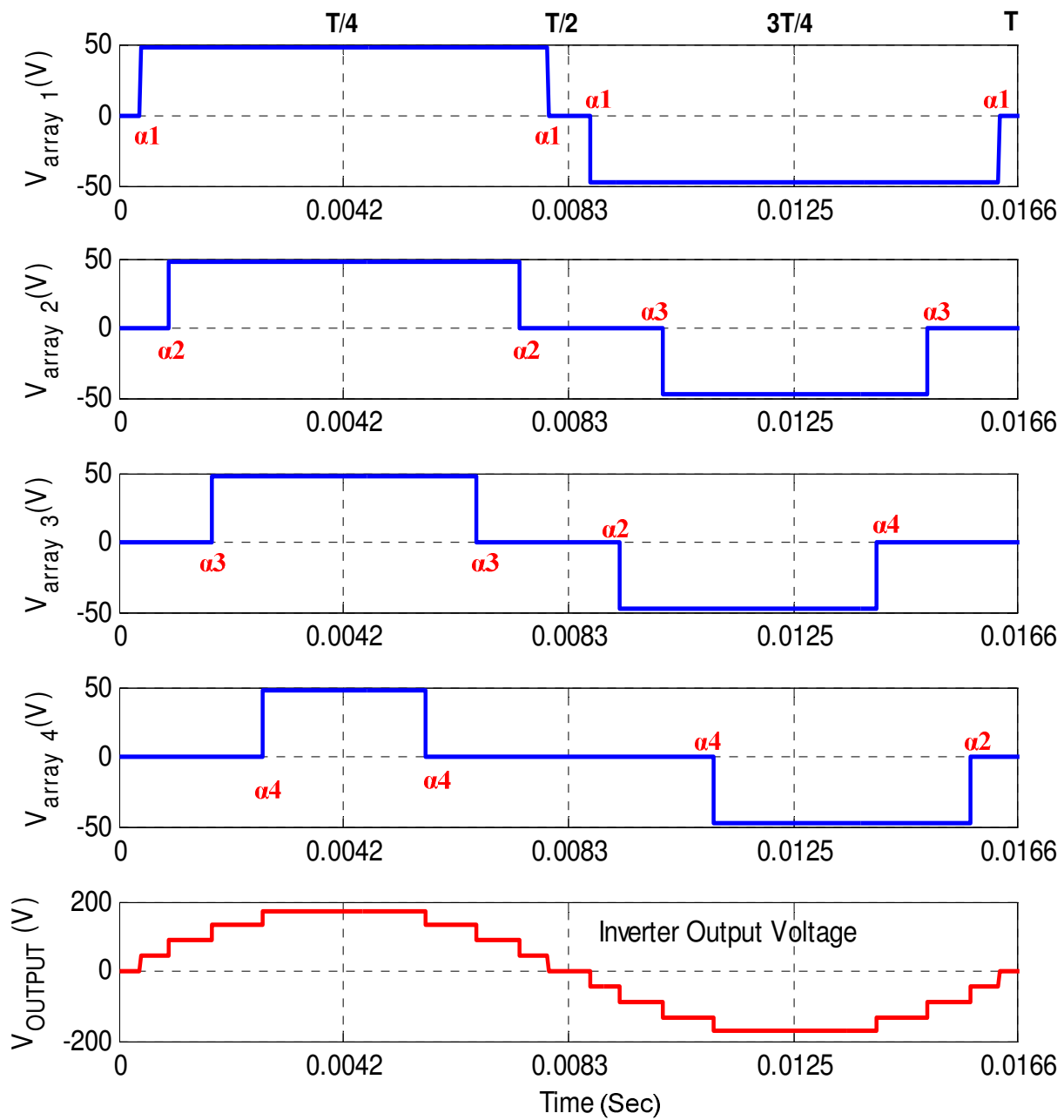

Figure 4.14: Individual cell output voltages and overall inverter output voltage.

Figure 4.15 shows the currents drawn from individual panels and overall inverter output currents through a resistive load. In this simulation, the commanded currents drawn from the individual solar panels were 11A, 10A, 9A and 7.5A. The control algorithm cycles the individual duty cycles around the multilevel inverter cells, and is able to produce the 
actual average currents of $11.47 \mathrm{~A}, 10.07 \mathrm{~A}, 8.92 \mathrm{~A}$ and $7.46 \mathrm{~A}$ respectively, which are very close to the commanded currents.
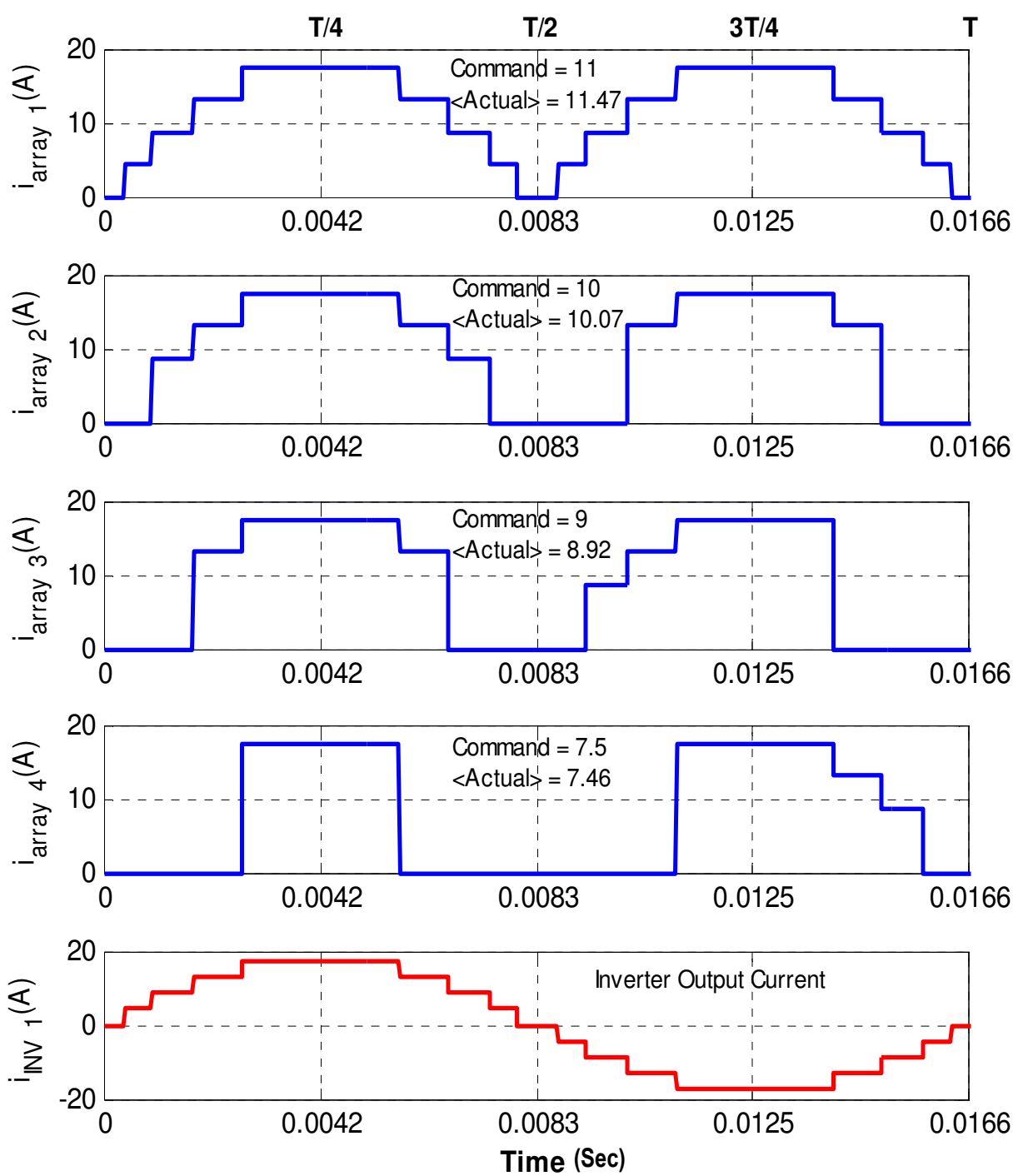

Figure 4.15: Individual cell currents and overall inverter output currents with a $10 \Omega$ resistive load where the current commands were 11A, 10A, 9A and 7.5A.

Figure 4.16 shows the simulation results for the commanded currents from the individual solar panels as $11 \mathrm{~A}, 10 \mathrm{~A}, 7.5 \mathrm{~A}$ and $9.5 \mathrm{~A}$. The control algorithm cycles the individual duty cycles to produce the actual average currents of $11.3 \mathrm{~A}, 9.66 \mathrm{~A}, 7.46 \mathrm{~A}$ and $9.48 \mathrm{~A}$ 
respectively, which are very close to the commanded currents. The results for these two simulations are summarized in Table 4.3.
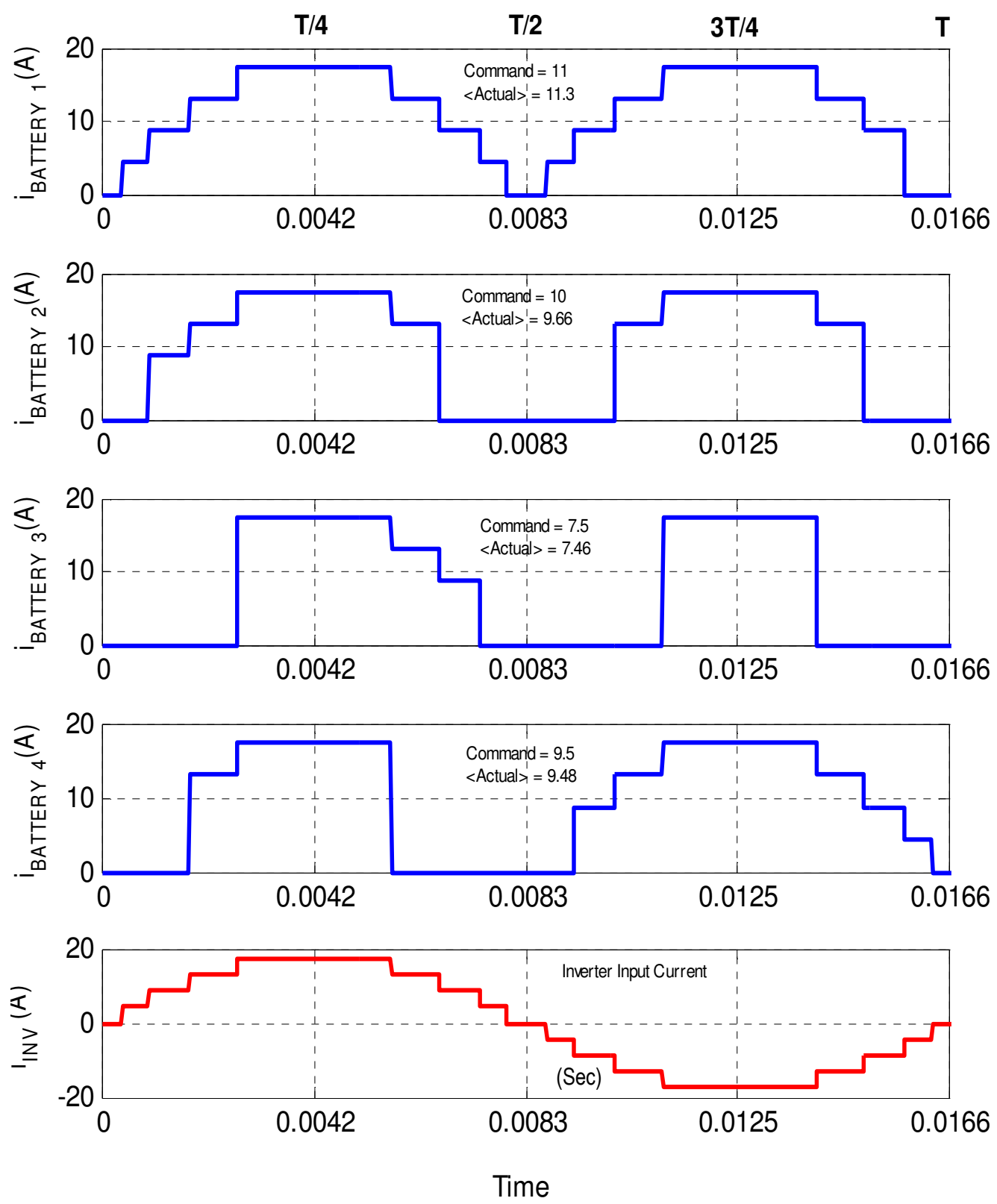

Figure 4.16: Individual cell currents and overall inverter output currents with a $10 \Omega$ resistive load where the current commands were $11 \mathrm{~A}, 10 \mathrm{~A}, 7.5 \mathrm{~A}$ and $9.5 \mathrm{~A}$. 
Table 4.3: Summary of test results for setup 1 and setup 2

\begin{tabular}{|c|c|c|}
\hline Panel No. & Current Commands & Actual Currents \\
\hline \multicolumn{3}{|c|}{ Setup 1 } \\
\hline 1 & $11 \mathrm{~A}$ & $11.47 \mathrm{~A}$ \\
\hline 2 & $10 \mathrm{~A}$ & $10.07 \mathrm{~A}$ \\
\hline 3 & $9 \mathrm{~A}$ & $8.92 \mathrm{~A}$ \\
\hline 4 & $7.5 \mathrm{~A}$ & $7.46 \mathrm{~A}$ \\
\hline \multicolumn{3}{|c|}{} \\
\hline 1 & Setup 2 \\
\hline 2 & $11 \mathrm{~A}$ & $11.3 \mathrm{~A}$ \\
\hline 3 & $10 \mathrm{~A}$ & $9.66 \mathrm{~A}$ \\
\hline 4 & $7.5 \mathrm{~A}$ & $7.46 \mathrm{~A}$ \\
\hline
\end{tabular}

\subsection{Summary}

The simulation results prove that, it is possible to draw different amounts of power from the individual solar panels by using the cascaded multilevel inverter. It also shows that using the developed algorithm, the currents drawn from the arrays can be controlled and are very close to the commanded inputs so that the arrays can operate at their individual MPP's. It is worth noting that each cell operates at the $60 \mathrm{~Hz}$ utility switching frequency.

These simulation results motivated us to do further research and design and implement the cascaded multilevel inverter prototype to test the control algorithm experimentally. In the next chapter, the prototype design and implementations are presented. 


\section{CHAPTER V}

\section{PROTOTYPE DESIGN AND IMPLEMENTATION}

\subsection{Introduction}

The simulation results prove that it is possible to control the output power of the individual solar panels by using the cascaded multilevel inverter which would allow them to be able to operate at their individual MPP. These results motivated us to design a prototype to validate the control algorithm with the experimental results. In this chapter, the hardware design and the software implementations are discussed in details.

\subsection{Hardware Implementation}

The power, gate driver, sensing, protection and interface circuitries were designed for a nine-level 800 watts multilevel inverter. The schematics of the detailed circuitry are drawn using ORCAD Capture CIS. The schematic design was followed by the PCB layout design using ORCAD PCB Layout Plus. PCB's are populated to form the system. The schematics and the PCB layouts of the overall system are given in Appendix B. The description of the individual circuit is presented in the following sections. The design specifications are given in Table 5.1. 
Table 5.1: Design specifications used for the hardware implementation

\begin{tabular}{|c|c|}
\hline $\begin{array}{c}\text { Rated power of the overall } \\
\text { inverter }\end{array}$ & $800 \mathrm{~W}$ \\
\hline Rated power of each module & $200 \mathrm{~W}$ \\
\hline $\begin{array}{c}\text { Rated input voltage for each } \\
\text { module }\end{array}$ & $30 \mathrm{~V}$ \\
\hline Output voltage & $71 \mathrm{~V}_{\mathrm{RMS}}$, \\
$60 \mathrm{~Hz}$ \\
\hline THD & $<10 \%$ \\
\hline
\end{tabular}

\subsubsection{MOSFET Driver Circuit}

The gate driver circuit consists of an ACPL-332J gate driver, a DC/DC converter and other circuit elements. ACPL-332J is an optically coupled gate driver with fault protection feature. These gate drivers are compatible to drive the MOSFETs used in the inverter.

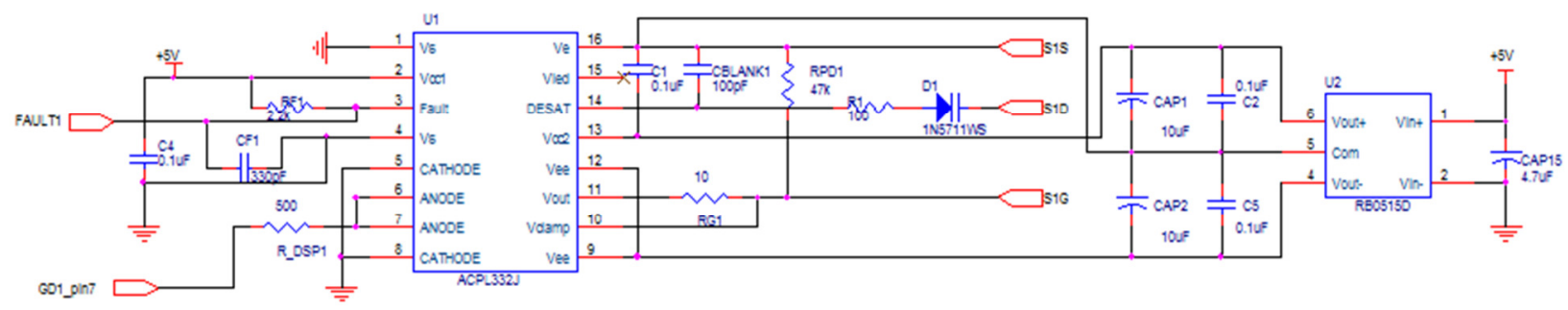

Figure 5.1: Gate driver circuit.

Gate driver is supplied with an isolated DC/DC converter, which converts $+5 \mathrm{~V}$ to $+15 \mathrm{~V}$ and $-15 \mathrm{~V}$. Gate resistors are chosen as $10 \Omega$ to limit gate currents at $1.5 \mathrm{~A}$.

\subsubsection{H-Bridge Module}

The H-Bridge module mainly consists of 4 MOSFETs and the DC link capacitors. The MOSFETs are n-channel and rated for $120 \mathrm{~V}, 80 \mathrm{~A}$. Four $1200 \mu \mathrm{F}, 50 \mathrm{~V}$ capacitors are 
used as the DC link capacitor. There are two connectors on both DC and AC side. The DC connector is to connect the PV panels to the H-Bridge and the AC side connector is to connect the AC outputs in a cascaded fashion.

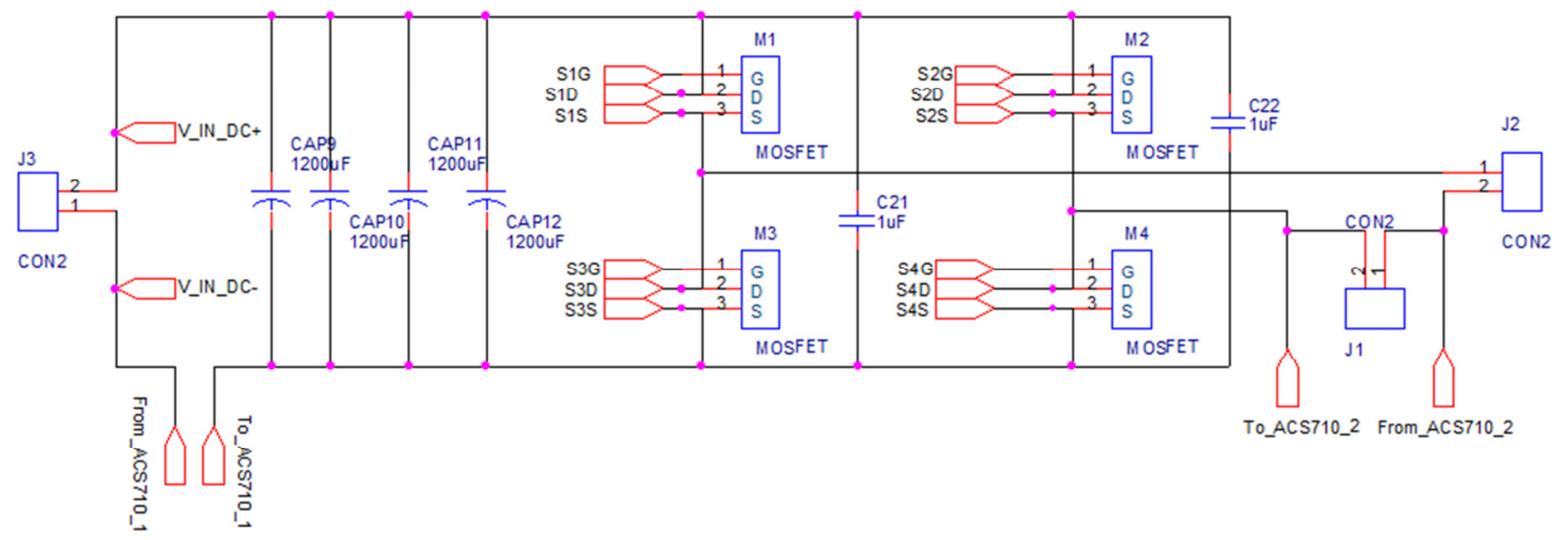

Figure 5.2: H-Bridge Module.

\subsubsection{Fault Detection and Protection Circuitry}

The fault protection circuit checks if there is any fault from the gate drivers. It also checks over-current and over-voltage protection condition. As soon as it receives a fault signal, the circuit stops sending PWM signals to the gate drivers. The circuit also consists of seven red LEDs and one green LED indicator to indicate the exact location of the fault signal.

\subsubsection{Current Sensor Circuit}

The current sensor circuit consists of an ACS710 high voltage isolated current sensor with over current protection. Resistor RH1 and RL1 in the circuit are chosen such that it limits the current up to $12 \mathrm{~A}$. If the current flows through this sensor exceeds $12 \mathrm{~A}$ it will send the over-current fault signal to the fault protection circuitry which will stop 
sending the PWM signals to the gate drivers. Figure 5.3 shows the current sensor circuitry.

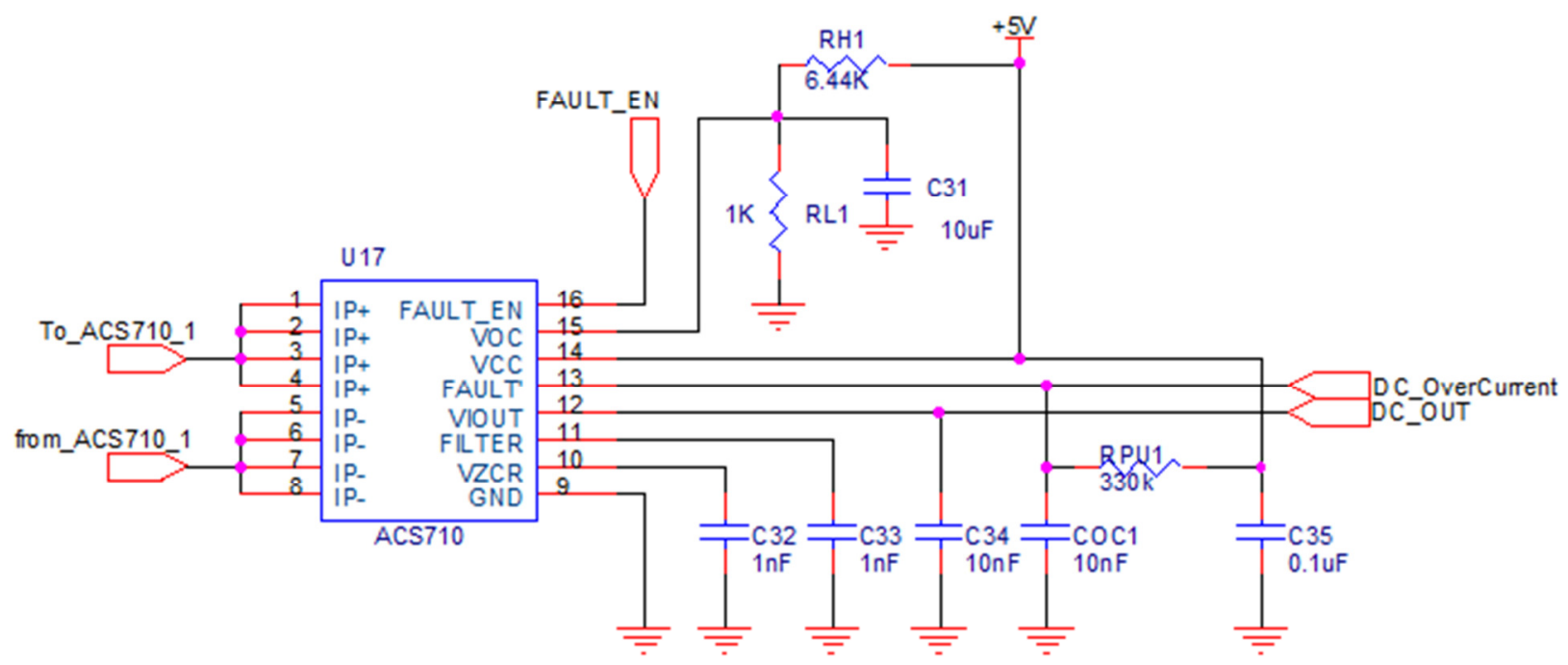

Figure 5.3: Current sensor circuitry.

\subsubsection{Grid Voltage Measurement Circuit}

The grid voltage information is necessary to synchronize the inverter output voltage to the grid. Figure 5.4 shows the voltage sensing circuitry. AD202 isolation amplifier is used to measure the grid voltage. The grid voltage is reduced with resistive devices. R2 and R4 are working as a voltage divider. For maximum input ac voltage, the voltage across $\mathrm{R} 4$ will be $-5 \mathrm{~V}$ to $+5 \mathrm{~V}$. The output of AD202 is the input of an inverting adder circuit consists of one of the TL081's. The output of this adder swings from -10V to $0 \mathrm{~V}$. This signal is fed into the second TL081, which is an inverting amplifier circuit with a fixed gain of $1 / 3$. The final output voltage swings between $0 \mathrm{~V}$ and $+3.3 \mathrm{~V}$ with a mid-point of $+1.67 \mathrm{~V}$. The signal is then fed into the DSP. 


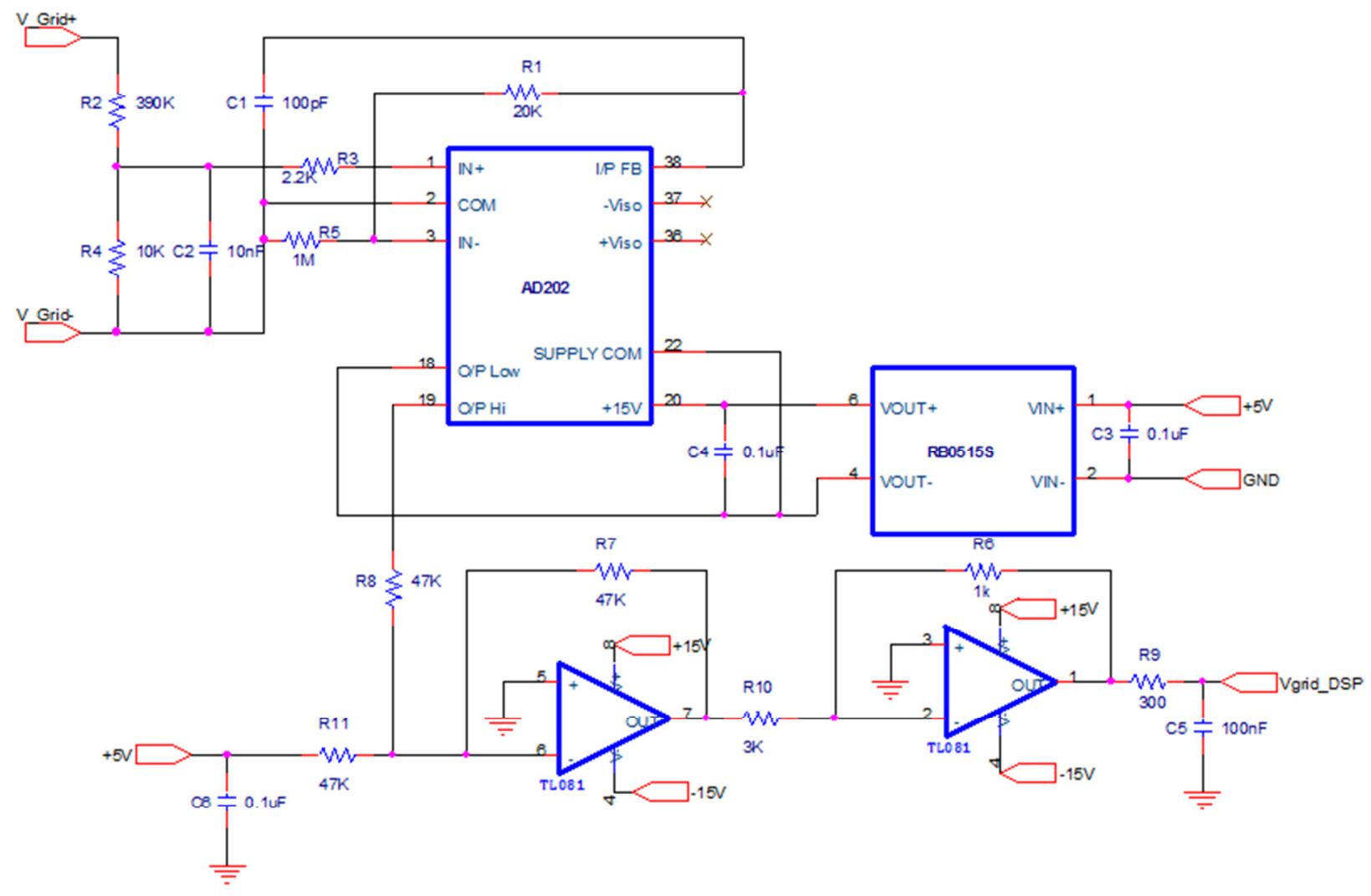

Figure 5.4: Grid voltage measurement circuit.

\subsection{Software Implementation}

The controller is based on one 16-bit Microchip DSP dsPIC33FJ64GS610. The control program is developed in the $\mathrm{C}$ language and the DSP is programmed by an InCircuit Debugger (ICD) interface using Explorer-16 development board. The interfacing between the DSP and the inverter was done by the Microchip PicTail Plus daughter board. The basic specifications of the DSP dsPIC33FJ64GS610 are given in Table 5.2. 
Table 5.2

\begin{tabular}{|l|c|}
\hline \multicolumn{1}{|c|}{ Parameter Name } & Value \\
\hline Architecture & $16-$ bit \\
\hline CPU Speed (MIPS) & 40 \\
\hline Memory Type & Flash \\
\hline Program Memory (KB) & 64 \\
\hline Temperature Range $\left({ }^{\circ} \mathrm{C}\right)$ & -40 to 125 \\
\hline Operating Voltage Range $(\mathrm{V})$ & 3 to $3.6 \mathrm{~V}$ \\
\hline I/O Pins & 85 \\
\hline Pin Count & 100 \\
\hline Internal Oscillator & $7.37 \mathrm{MHz}$ \\
\hline ADC Channel & 24 \\
\hline 16-Bit PWM Channel & 18 \\
\hline Timers & $4 \times 16-b i t 1 \times 32-b i t$ \\
\hline
\end{tabular}

There are two lookup tables assigned in the control program. The first one is the different combinations of a set of 16 switching angles for four modules generated offline. In the case of four inverter cells, there will be 427 different switching combinations. The second lookup table is of the calculated per unit estimated currents. These per unit currents are the normalized values and are calculated based on the switching angles lookup table. Each combination of the switching angles corresponds to an estimated per unit current, which is later used to compare with the commanded currents to find the corresponding set of switching angles.

In the DSP dsPIC33FJ64GS610, there are five Timers, nine analog input channels and sixteen PWM channels used in the control algorithm. The brief descriptions of each module are given in the following sections. 


\subsubsection{Timers}

The dsPIC33FJ64GS610 offers several 16-bit Timer modules. Each Timer module is a 16-bit timer/counter consisting of TMRx, PRx and TxCON registers and associated interrupt control bits. Figure 5.5 shows a block diagram of the different Timers' operations in the control algorithm.

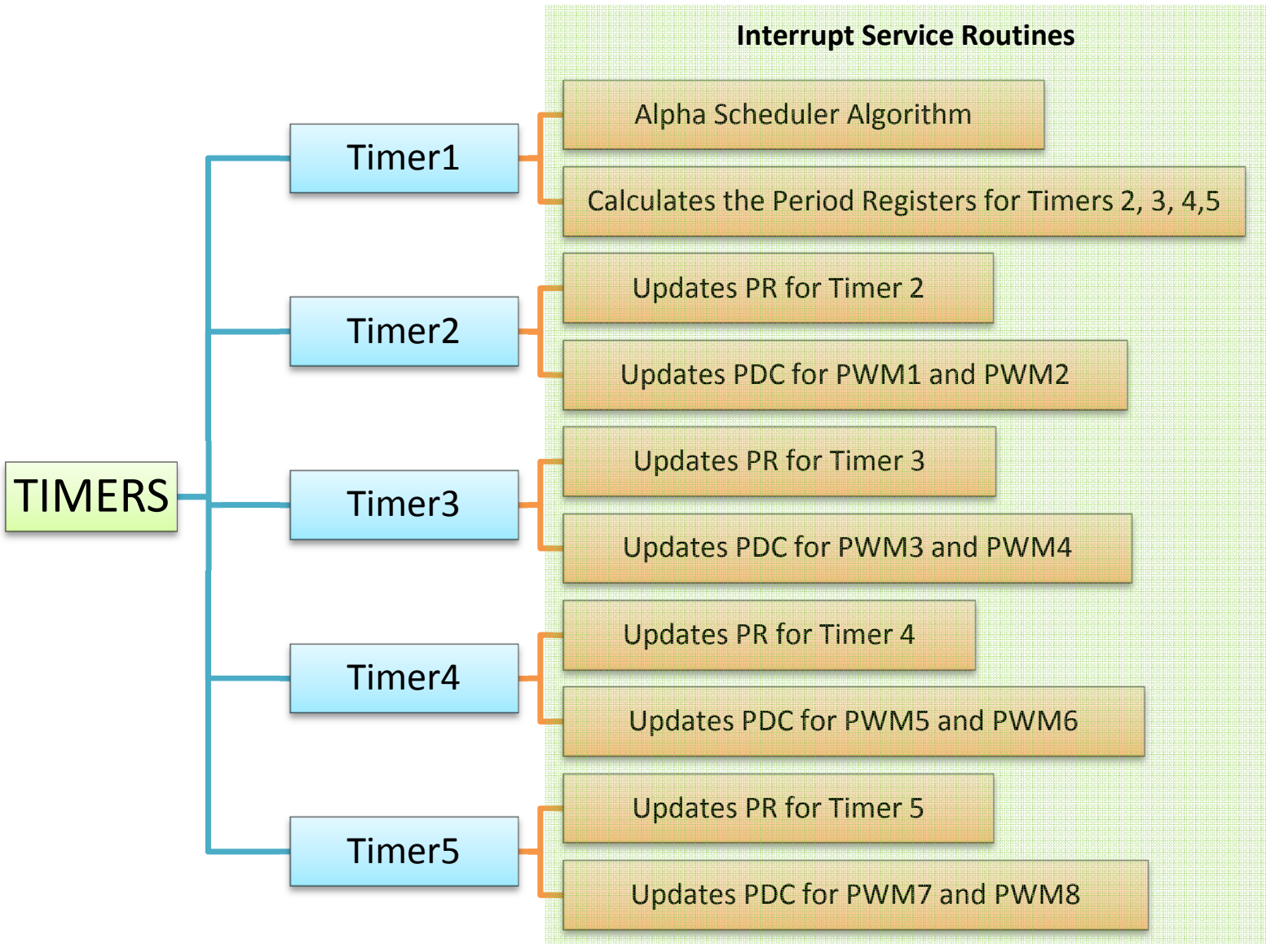

Figure 5.5: Block diagram of the Timers' operations.

In Timer 1 interrupt service routine (ISR), $\alpha$-Scheduler algorithm is implemented.

The algorithm iterates to look for the minimum error between commanded and the estimated Per Unit currents and finds the optimum set of sixteen switching angles. The interrupt service routine also converts the switching angles from radian to mili-seconds. 
A complete inverter output cycle is divided into eight segments. The duration of each segment is calculated by using a set of four $\alpha$ 's for each inverter module.

In Timer 2 ISR, the program checks the segment number and updates its period register accordingly. During each segment, the program updates the duty cycle of PWM1H and PWM2H for the switches S1 and S2, respectively. PWM1L and PWM2L are the complementary signal of PWM1H and PWM2H, and applied to the switches S3 and $\mathrm{S} 4$, respectively.

Timer 2 ISR updates the duty cycle of PWM1 and PWM2 for the inverter module1, while it also updates its period register (PR). Timer 3, Timer 4 and Timer 5 perform the same operation of PWM3 to PWM8 for the inverter module 2, module 3 and module 4. PWM3H, PWM3L, PWM4H and PWM4L are applied to switches S1, S2, S3 and S4 of the inverter module 2, respectively. In the same fashion, PWM5H, PWM5L, PWM6H and PWM6L are applied to switches S1, S2, S3 and S4 of the inverter module 3 and PWM7H, PWM7L, PWM8H and PWM8L are applied to switches S1, S2, S3 and S4 of the inverter module 4, respectively. Figure 5.6 shows the above operation graphically for Timer 2. As mentioned above, Timer 3, Timer 4 and Timer 5 perform the same operation, and the period registers of different Timers depend on the corresponding set of 4 switching angles of that particular module. 

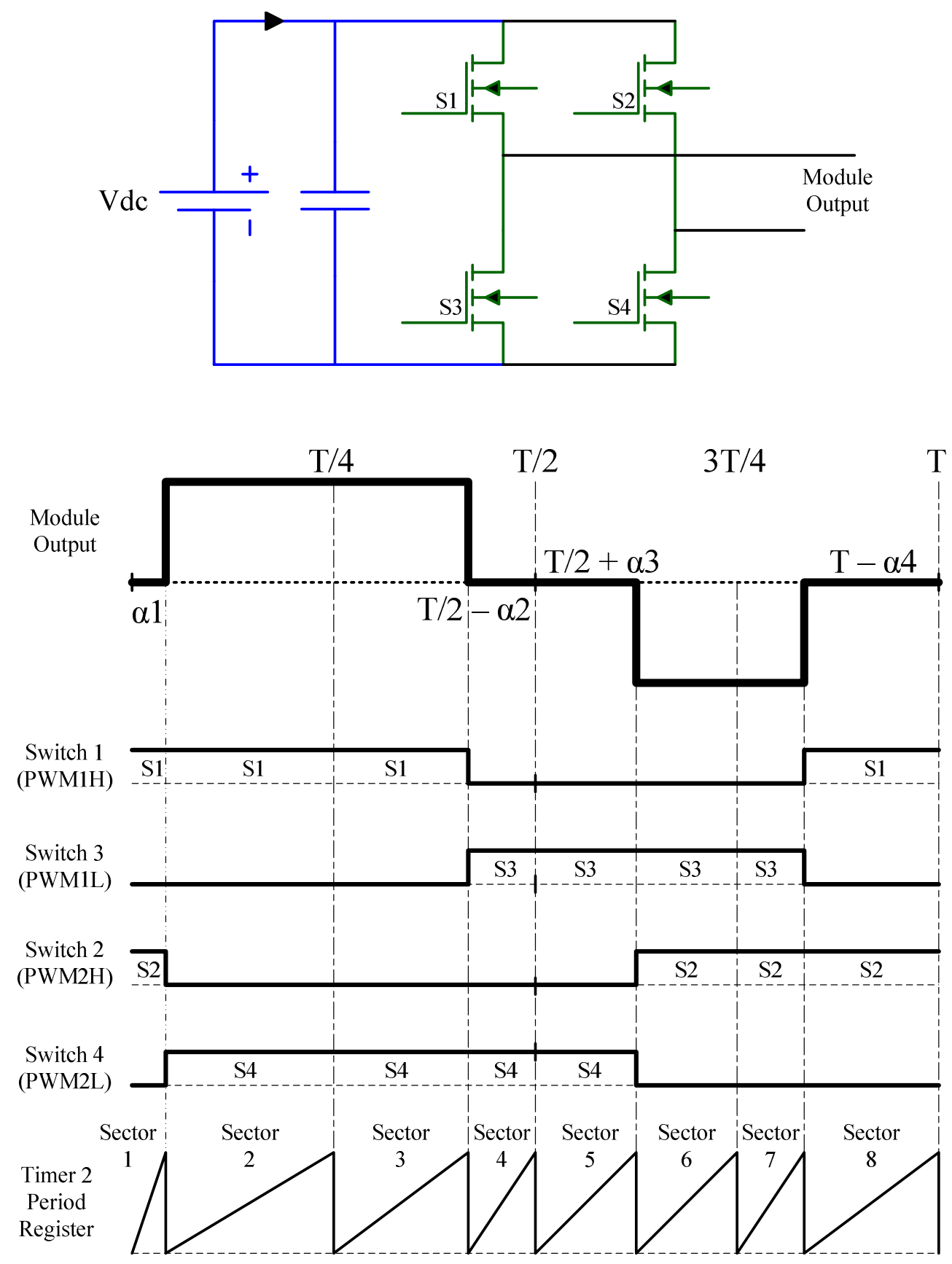

Figure 5.6: Module output, state of the switches 1,2, 3 and 4 in one utility cycle and the Timer 2 period register/counter. 


\subsubsection{PWM Generator}

The DSP dsPIC33FJ64GS610 has nine high speed PWM generators. It offers individual time base and duty cycle for each PWM output with a frequency resolution of 1.04 ns. The primary control registers of the PWM module are PTCON, PTPER, PDCx, PWMCONx, DTRx, ALTDTRx and IOCONx. Figure 5.7 shows the distribution of PWM signal generation for the four switches in each inverter module using the eight PWM generator modules in the DSP.

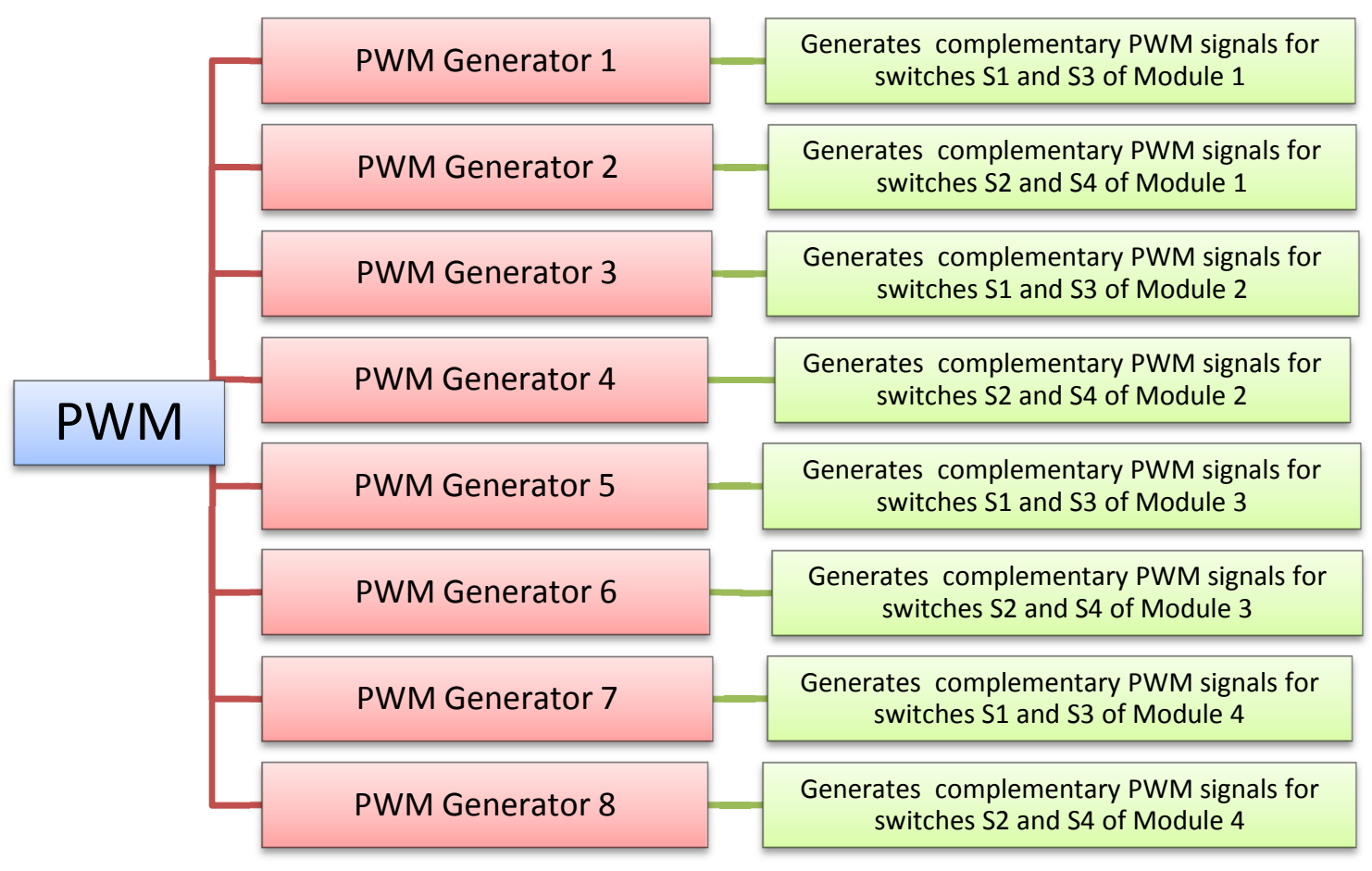

Figure 5.7: PWM generation for the inverter switches using the eight PWM generator modules in the DSP. 


\subsubsection{Analog to Digital Converter}

The DSP dsPIC33FJ64GS610 has a 10-bit high speed Analog-to-Digital converter (ADC) module with 4 mega samples per second conversion rate. It has twenty-four analog input channels grouped into six conversion pairs. The primary control registers of the ADC module are ADCON, ADSTAT, ADBASE, and ADPCFG. The current and voltage sensors send the analog signals to the DSP. The ADC module converts the analog signal into digital form for using in the control algorithm. Figure 5.8 shows the block diagram of the ADC operation in the control algorithm.

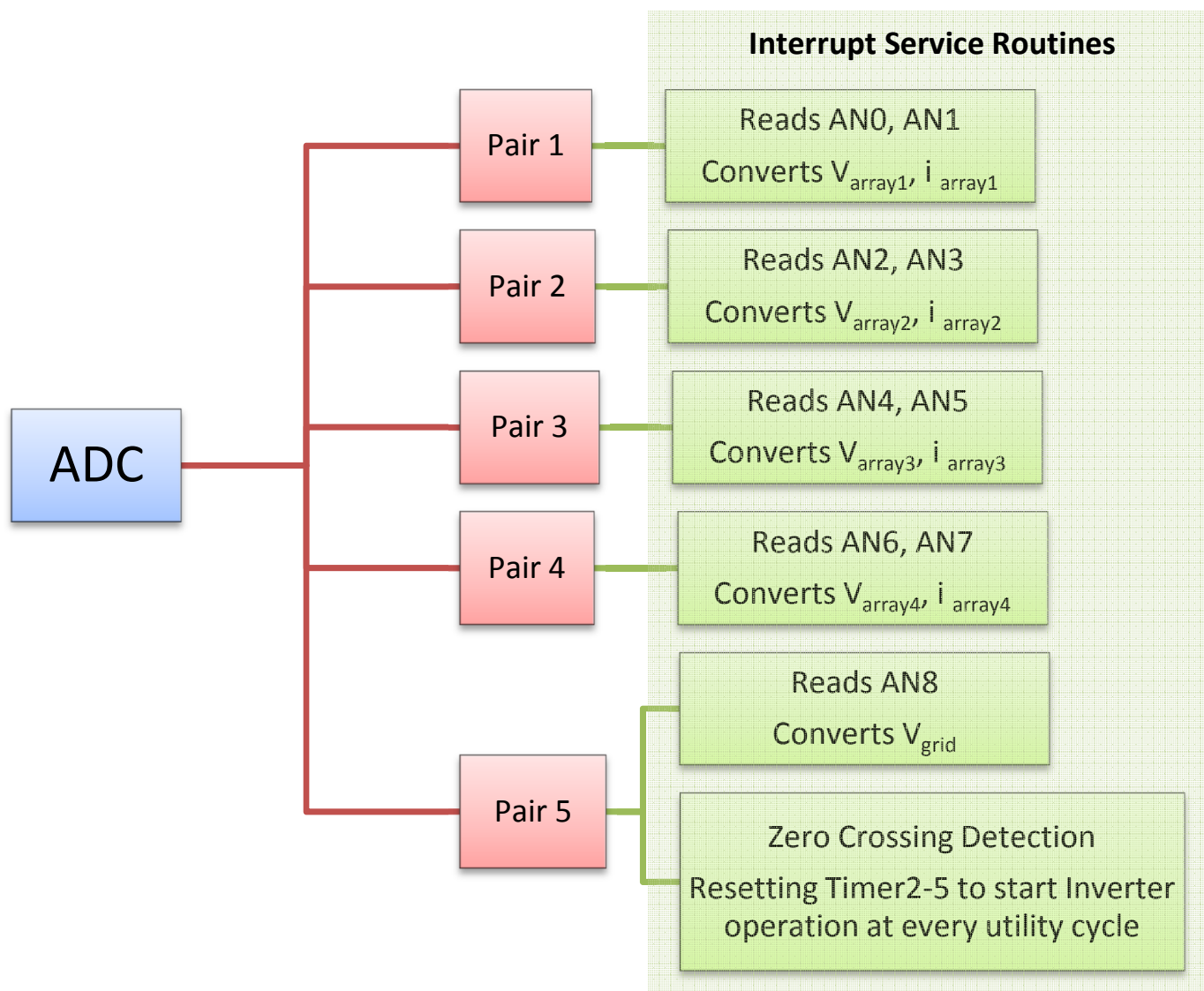

Figure 5.8: Block diagram of ADC operation. 
The zero crossing detection algorithm is implemented in the ADC Pair5 interrupt service routine, where the algorithm checks the positive zero crossing of the grid voltage. As soon as it detects the positive zero crossing, it resets the Timer 2, Timer 3, Timer 4 and Timer 5 and starts the inverter operation. The zero crossing detection is performed at every positive zero crossing instants of the grid voltage to synchronize the inverter output voltage with the grid voltage.

\subsection{Summary}

In this chapter, the hardware design and the software implementations are discussed in details. The prototype of the multilevel inverter is implemented by using four inverter modules with each module fabricated in a four layer printed circuit board. The control algorithm is developed in a Microchip 16-bit DSP dsPIC33FJ64GS610 using the In-Circuit Debugger (ICD) and the Explorer-16 development board.

In the next chapter, the experimental results obtained by using the implemented inverter are presented. These results demonstrated that it is possible to control the power from the individual solar panels by using the cascaded multilevel inverter, and the developed control algorithm. 


\section{CHAPTER VI \\ EXPERIMENTAL RESULTS}

\subsection{Introduction}

The developed experimental system has been tested extensively to evaluate the control algorithms for standalone and grid-connected operations. In these tests, high precision measurement instruments were used for better data collection and evaluation. The efficiency measurements were done using a high precision power analyzer (Yokogawa WT3000 Power Analyzer [29]). Voltage and current waveforms were acquired using the Tektronix four channel digital oscilloscopes (Tektronix MSO 2024), HV differential voltage probes (Tektronix P5200), and the AC/DC current probes (Tektronix A622).

\subsection{Experimental Setup}

A single-phase structure of a nine-level cascaded multilevel inverter with four $25 \mathrm{~V}$ battery units as solar panel emulators have been utilized in the experimental setup. Each power stage is supplied by a $25 \mathrm{~V}$ DC battery pack. Each battery pack has two $12.5 \mathrm{~V}, 18 \mathrm{AH}$ battery modules connected in series. In the control circuit, 16-bit DSP dsPIC33FJ64GS610 is employed to generate the required gate signals. A $2.5 \mathrm{mH}$ inductor 
is used as the line inductance. Figure 6.1 shows the pictures of the experimental setup. All experiments were done at the room temperature conditions.

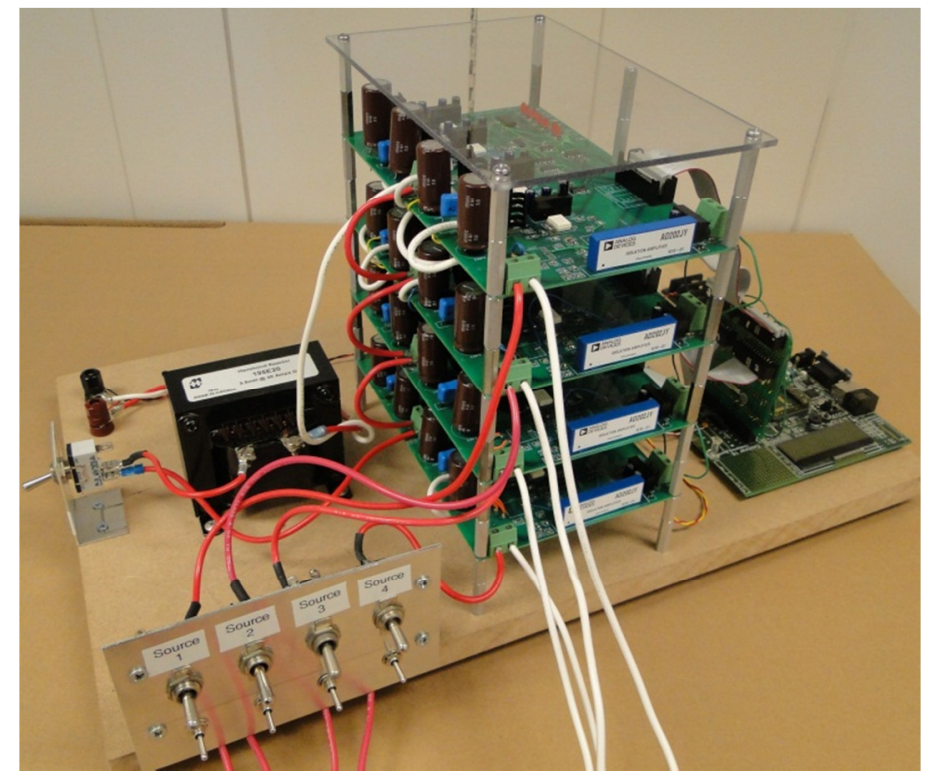

(a)

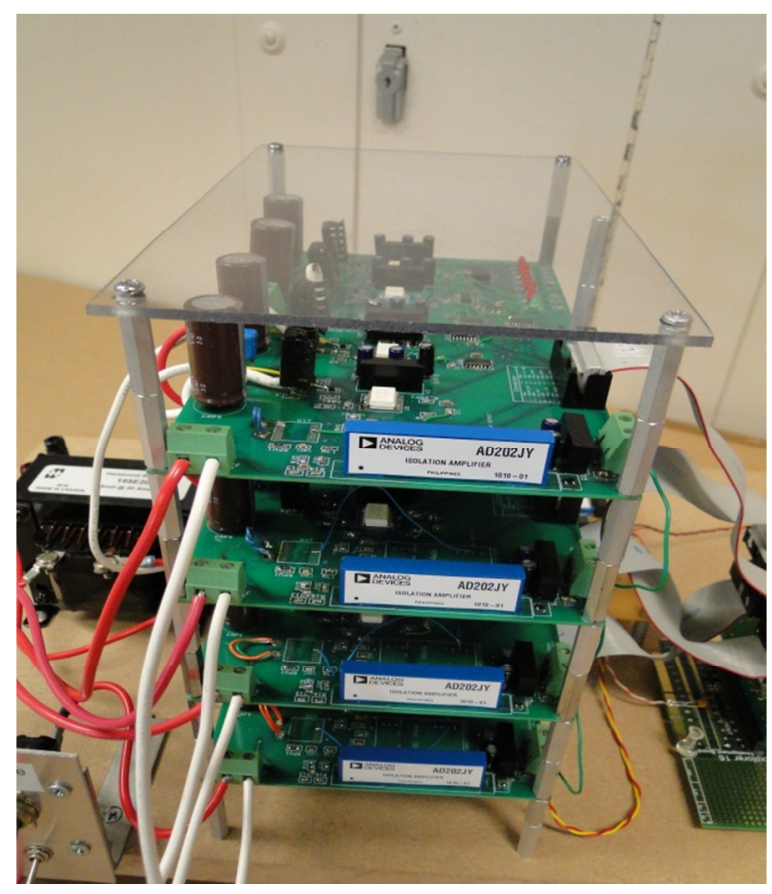

(b)

Figure 6.1: (a) Experimental setup (b) Cascaded multilevel inverter. 


\subsection{Inverter Output Voltage Analysis}

An inverter essentially acts as a voltage source output. A nine-level staircase output voltage waveforms are shown in Figure 6.2.

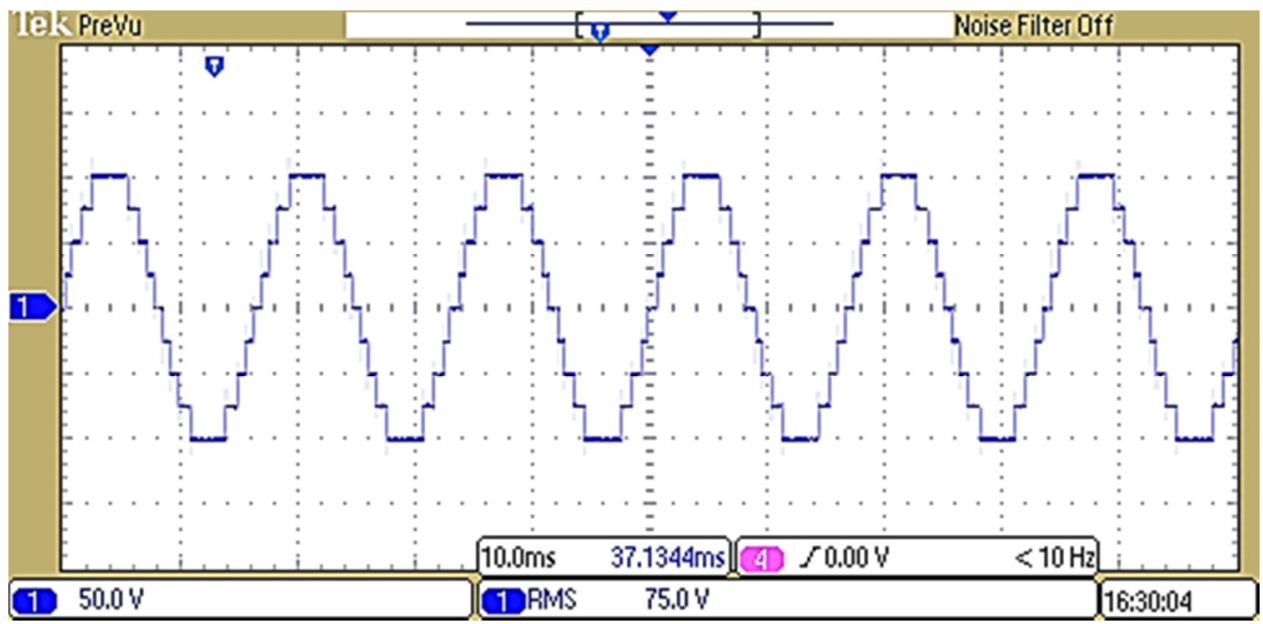

(a)

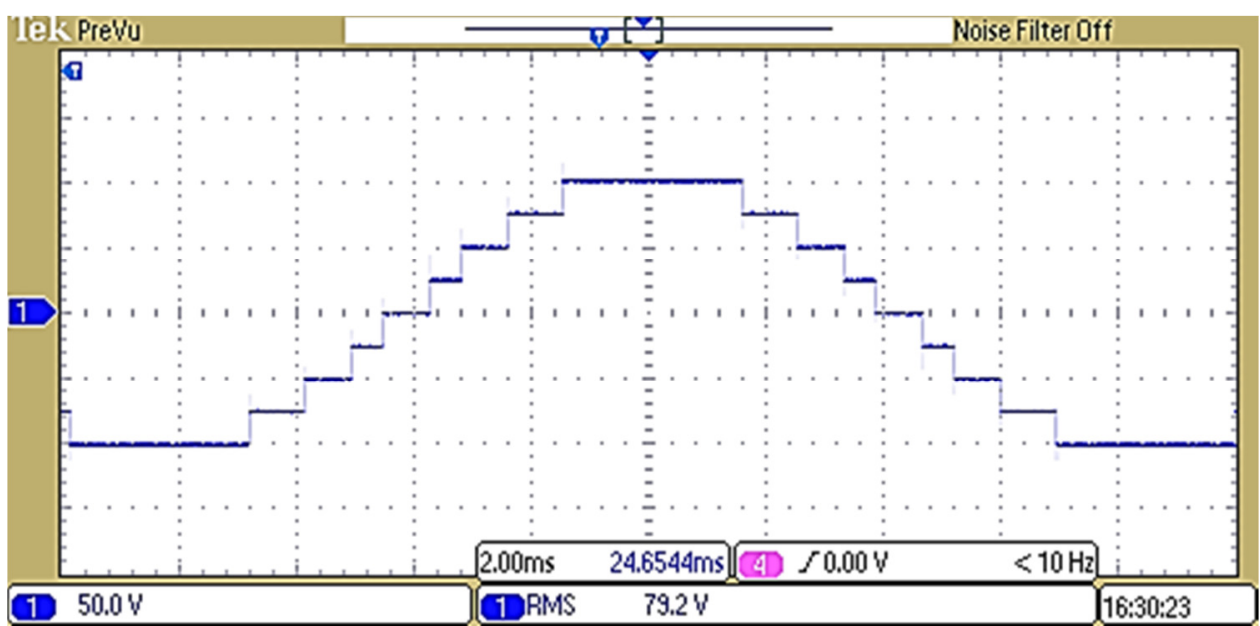

(b)

Figure 6.2: (a) Inverter output voltage waveform (6 cycles) with no load (b) No load output voltage (zoom: half cycle).

As from these figures, the output voltage waveform approximates a nearly perfect sinusoidal waveform without any filtering. From Figure 6.2, it can be seen that the peak 
voltage is $100 \mathrm{~V}$ as there are four modules. Therefore, the output voltage swings from $100 \mathrm{~V}$ to $-100 \mathrm{~V}$ with $71 \mathrm{~V}$ RMS. Figure 6.3 shows the screen-shot of the Yokogawa power analyzer for THD measurement of the inverter output voltage.

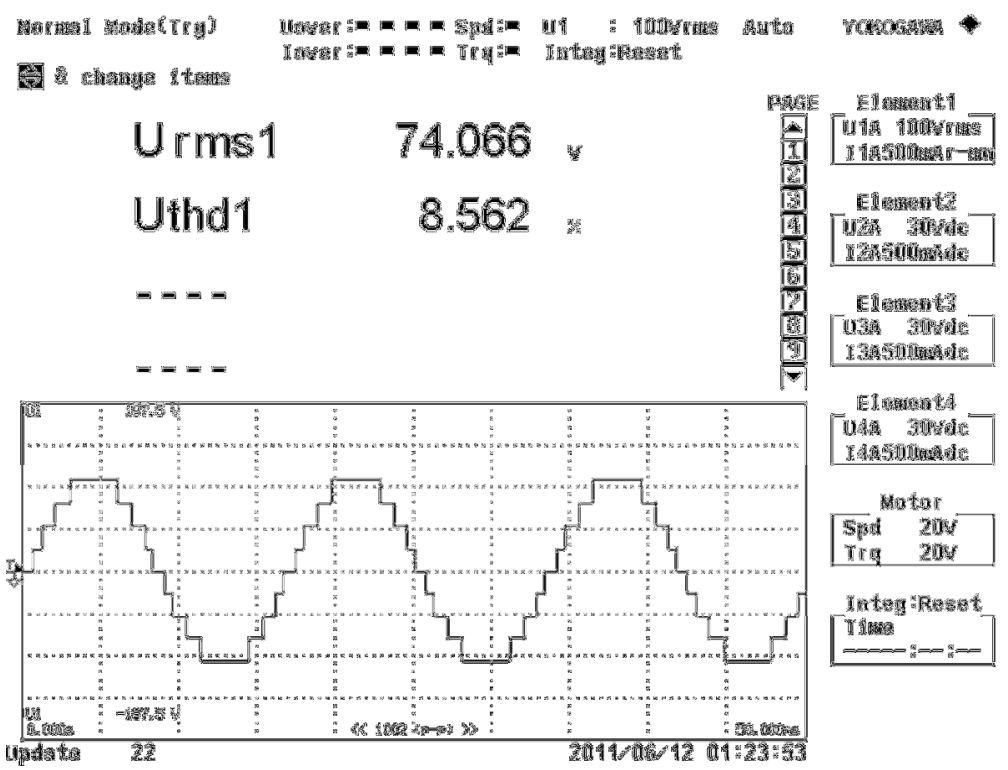

Figure 6.3: Screen-shot of the Yokogawa power analyzer for THD measurement.

As seen from Figure 6.3, the inverter output voltage waveform has total harmonic distortion of $8.56 \%$ at no load condition. The THD depends on the good choice of switching angles and also it is inversely proportional to the number of modules. The THD can be reduced by increasing the number of modules with appropriate values of switching angles. 


\subsection{Switching Waveforms Analysis}

The operation of the switch transitions are analyzed to analyze the blanking time between the complementary switches. Figure 6.4(a) shows the voltage across all H-bridge switches at no load condition. Figure 6.4(b) shows a zoomed view to calculate the switching time.

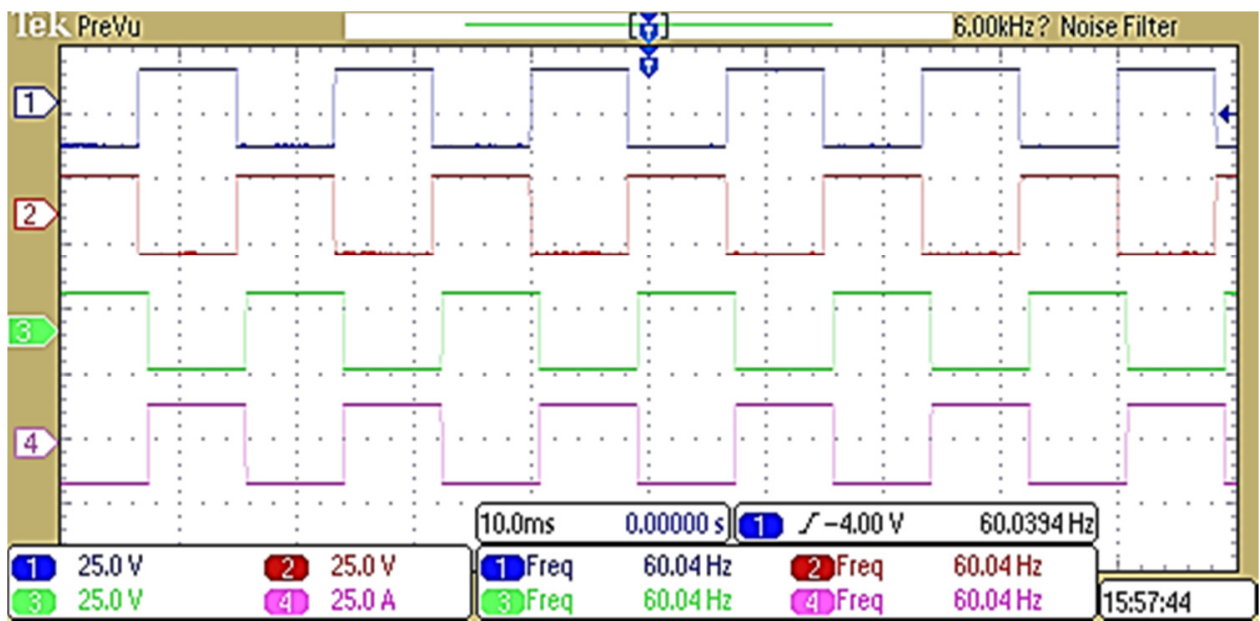

(a)

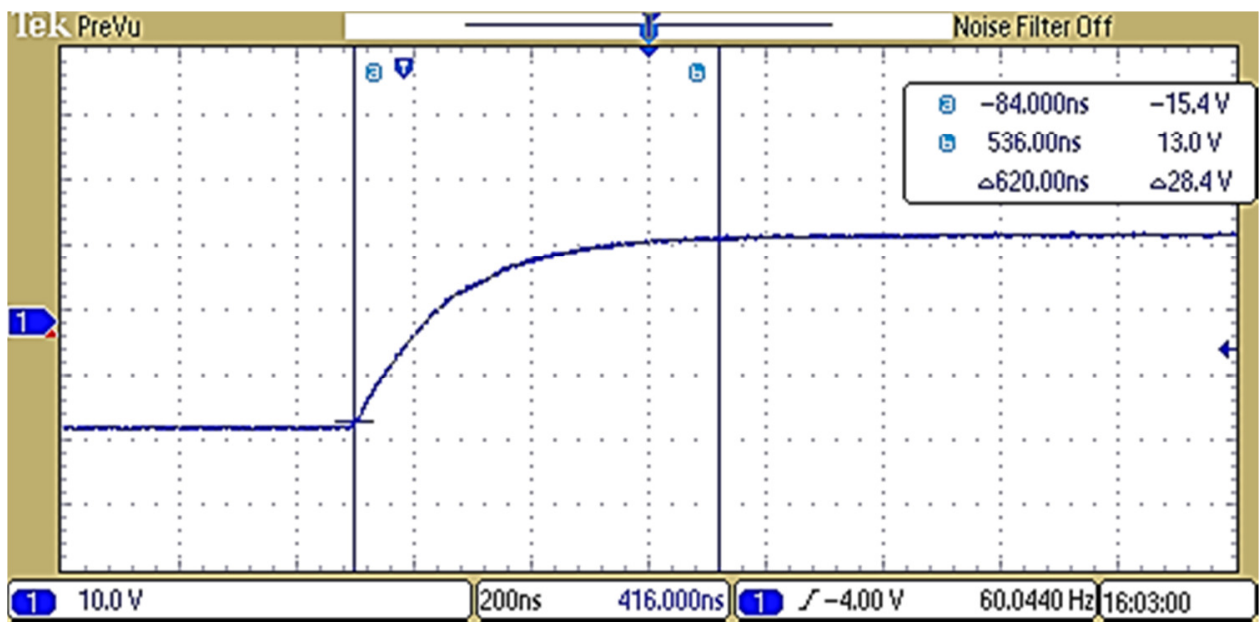

(b)

Figure 6.4: (a) Voltage across all H-bridge switches (b) Zoomed view of the switch transition. 
Figure 6.5 shows the blanking time between the complementary switches, which were introduced to avoid short-through during the switching transitions. The blanking times are kept approximately as $1.668 \mu$ s for the H-bridge modules.

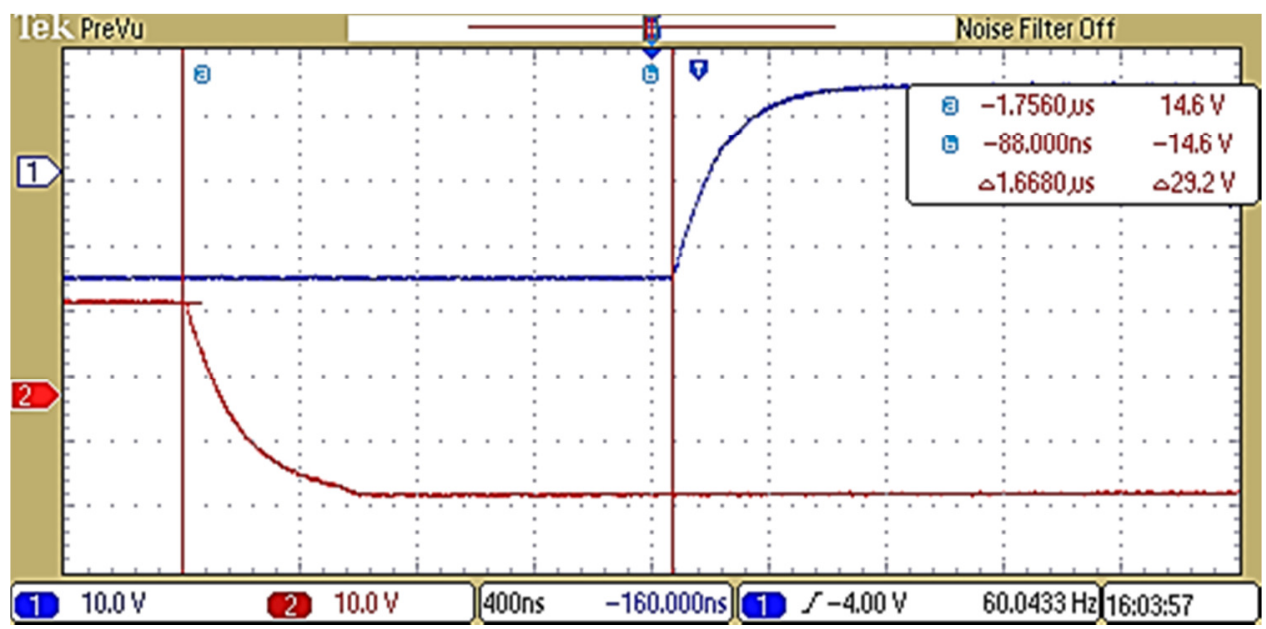

Figure 6.5: Blanking time between complementary switches.

\subsection{Standalone Multilevel Inverter with the Resistive Load}

Several tests were performed to evaluate the standalone operation of the multilevel inverter with the resistive load. The input currents drawn from the individual DC sources, the output voltage across the resistive load and the currents through them were measured. The DC source output currents were commanded on a weight basis such that the input power is distributed among the four panels. In this setup, a $25 \%$ weight was applied to each panel to distribute the input power equally among the four DC sources. Figure 6.6 shows the inverter output voltage, current and the delivered power to a $200 \Omega$ output load resistor. The individual input currents drawn from the individual DC sources are shown in Figure 6.7. 


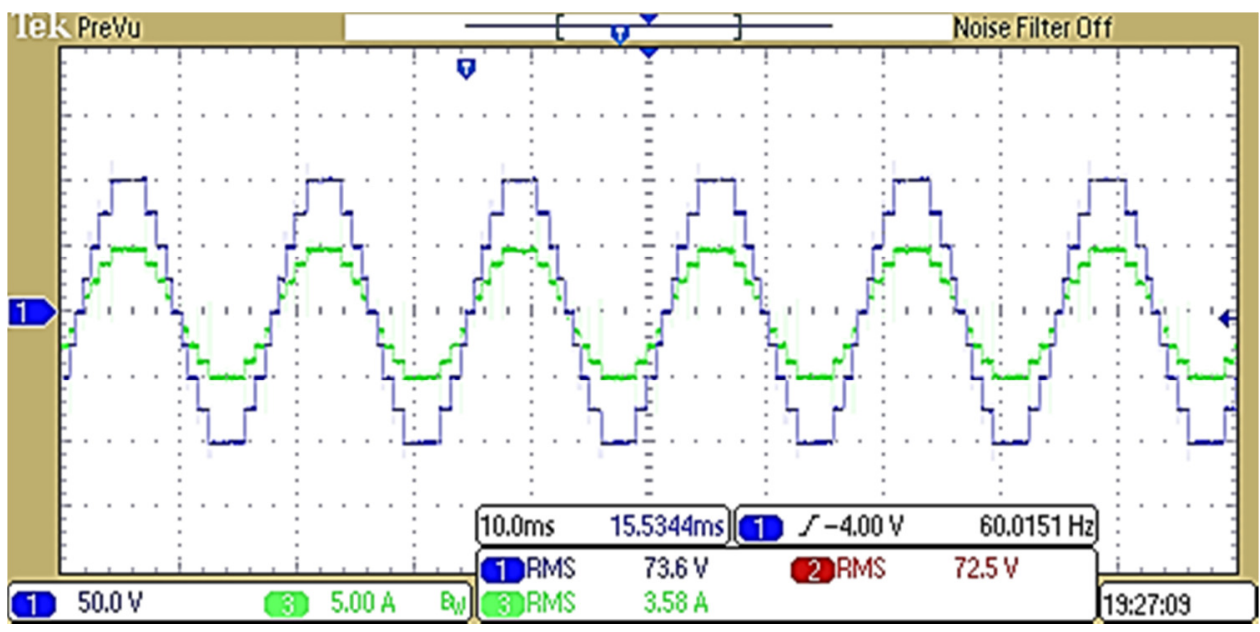

(a)

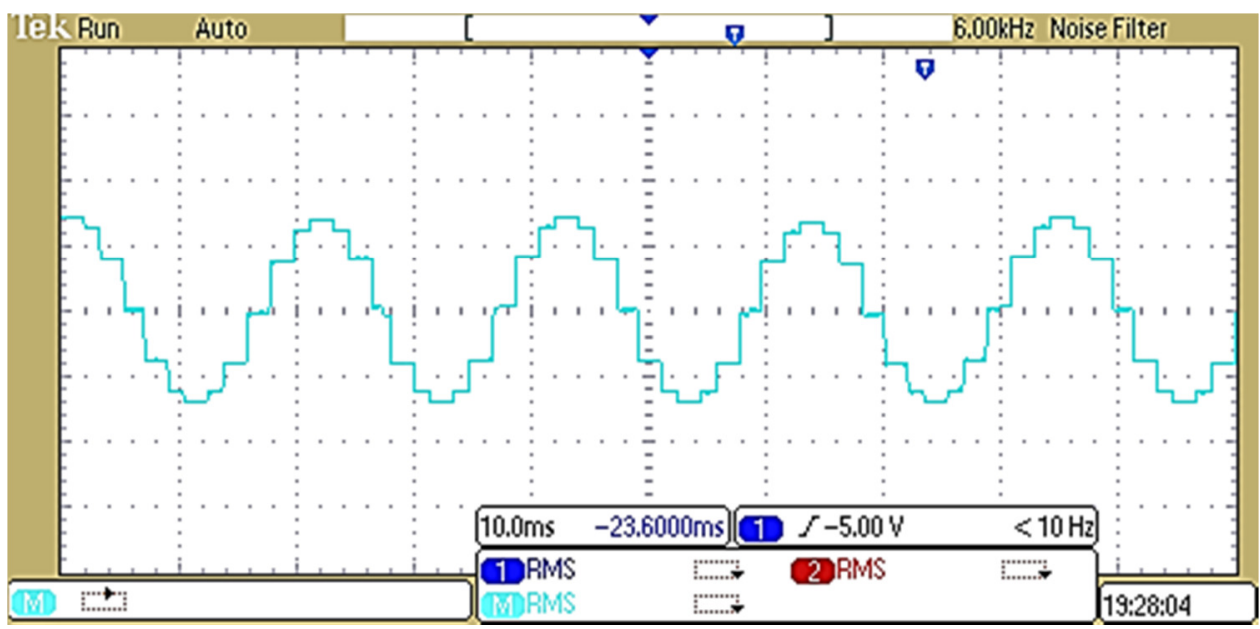

(b)

Figure 6.6: (a) Inverter output voltage and current with a $200 \Omega$ resistive load (b) Power delivered to a $200 \Omega$ load resistor. 


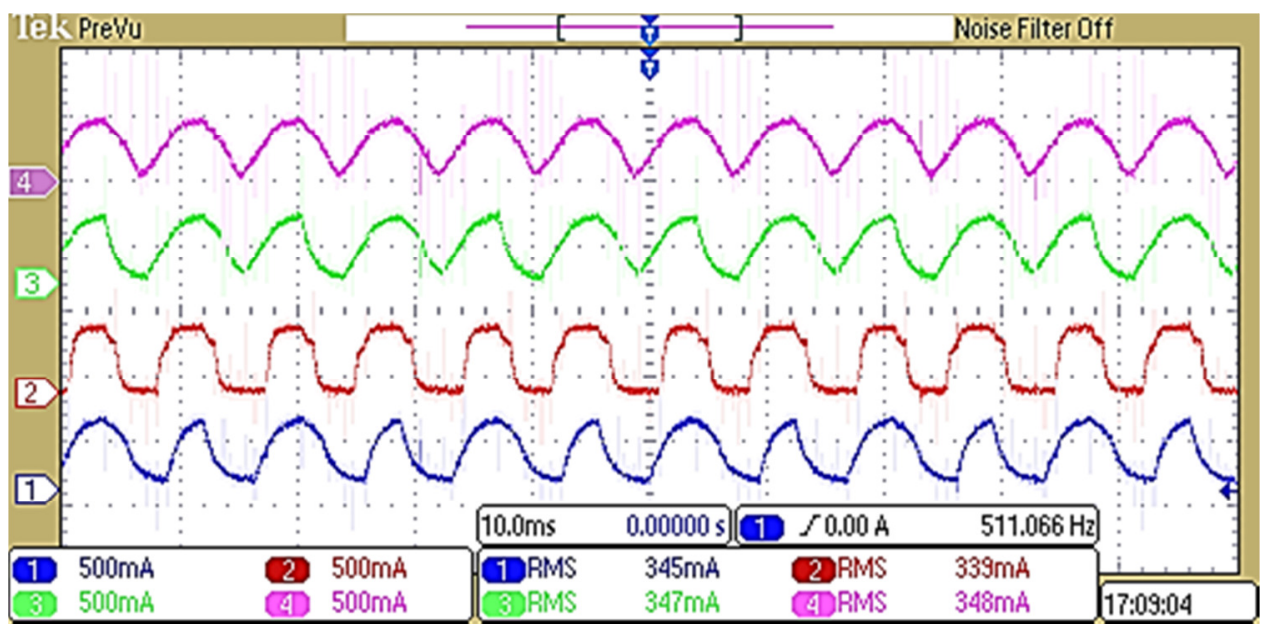

Figure 6.7: Input currents drawn from the individual DC sources.

It can be seen from Figure 6.6 that the output voltage waveform swings with nine levels with a frequency of $60 \mathrm{~Hz}$. The voltage and current are in phase due to the resistive load. Figure 6.7 shows that the currents drawn from the DC sources are very close to the commanded currents to be able to operate at their individual MPP. The results of this test are summarized in Table 6.1.

Table 6.1: Summary of the test results for the standalone multilevel inverter operation with a $200 \Omega$ resistive load

\begin{tabular}{|c|c|c|c|c|}
\hline $\begin{array}{c}\text { Input } \\
\text { Voltage } \\
(\mathrm{V})\end{array}$ & $\begin{array}{c}\text { Currents } \\
\text { Drawn } \\
(\mathrm{A})\end{array}$ & $\begin{array}{c}\text { Input } \\
\text { Power } \\
(\mathrm{W})\end{array}$ & $\begin{array}{c}\text { Weights } \\
\text { Commanded } \\
\%\end{array}$ & $\begin{array}{c}\text { Actual } \\
\text { Weights } \\
\%\end{array}$ \\
\hline 25.05 & 0.345 & 8.64 & 25 & 24.7 \\
\hline 25.14 & 0.339 & 8.72 & 25 & 25.0 \\
\hline 25.25 & 0.347 & 8.76 & 25 & 25.13 \\
\hline 25.10 & 0.348 & 8.73 & 25 & 25.05 \\
\hline \multicolumn{2}{|c|}{ Total Input Power } & 34.85 & & \\
\hline \multicolumn{2}{|c|}{ Total Output Power } & 34.50 & \\
\hline \multicolumn{5}{|c|}{ Inverter Efficiency, $\eta=98.99 \%$} \\
\hline
\end{tabular}




\subsection{Multilevel Inverter with Grid Interfacing}

The next experiment was done for the multilevel inverter with grid interfacing using a transformer. A $2.5 \mathrm{mH}$ inductor connected in series is used as the line inductance to interface the inverter output and the grid. The currents were commanded on a weight basis such that the input power is distributed among the four DC sources. In the first setup, the phase angle $\delta$ is 0.13 radian $\left(7.4^{\circ}\right)$ and the weights of $15 \%, 20 \%, 30 \%$ and $35 \%$ for the four panels were commanded. Figure 6.8 shows the inverter output voltage, grid voltage and the line current.

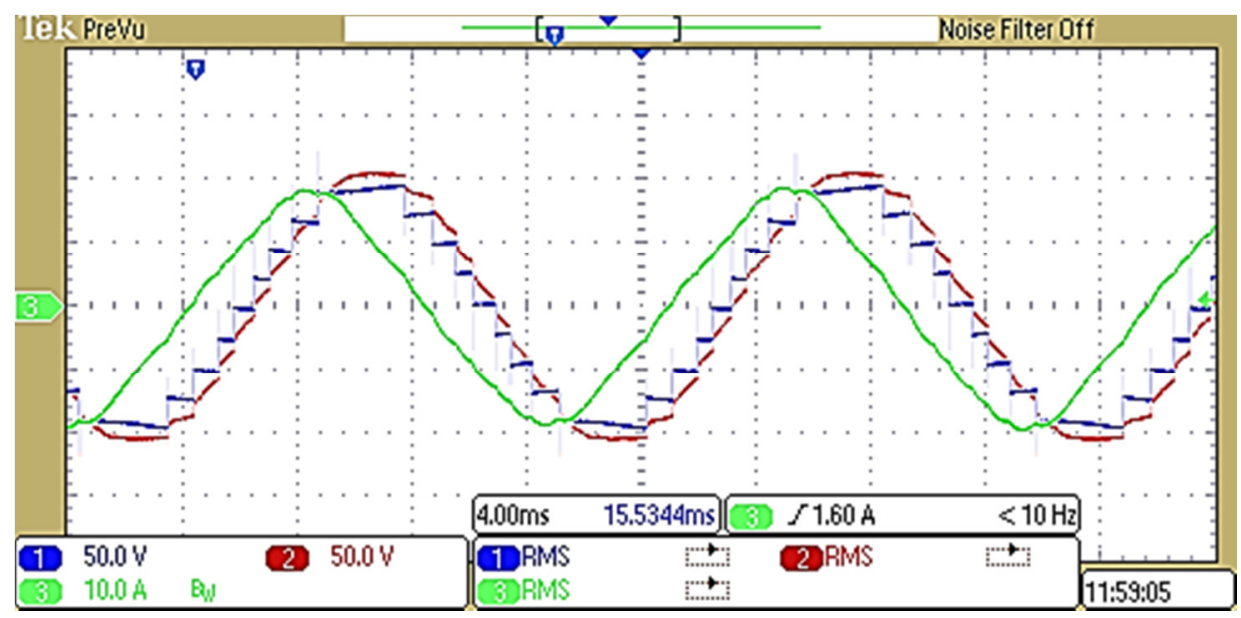

Figure 6.8: Inverter output voltage, grid voltage and the line current.

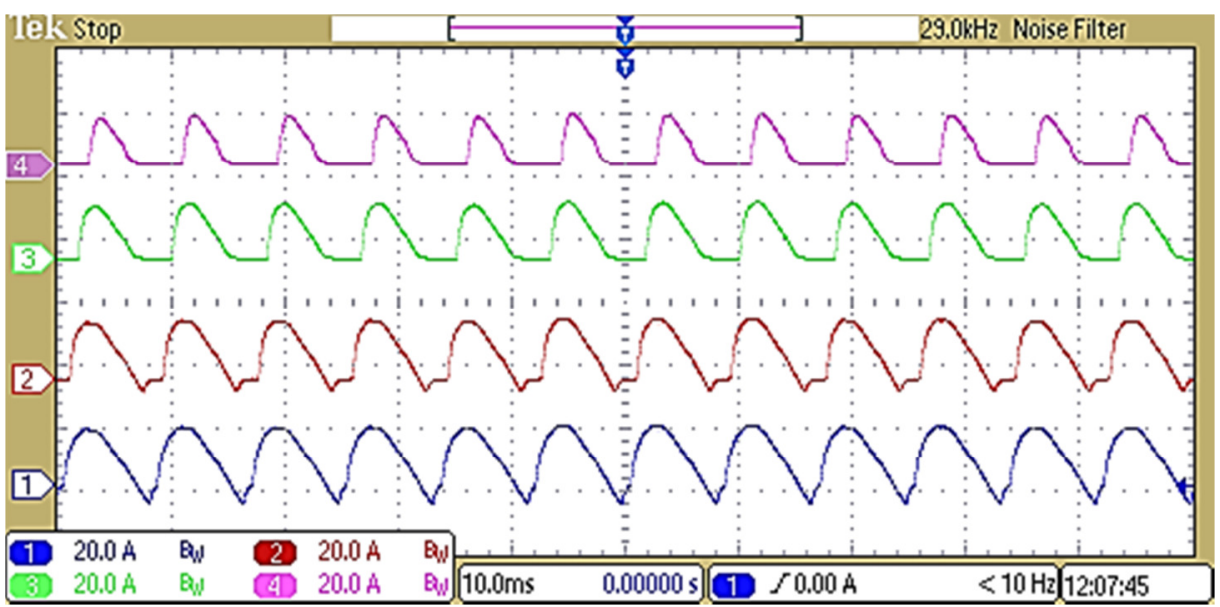

Figure 6.9: Input currents drawn from the individual DC sources. 
The currents drawn from the individual DC sources are shown in Figure 6.9. As shown in this figure, the currents drawn from the different DC sources are very close to the commanded currents.

In the second test, the phase angle between the inverter output voltage and the grid voltage is changed to 0.03 radian $\left(1.76^{\circ}\right)$ the weights commanded are $32 \%, 28 \%$, $20 \%$ and $20 \%$ for the four panels. Figure 6.10 shows the inverter output voltage, grid voltage and the line current for the second setup. The input currents drawn from the individual DC sources for this setup are shown in Figure 6.11.

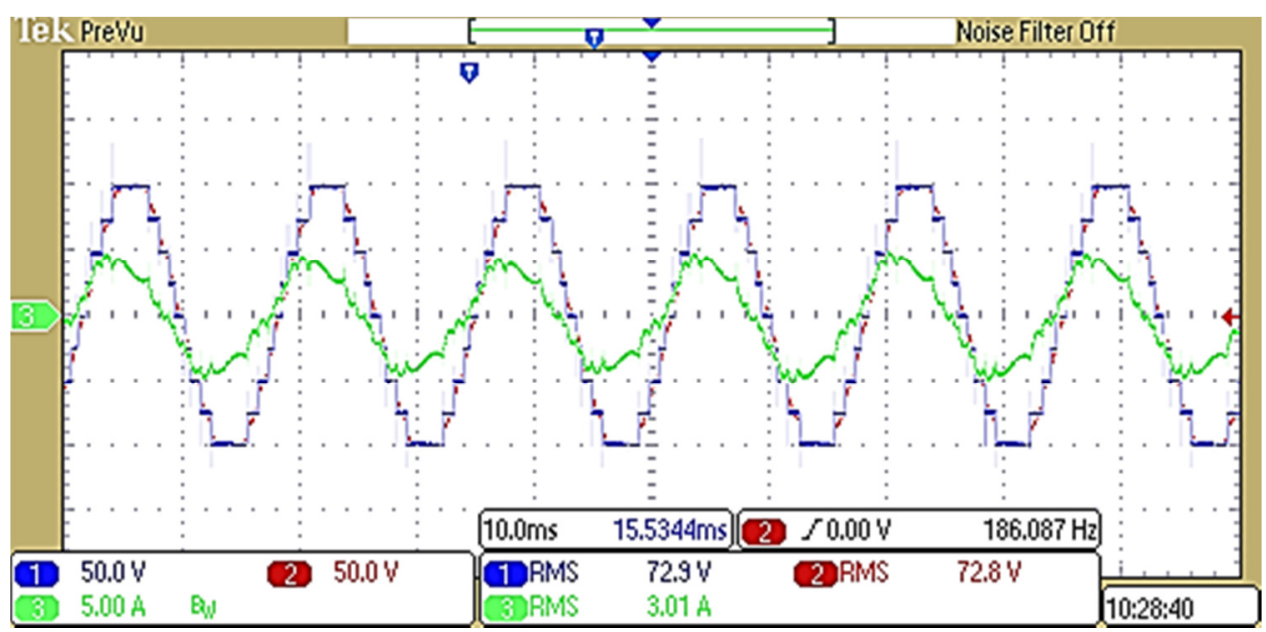

Figure 6.10: Inverter output voltage, grid voltage and the line current.

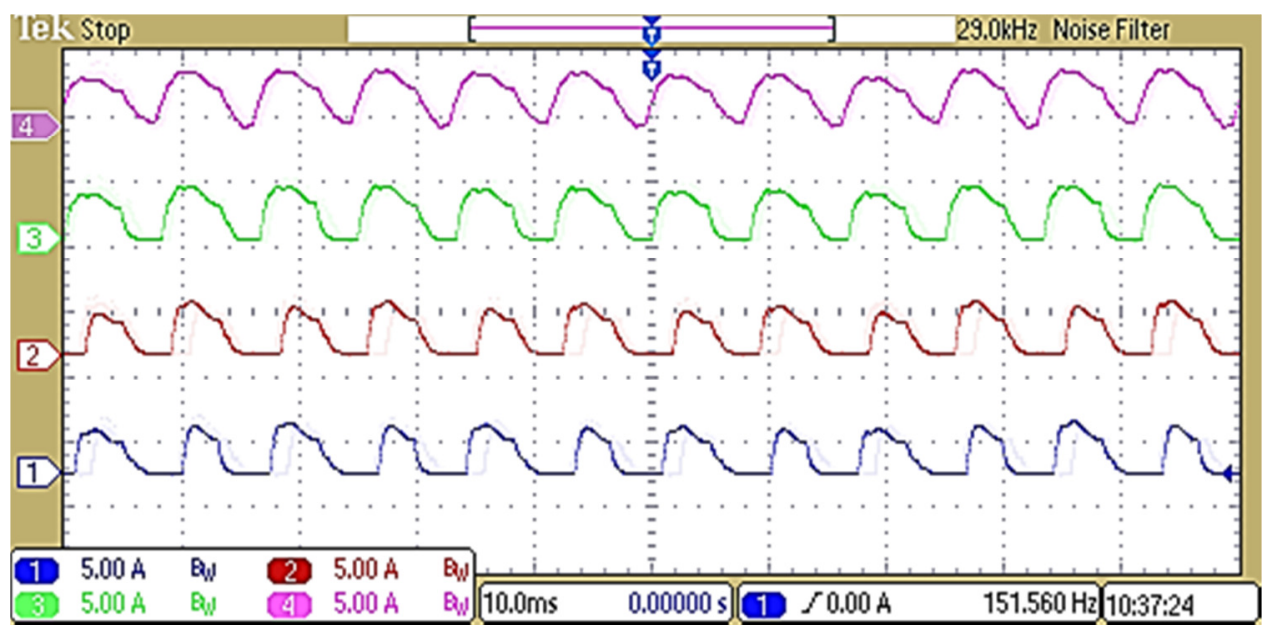

Figure 6.11: Input currents drawn from the individual DC sources. 
The experimental results prove that it is possible to draw different amounts of power from the individual DC sources by using the cascaded multilevel inverter. It also shows that using the developed algorithm, the currents drawn from the DC sources are very close to the commanded inputs to be able to operate at their individual MPP. Table 6.2 and 6.3 show the summary of the test results.

Table 6.2: Summary of the grid interactive test results for setup 1

\begin{tabular}{|c|c|c|c|c|}
\hline $\begin{array}{c}\text { Input } \\
\text { Voltage } \\
\text { (V) }\end{array}$ & $\begin{array}{l}\text { Currents } \\
\text { Drawn } \\
\text { (A) }\end{array}$ & $\begin{array}{l}\text { Input } \\
\text { Power } \\
(\mathrm{W})\end{array}$ & $\begin{array}{c}\text { Weights } \\
\text { Commanded } \\
\%\end{array}$ & $\begin{array}{c}\text { Actual } \\
\text { Weights } \\
\%\end{array}$ \\
\hline 23.93 & 5.54 & 128.47 & 15 & 16.7 \\
\hline 23.57 & 8.1 & 187.73 & 20 & 24.5 \\
\hline 23.63 & 9.4 & 220.24 & 30 & 28.7 \\
\hline 23.58 & 9.8 & 229.42 & 35 & 30 \\
\hline \multicolumn{2}{|c|}{ Total Input Power } & 765.86 & & \\
\hline \multicolumn{2}{|c|}{ Total Output Power } & 733.50 & & \\
\hline & Inve & $n$ & $77 \%$ & \\
\hline
\end{tabular}

Table 6.3: Summary of the grid interactive test results for setup 2

\begin{tabular}{|c|c|c|c|c|}
\hline $\begin{array}{c}\text { Input } \\
\text { Voltage } \\
\text { (V) }\end{array}$ & $\begin{array}{l}\text { Currents } \\
\text { Drawn } \\
\text { (A) }\end{array}$ & $\begin{array}{l}\text { Input } \\
\text { Power } \\
\text { (W) }\end{array}$ & $\begin{array}{c}\text { Weights } \\
\text { Commanded } \\
\%\end{array}$ & $\begin{array}{c}\text { Actual } \\
\text { Weights } \\
\%\end{array}$ \\
\hline 24.50 & 2.24 & 54.70 & 32 & 30.93 \\
\hline 24.61 & 2.00 & 49.11 & 28 & 27.77 \\
\hline 24.75 & 1.51 & 37.31 & 20 & 21.09 \\
\hline 24.84 & 1.44 & 35.76 & 20 & 20.19 \\
\hline \multicolumn{2}{|c|}{ Total Input Power } & 176.8 & & \\
\hline \multicolumn{2}{|c|}{ Total Output Power } & 173.8 & & \\
\hline \multicolumn{5}{|c|}{ Inverter Efficiency, $\eta=98.3 \%$} \\
\hline
\end{tabular}


Figure 6.12 and 6.13 show the screen-shot of the Yokogawa power analyzer for setup 1 and 2 .

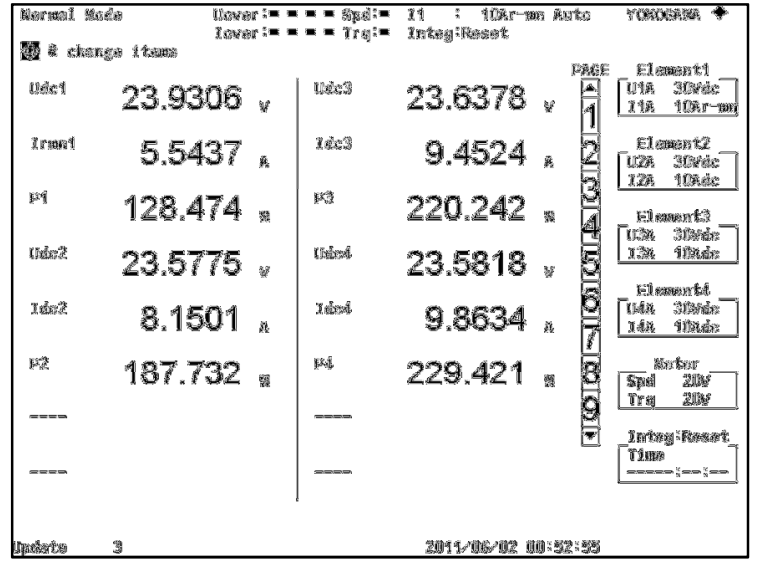

(a)

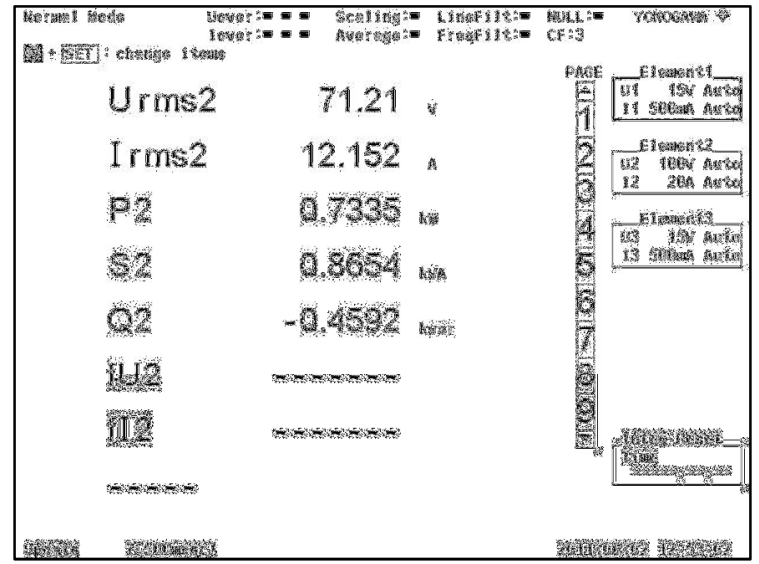

(b)

Figure 6.12: Screen-shot of the power analyzer for the test setup 1: (a) Individual panel voltages, currents and powers, (b) Inverter output voltage, current and power.

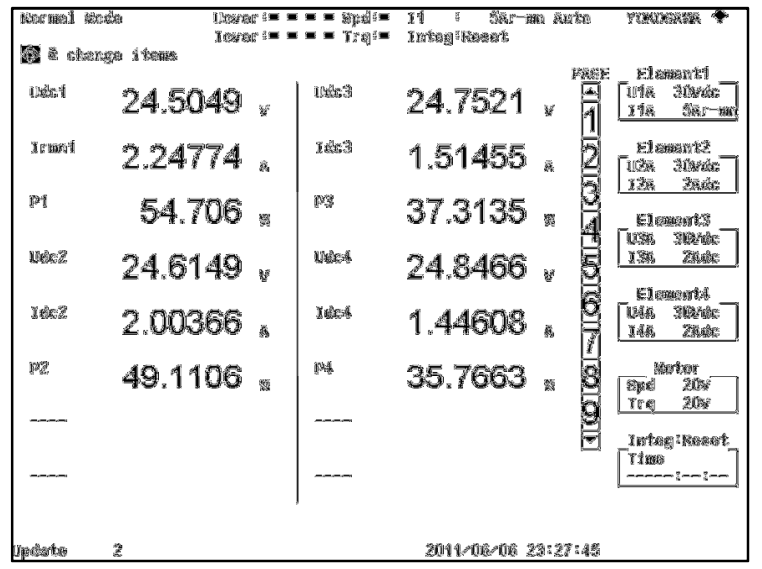

(a)

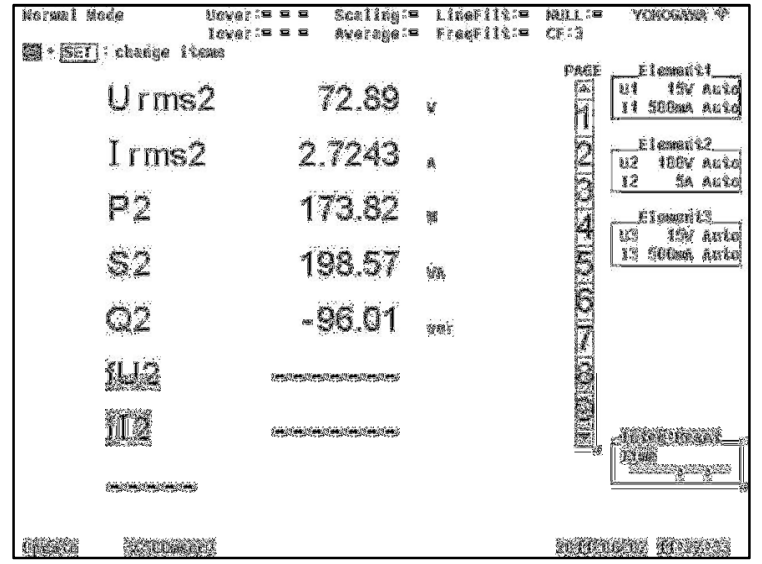

(b)

Figure 6.13: Screen-shot of the power analyzer for the test setup 2: (a) Individual panel voltages, currents and powers, (b) Inverter output voltage, current and power. 


\subsection{Battery Charging Operation of the Multilevel Inverter}

In the previous section, it has been demonstrated that the currents drawn from the different DC sources are very close to the commanded inputs using the developed algorithm. The results also lead to the idea of using this multilevel inverter as a battery charger with a modified control algorithm. The control algorithm cycles the duties among different H-bridge modules to deliver different amounts of charging currents to the individual battery modules.

The same nine-level cascaded multilevel inverter with four $25 \mathrm{~V}$ battery units have been utilized in the experimental setup to verify the battery charging operation from the grid. The amount and the direction of power flow are controlled based on the following equation:

$$
P=\frac{\left(V_{i n v} V_{g r i d}\right)}{X_{L}} \sin (\delta)
$$

where $V_{i n v}$ and $V_{\text {grid }}$ are the inverter voltage and grid voltage, respectively and $\delta$ is the phase angle between the inverter output and the grid voltages.

It is possible to control the amount of power flow by varying the phase angle $\delta$. The direction of power flow is controlled by varying the sign of $\delta$. The sign of $\delta$ has been chosen such that the power flows from the grid to the battery modules and the cascaded multilevel inverter acts as an AC-to-DC converter. The module currents were commanded on a weight basis such that the output power is distributed among the four battery modules. In the first setup, phase angle $\delta$ is 0.045 radians $\left(2.6^{\circ}\right)$ and the weights of $35 \%, 30 \%, 20 \%$ and $15 \%$ for the four battery modules were applied. Figure 6.14 
shows the inverter output voltage, grid voltage and the line current. Figure 6.15 shows the charging currents delivered to the four battery modules.

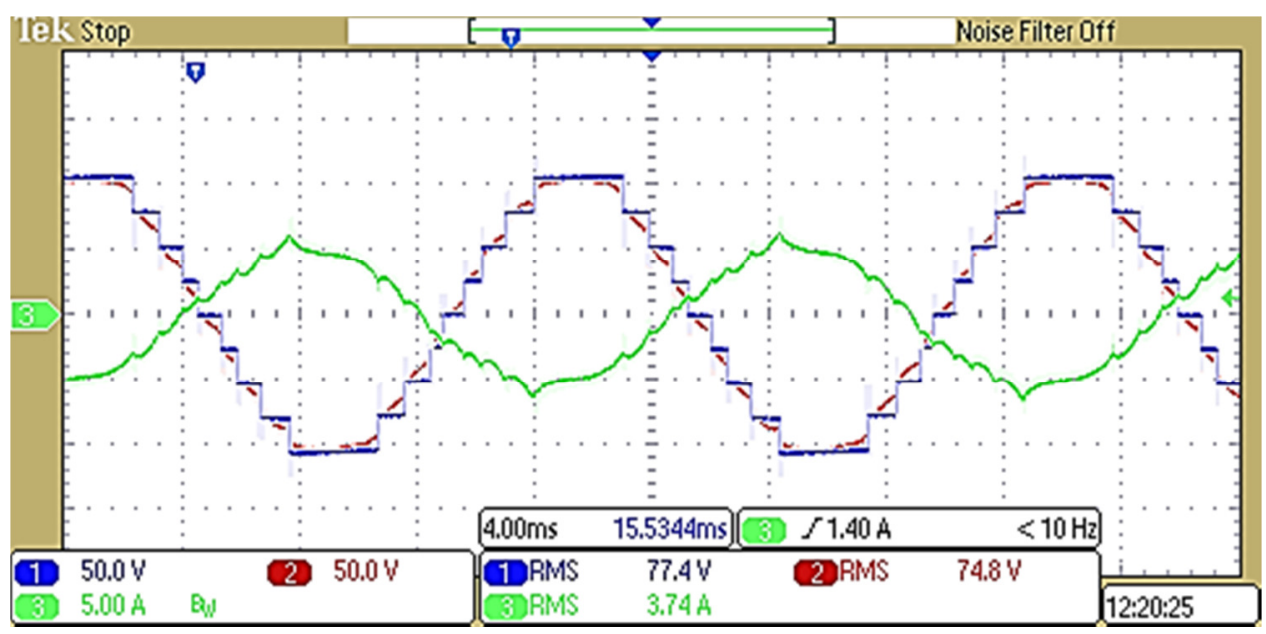

Figure 6.14: Inverter output voltage, grid voltage and the line current.

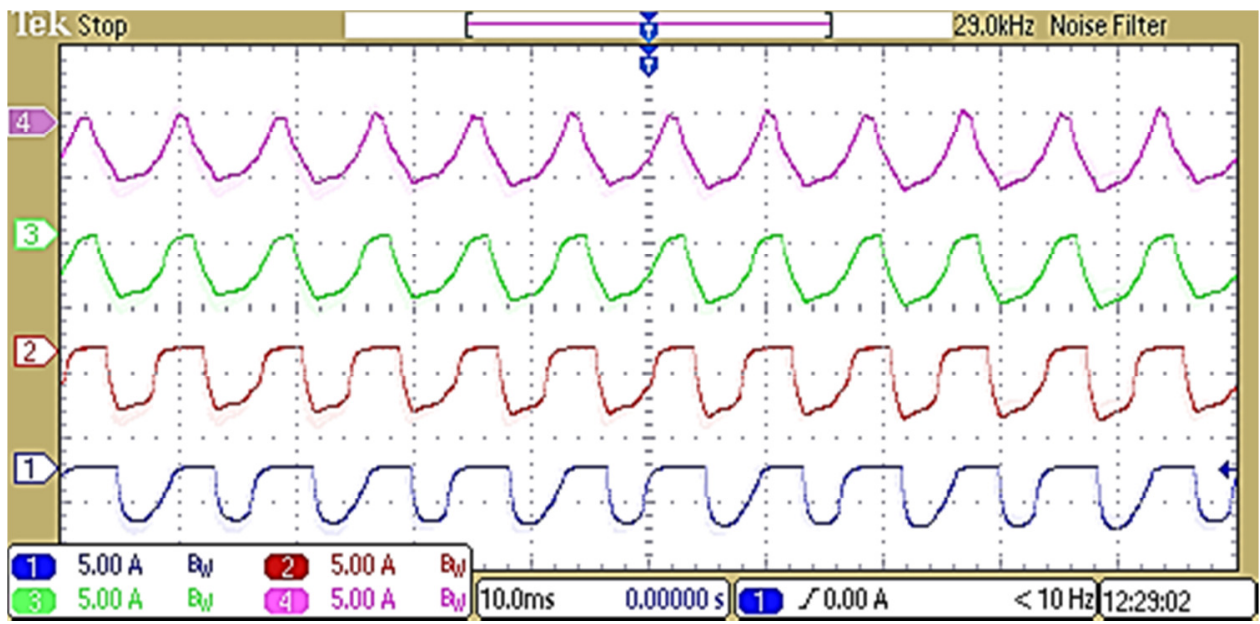

Figure 6.15: Different charging currents for the first setup, which are very close to the commanded currents. 
In the second setup, power angle $\delta$ is changed to 0.1 radian $\left(6^{\circ}\right)$ and the weights of $15 \%, 20 \%, 30 \%$ and $35 \%$ were applied to the four battery modules. The charging currents were commanded accordingly; Figure 6.14 shows the inverter voltage and the grid voltage and the line current. Figure 6.15 shows the charging currents delivered to the battery modules, which are close to the commanded currents.

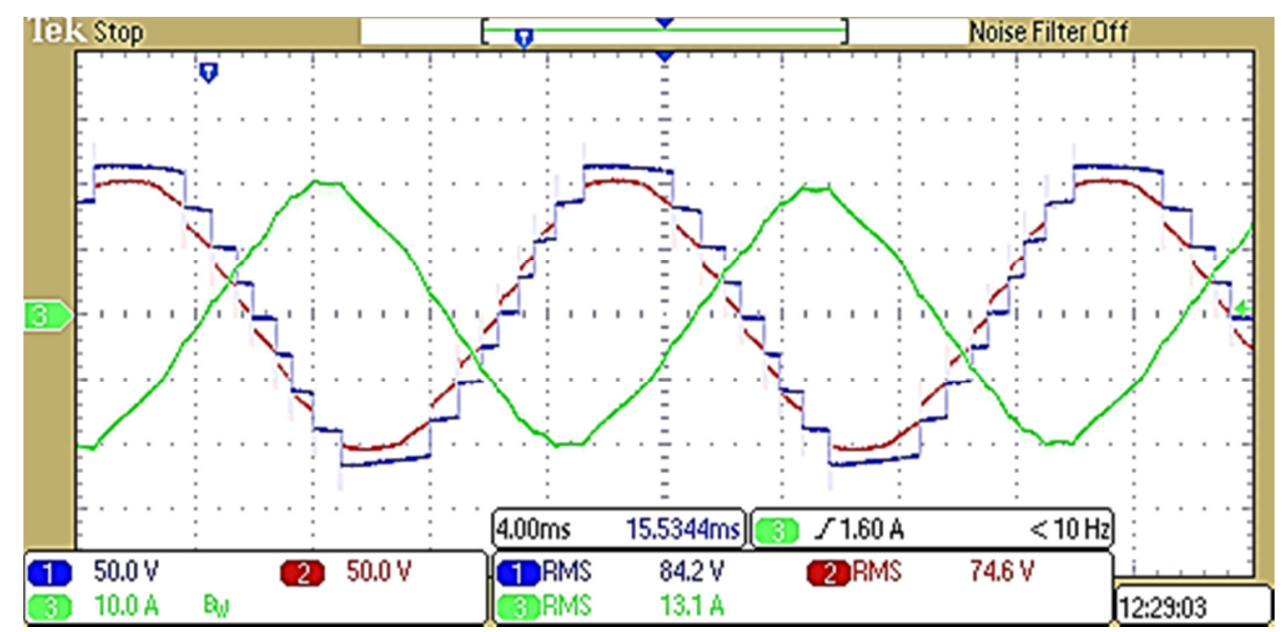

Figure 6.16: Inverter output voltage, grid voltage and the line current.

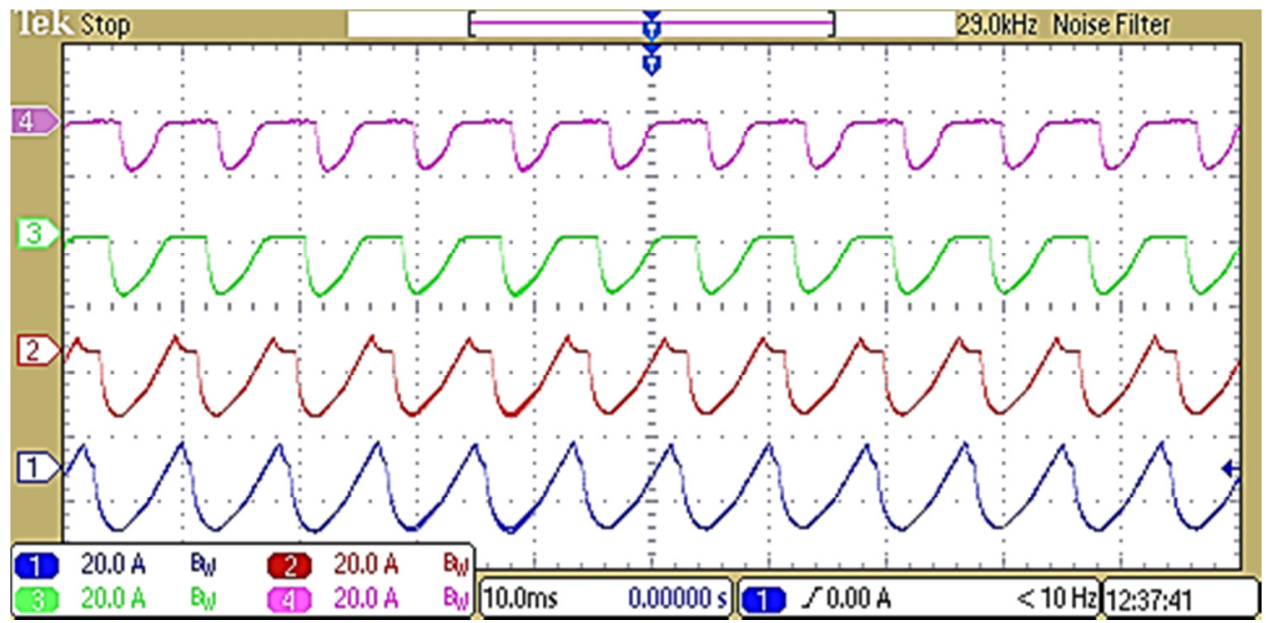

Figure 6.17: Different charging currents for the second setup, which are very close to the commanded currents. 
Table 6.4 and 6.5 show the summary of the test results acquired from the setup 1 and setup 2, respectively.

Table 6.4: Summary of battery charging operation test results for setup 1

\begin{tabular}{|c|c|c|c|c|}
\hline $\begin{array}{c}\text { Input } \\
\text { Voltage } \\
(\mathrm{V})\end{array}$ & $\begin{array}{c}\text { Currents } \\
\text { Drawn (A) }\end{array}$ & $\begin{array}{c}\text { Input } \\
\text { Power } \\
(\mathrm{W})\end{array}$ & $\begin{array}{c}\text { Weights } \\
\text { Commanded } \\
\%\end{array}$ & $\begin{array}{c}\text { Actual } \\
\text { Weights } \\
\%\end{array}$ \\
\hline 25.55 & 3.22 & 81.75 & 35 & 30.08 \\
\hline 25.56 & 3.02 & 77.65 & 30 & 28.60 \\
\hline 25.41 & 2.47 & 63.32 & 20 & 23.30 \\
\hline 25.43 & 1.90 & 48.89 & 15 & 18.00 \\
\hline \multicolumn{6}{|c|}{ Total Input Power } & 271.59 & & \\
\cline { 1 - 2 } Total Output Power & 279.02 & \\
\hline \multicolumn{5}{|c|}{ Inverter Efficiency, $\eta=97.33 \%$} \\
\hline
\end{tabular}

Table 6.5: Summary of battery charging operation test results for setup 2

\begin{tabular}{|c|c|c|c|c|}
\hline $\begin{array}{c}\text { Input } \\
\text { Voltage } \\
\text { (V) }\end{array}$ & $\begin{array}{c}\text { Currents } \\
\text { Drawn (A) }\end{array}$ & $\begin{array}{c}\text { Input } \\
\text { Power } \\
(\mathrm{W})\end{array}$ & $\begin{array}{c}\text { Weights } \\
\text { Commanded } \\
\%\end{array}$ & $\begin{array}{c}\text { Actual } \\
\text { Weights } \\
\%\end{array}$ \\
\hline 25.83 & 4.03 & 106.39 & 15 & 16.07 \\
\hline 26.28 & 6.03 & 161.57 & 20 & 24.41 \\
\hline 26.47 & 7.10 & 191.39 & 30 & 28.92 \\
\hline 26.63 & 7.45 & 202.39 & 35 & 30.58 \\
\hline \multicolumn{2}{|c|}{ Total Input Power } & 661.4 & & \\
\hline \multicolumn{2}{|c|}{ Total Output Power } & 693.7 & & \\
\hline \multicolumn{5}{|c|}{ Inverter Efficiency, $\eta=95.34 \%$} \\
\hline
\end{tabular}

Figures 6.18 and 6.19 show the screen-shot of the Yokogawa power analyzer for setup 1 and setup 2 of the battery charging operation. 


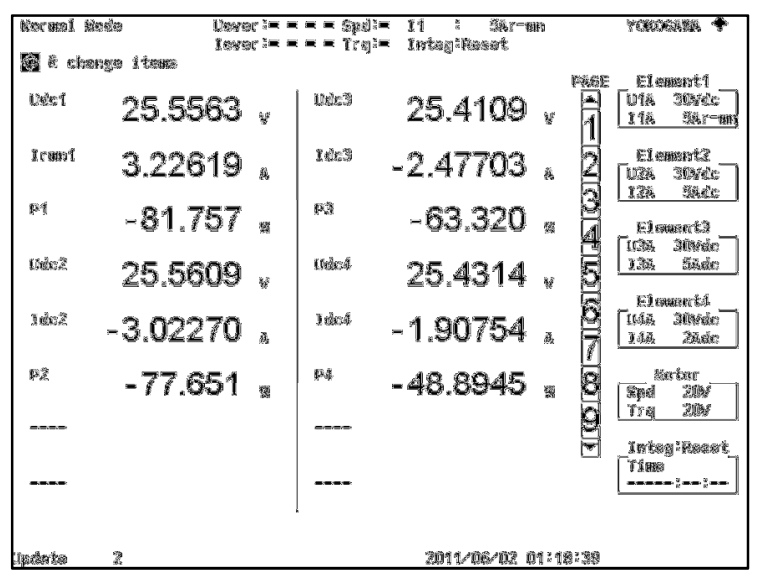

(a)

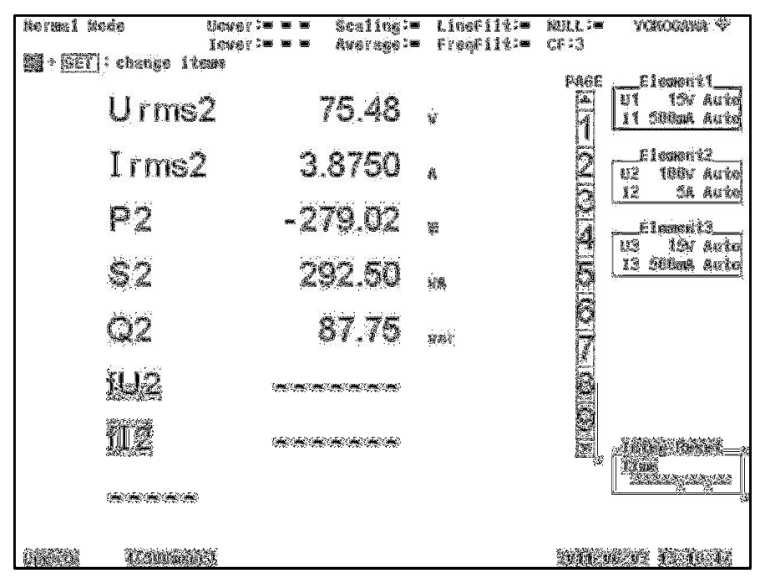

(b)

Figure 6.16: Screen-shot of the power analyzer for the test setup 1 (a) Individual panel voltages, currents and powers; (b) Inverter output voltage, current and power.

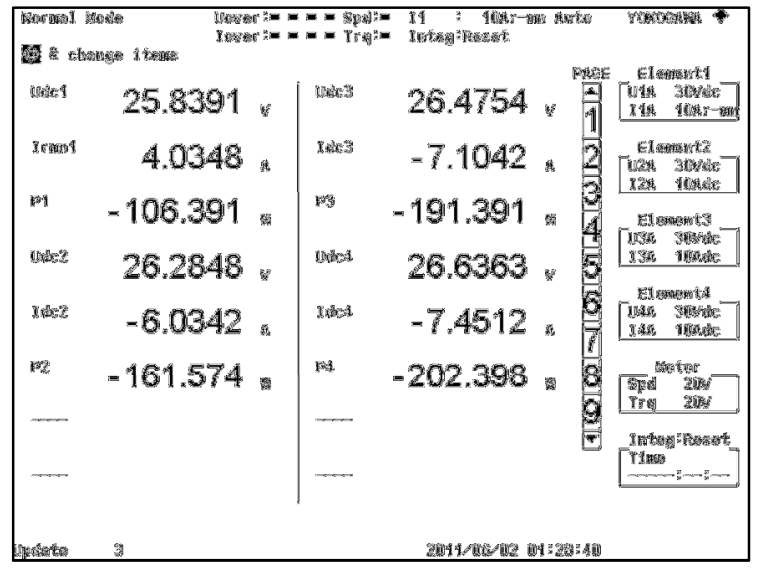

(a)

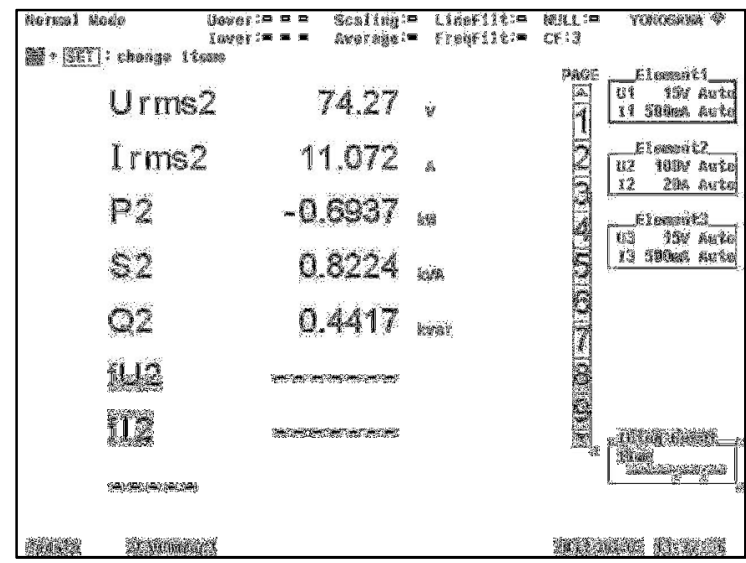

(b)

Figure 6.17: Screen-shot of the power analyzer for the test setup 2 (a) Individual panel voltages, currents and powers; (b) Inverter output voltage, current and power. 


\subsection{Inverter Efficiency Analysis}

The developed cascaded multilevel inverter experimental system has been tested extensively to evaluate the inverter efficiency. Figure 6.18 shows the efficiency vs. output power level characteristic of the multilevel inverter and the control algorithm developed in this research.

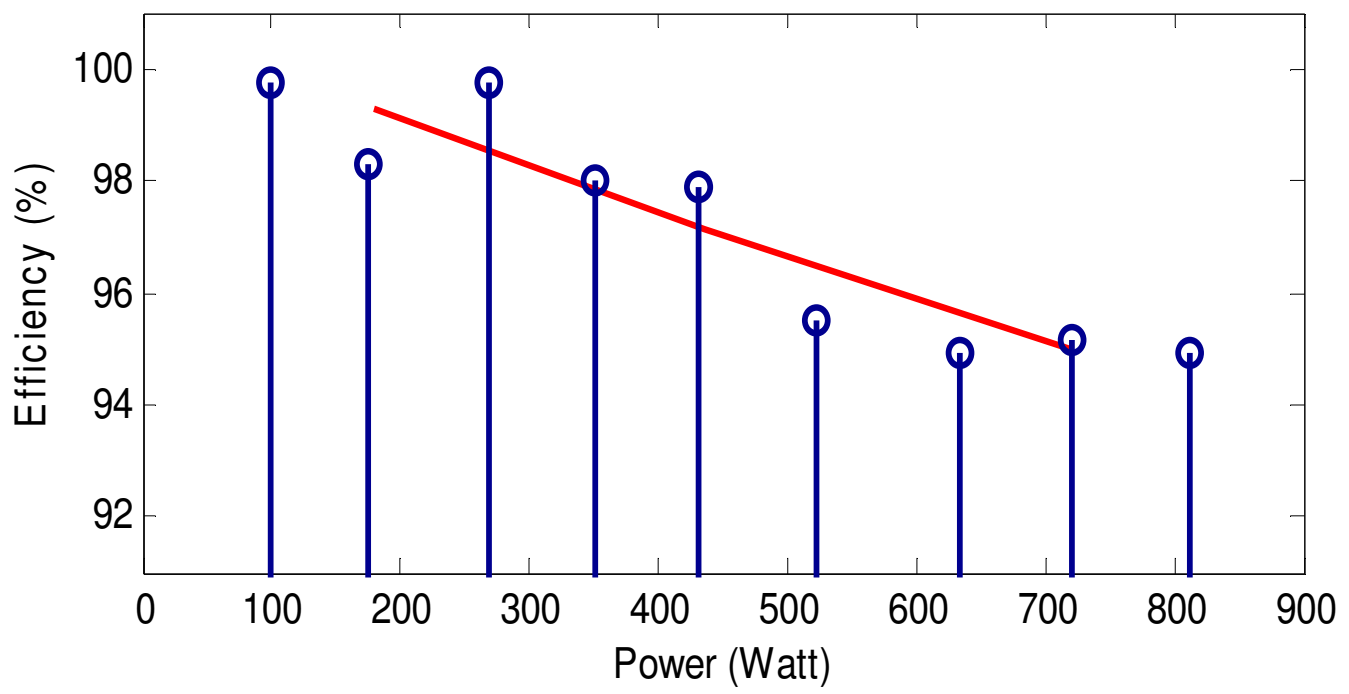

Figure 6.18: Inverter efficiency vs. output power characteristics.

As seen from the above figure, the inverter is more efficient at lower power levels, where the efficiency is almost $98.5 \%$. At higher power levels, the efficiency is approximately $95 \%$. As the grid voltage and the inverter output voltage remained steady while the current is increased with the increase in power, the $i^{2} R$ copper loss is also increased. Therefore, the efficiency is inversely proportional to the output power. 


\subsection{Summary}

In this chapter, several test results are presented to evaluate the cascaded multilevel inverter and the control algorithm for standalone and grid-connected modes of operation. The test results of the battery charging from the grid using the multilevel inverter and modified control algorithm are also presented.

The results demonstrate that it is possible to draw different amounts of power from the individual solar panels by using the cascaded multilevel inverter. It also shows that the currents drawn from the arrays are very close to the commanded inputs using the developed algorithm to be able to operate at their individual maximum power points. The proposed multilevel inverter can be used as a battery charging station that can charge battery modules with different state of charge separately by delivering different charging currents. 


\section{CHAPTER VII}

\section{CONCLUSIONS AND FUTURE WORKS}

\subsection{Conclusions}

The cascaded multilevel inverter along with the developed control algorithm can achieve maximum power point tracking (MPPT) for individual panels rather than from a centralized structure. The simulation and experimental results show that the developed algorithm allows the current drawn from the DC sources to be very close to the commanded inputs and to operate at their individual maximum power points (MPP) for the different panels. The resulting output AC voltage swings with nine levels and forms a staircase waveform which is nearly sinusoidal, even without passing through any filter. A stable grid interfacing is achieved to feed the power to the grid; the power flow is controlled by varying the power angle without any fluctuation. The control algorithm assures the capture of maximum energy on the DC side to deliver it to the utility grid and compensate the shading effect substantially which results in increasing the overall energy harvesting.

The developed multilevel inverter system is capable of being a grid connected battery charger system. The multilevel inverter control algorithm can charge individual battery modules with different state of charge in a battery pack separately by delivering different charging currents, and achieve the charge balancing at the same time. 


\subsection{Future Works}

There are few improvements and modifications that can be done on the existing cascaded multilevel inverter system. The currents were commanded in an open loop fashion in the experiments; the current commands should be generated by the MPPT algorithm in future implementations. The number of modules can be increased to increase the output voltage level matching with the grid and to interface the grid without using transformer. The modulation index can be used in the PWM module to control the output voltage level of each module.

In the battery charging mode of operation, battery modules with different state of charge have to be separated before connecting to the cascaded multilevel inverter modules. This can be avoided by replacing the cascaded multilevel inverter by a diodeclamped multilevel inverter. The advantage of the diode-clamped inverter is that the DC sources can be connected in a series string which is how battery modules are connected in a battery pack. The diode-clamped configuration will be ideal for the battery charging operation.

\subsubsection{Diode-Clamped Multilevel Inverter}

A seven-level diode clamped inverter was simulated in the MATLAB/Simulink environment. Figure 7.1 shows the diode-clamped inverter configuration. The inverter output voltage and current with a $5 \Omega$ resistive load from the simulation is shown in Figure 7.2. The detailed Simulink blocks are presented in Appendix A. 


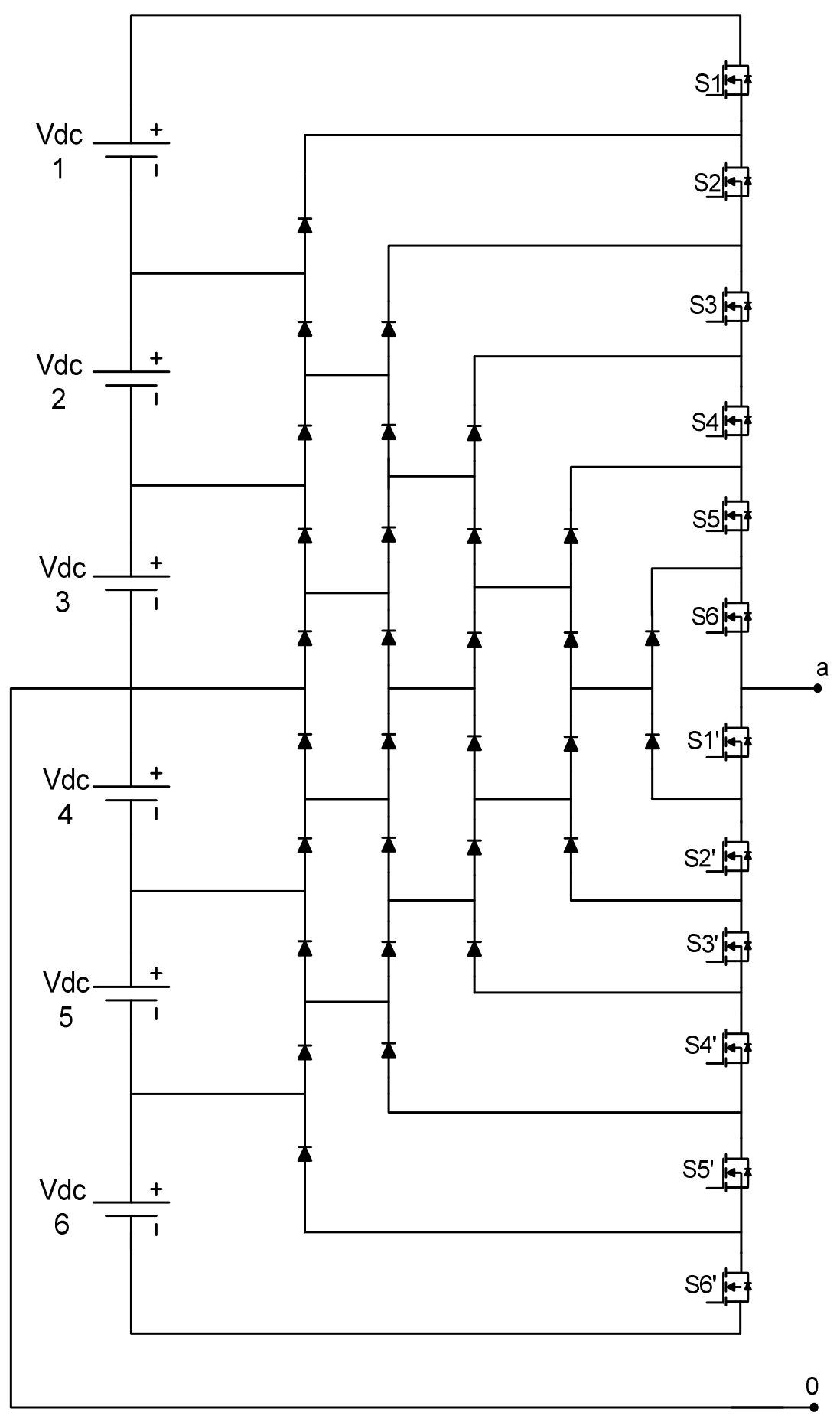

Figure 7.1: A seven-level diode-clamped inverter configuration. 


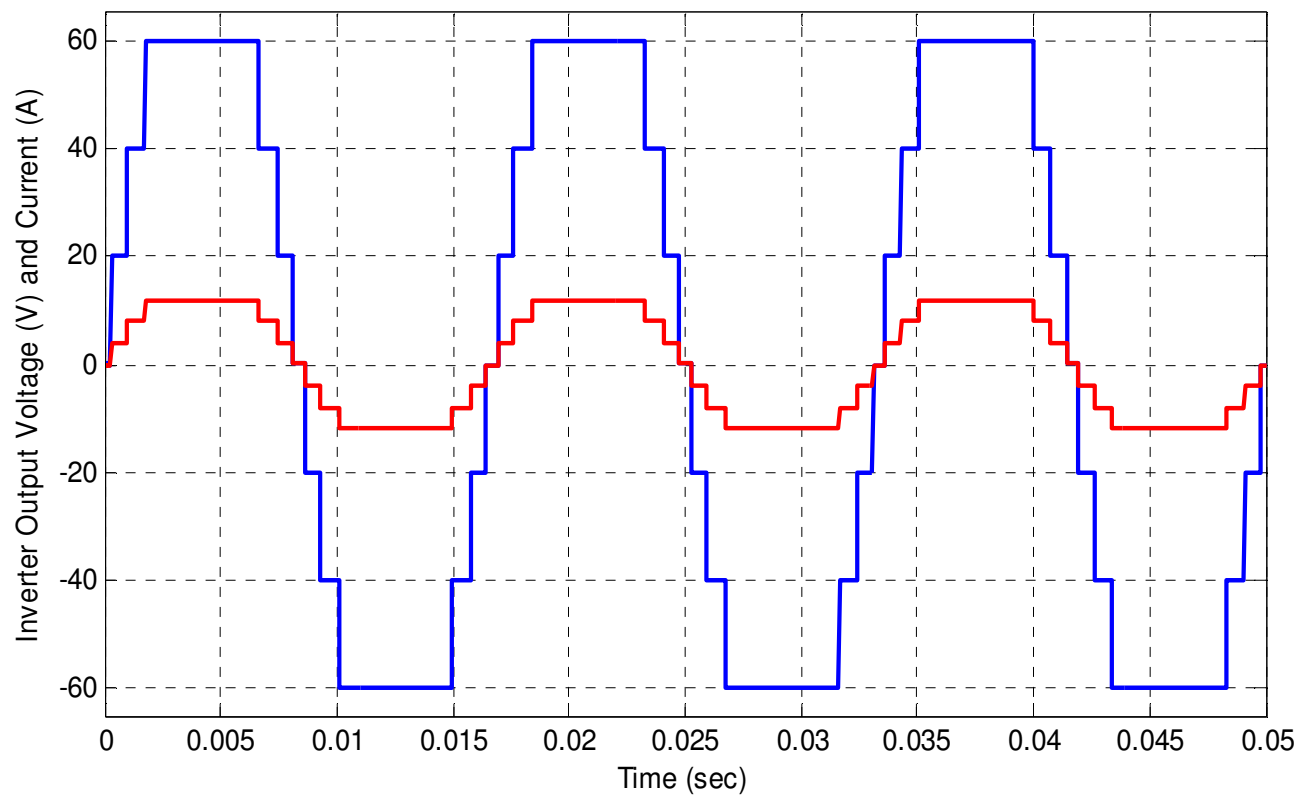

Figure 7.1: A seven-level diode-clamped inverter output voltage and current with a $5 \Omega$ resistive load.

\subsubsection{System Design}

The number of inverter modules is directly related to the inverter output voltage and power. To match the inverter output voltage to the grid voltage, the overall system should be designed carefully. The inverter module ratings are set by the voltage and current ratings of the connected DC sources. For example, if only one solar PV panel is connected to the inverter module, then module ratings will be approximately $20 \mathrm{~V}, 10 \mathrm{~A}$ and 200W. These ratings would increase with the increase of the number of series/parallel configured solar PV panels connected to each inverter module.

If the required inverter output voltage is $U \mathrm{~V}_{\mathrm{RMS}}$. The required number of the inverter modules, $N$ will be as follows 


$$
N=\frac{U \sqrt{2}}{M}
$$

where $M$ is the amount of the voltage connected in each inverter module.

The ratings of the existing inverter modules are $25 \mathrm{~V}, 10 \mathrm{~A}$ and $200 \mathrm{~W}$. To match the inverter output voltage with the grid voltage $\left(120 \mathrm{~V}_{\mathrm{RMS}}\right)$, the number of the required inverter modules would be as follows

$$
N=\frac{120 \sqrt{2}}{25}=6.7 \approx 7
$$

The inverter output voltage would be $175 \mathrm{~V}$ peak with $123 \mathrm{~V}$ RMS. Therefore, by increasing the number of modules, the transformer can be avoided for grid interfacing. 


\section{REFERENCES}

[1] Kjaer, S.B., Pedersen, J.K., Blaabjerg, F., "A review of single-phase grid-connected inverters for photovoltaic modules," IEEE Transactions on Industry Applications, vol. 41, no. 5, September/October 2005.

[2] Sozer, Y., Torrey, D.A. , "Modeling and Control of Utility Interactive Inverters," IEEE Transactions on Power Electronics, vol. 24, no. 11, November 2009.

[3] Torrey, D.A., and Kokernak J. M., "Increasing the productivity of solar photovoltaic systems," Proceedings of American Solar Energy Society, Solar 2006 Conference, July 8-13, 2006.

[4] Mayer, D., Heidenreich, M., "Performance analysis of standalone PV systems from a rational use of energy point of view," Proceedings of 3rd World Conference on Photovoltaic Energy Conversion, May 2003, pp. 2155-2158.

[5] Gules, R., De Pellegrin Pacheco, J., Hey, H.L., Imhoff, J., “A Maximum Power Point Tracking System with Parallel Connection for PV Stand-Alone Applications," IEEE Transactions on Industrial Electronics, Vol. 55, No 7, pp 2674-2683, Jul 2008.

[6] Esram, T., Chapman, P.L., "Comparison of photovoltaic array maximum power point tracking techniques," IEEE Transactions on Energy Conversion, vol. 22, no 2 pp. 439449, June 2007.

[7] Weidong Xiao, Ozog, N., Dunford, W.G., "Topology study of photovoltaic interface for maximum power point tracking," IEEE Transactions on Industrial Electronics, vol. 54, no. 3, pp.1696-1704.

[8] Jih-Sheng Lai, Fang Zheng Peng, "Multilevel converters - a new breed of power converters," IEEE Transactions on Industrial Applications, vol. 32, pp. 509-517, October 1995.

[9] Tolbert, L.M. Fang Zheng Peng Habetler, T.G., "Multilevel converters for large electric drives," IEEE Transactions on Industrial Applications, vol. 35, pp. 36-44, January/February 1999.

[10] R. Teodorescu, F. Beaabjerg, J. K. Pedersen, E. Cengelci, S. Sulistijo, B. Woo, and P. Enjeti, "Multilevel converters - A survey," Proceedings of European Power Electronics Conference, Lausanne, Switzerland, 1999. 
[11] Rodriguez, J. Jih-Sheng Lai Fang Zheng Peng, "Multilevel Inverters: A Survey of Topologies, Controls and Applications," IEEE Transactions on Industrial Electronics, vol. 49, no. 4, pp. 724-738, August 2002.

[12] Nabae, Akira Takahashi, Isao Akagi, Hirofumi, "A new neutral-point clamped PWM inverter," IEEE Transactions on Industrial Electronics, vol. IA-17, pp. 518-523, September/October 1981.

[13] Meynard, T. A., Foch H., "Multi-level choppers for high voltage applications," European Power Electronic Drives Journal, vol. 2, no. 1, p. 41, March 1992.

[14] Hochgraf, C. Lasseter, R. Divan, D. Lipo, T.A., "Comparison of multilevel inverters for static var compensation," Industry Applications Society Annual Meeting, pp. 921928, October 1994.

[15] Walker, G.R. Sernia, P.C., "Cascaded DC-DC Converter Connection of Photovoltaic Modules," IEEE Transactions on Power Electronics, Vol. 19, No. 4, pp. 1130-1139, July 2004.

[16] Linares, L. Erickson, R.W. MacAlpine, S. Brandemuehl, M., "Improved energy capture in series string photovoltaic via smart distributed power electronics" IEEE Applied Power Electronics Conference and Exposition, pp. 904-910, 2009.

[17] Herrmann, W. Wiesner, W. Vaassen, W., "Hot spots investigations on PV modulesnew concepts for a test standard and consequences for module design with respect to by-pass diodes", Proceedings of the IEEE Photovoltaic Specialists Conference, pp. 1129-1132, 1997.

[18] Klenk, M., Keller, S., Weber, L., Marckmann, C., Boueke, A., Nussbaumer, H., Fath, P., Burkhart, R., "Investigation of the hot-spot behavior and formation in crystalline silicon power cells, PV in Europe, from PV technology to energy solutions," Proceedings of the International Conference, pp. 272-275, 2002.

[19] Esram, T. Chapman, P.L., "Comparison of Photovoltaic Array Maximum Power Point Tracking Techniques", IEEE Transactions on Energy Conversion, vol. 22, June 2007.

[20] Quan Li Wolfs, P., "Recent Development in the Topologies for Photovoltaic Module Integrated Converters," Power Electronics Specialists Conference, 2006.

[21] Koizumi, H. Kurokawa, K., "A Novel Maximum Power Point Tracking Method for PV Module Integrated Converter" IEEE Applied Power Electronics Conference and Exposition, pp. 904-910, 2009.

[22] H. Shan, Y. Kang, S. Duan, Y. Zhang, M. Yu, Y. Liu, G. Chen, F. Luo, "Research on novel parallel current sharing control technique of the stand-alone photovoltaic 
inverter," Proceedings of the IEEE Annual Conference of the Industrial Electronics Society, pp. 1645-1649, November 2007.

[23] Khan, I.A. , "Battery Chargers For Electric And Hybrid Vehicles", IEEE Transaction on Power Electronics in Transportation, October 1994.

[24] Sirisukprasert, S. Jih-Sheng Lai Tian-Hua Liu, "Optimum harmonic reduction with a wide range of modulation indexes for multilevel converters," IEEE Industry Applications Conference, pp. 2094-2099, October 2000.

[25] Muyulema, S. Bueno, E.J. Rodriguez, F.J. Cobreces, S. Diaz, D., "Response of the grid converters synchronization using P. U. magnitude in the control loop," IEEE International Symposium on Industrial Electronics, pp. 186-191, June 2007.

[26] Freijedo, F.D. Doval-Gandoy, J. Lopez, O. Cabaleiro, J., "Robust phase locked loops optimized for DSP implementation in power quality applications," Annual Conference of IEEE Industrial Electronics, pp. 3052-3057, November 2008.

[27] Camargo, R. F., Pinheiro, H., "Synchronization method for three phase PWM converters under unbalanced and distorted grid," Power Electronics Specialists Conference, vol. 153, no. 5, pp. 763-772, September 2006.

[28] Guan-Chyun Hsieh Hung, J.C., "Phase-locked loop techniques: A survey," IEEE Transactions on Industrial Electronics, vol. 43, no. 6, pp. 609-615, December 1996.

[29] Iwase Hisashi, I. Osamu, T. Katsuya, "WT3000 Precision Power Analyzer," Yokogawa Technical Report English Edition, no. 39. 2005. 
APPENDICES 


\section{APPENDIX A}

\section{SIMULINK DIAGRAMS}

\section{A.1 Generalized Solar PV Model}

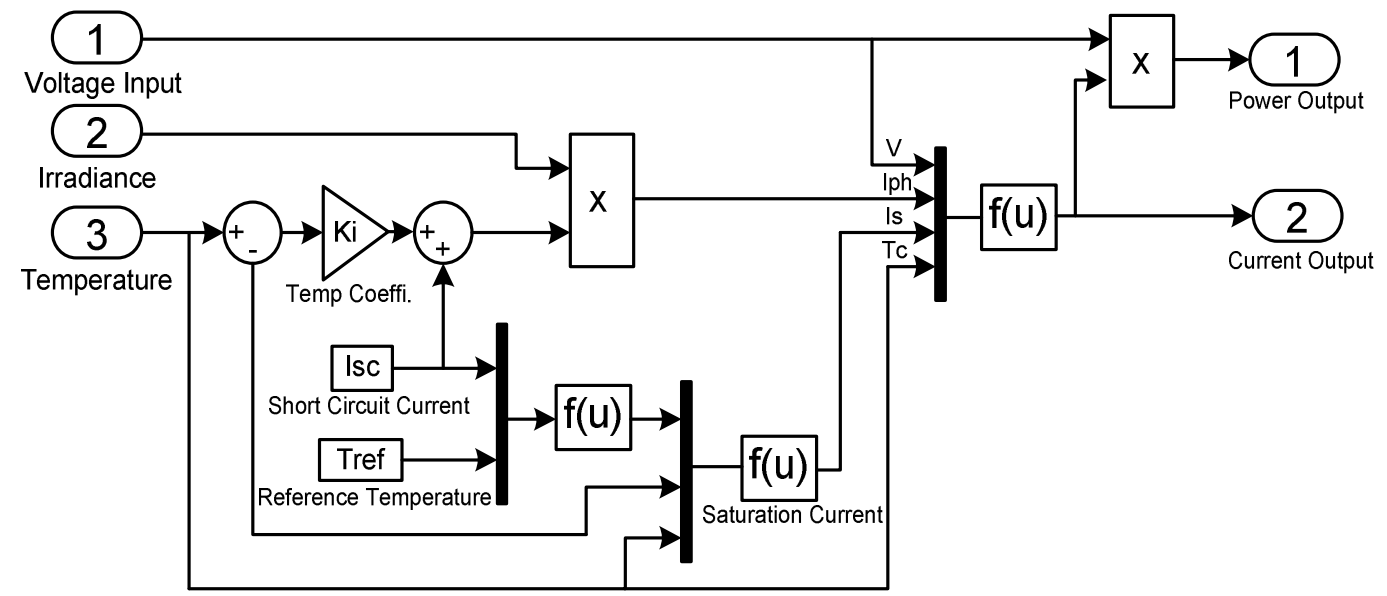

\footnotetext{
MATLAB Parameters

$\mathrm{TC}=0+273 ;$

Tref $=25+273$;

$q=1 \cdot 6 e-19$;

$\mathrm{Np}=1$;

$\mathrm{NS}=1$;

$\mathrm{VOC}=.596$;

I SC $=2$;

$\mathrm{k}=1.38 \mathrm{e}-23$;

$\mathrm{A}=1.2$;

$\mathrm{Eg}=1.11 ;$

$\mathrm{Ki}=3 \mathrm{e}-3$;

Insolation $=1$;

$\mathrm{RS}=0$;

Rsh = inf;
} 


\section{A.2 Multilevel Inverter with Control Algorithm}

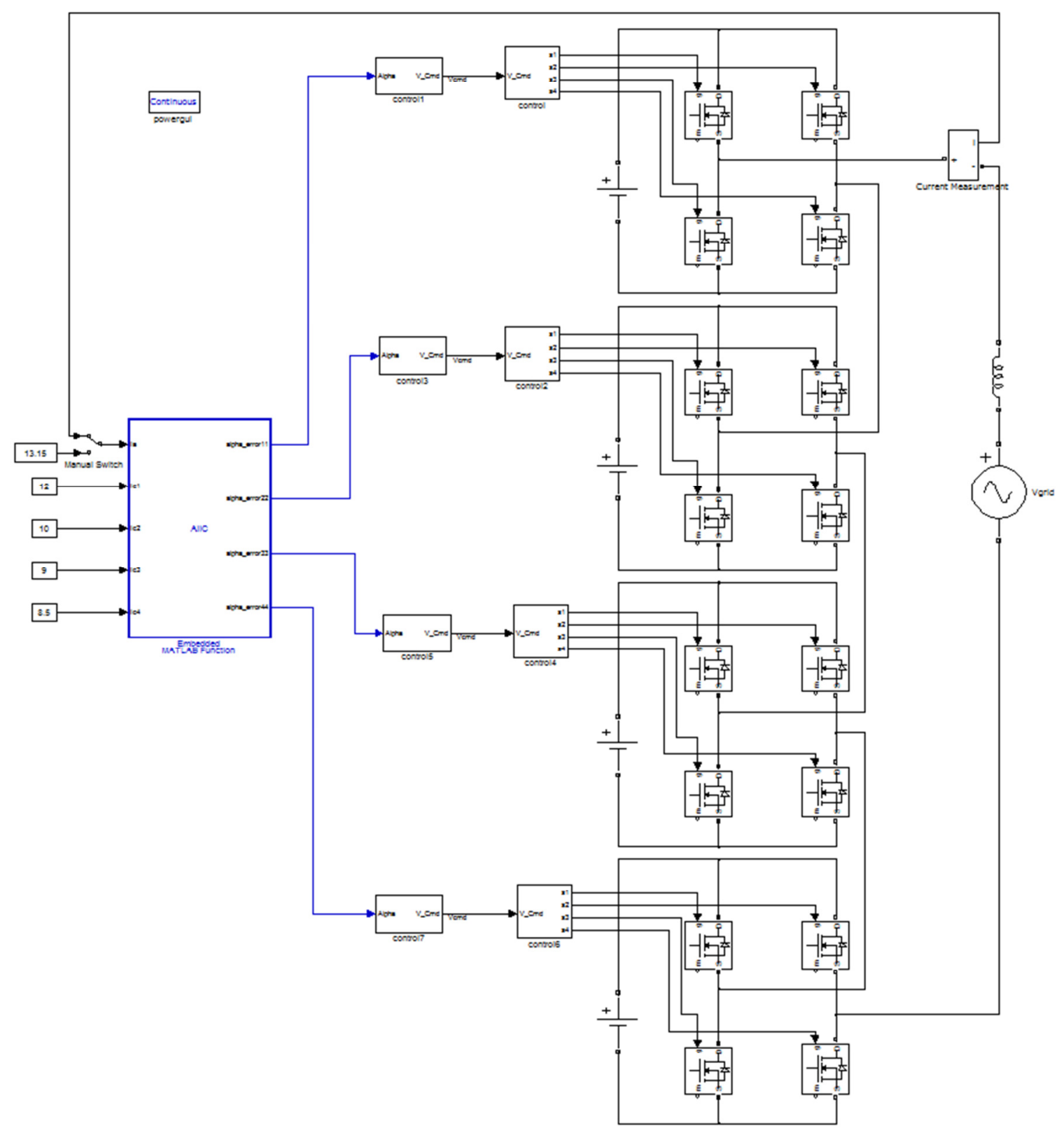




\section{APPENDIX B}

\section{SCHEMATICS \& PCB LAYOUTS}

\section{B.1 Schematics of the Gate Driver Circuit}
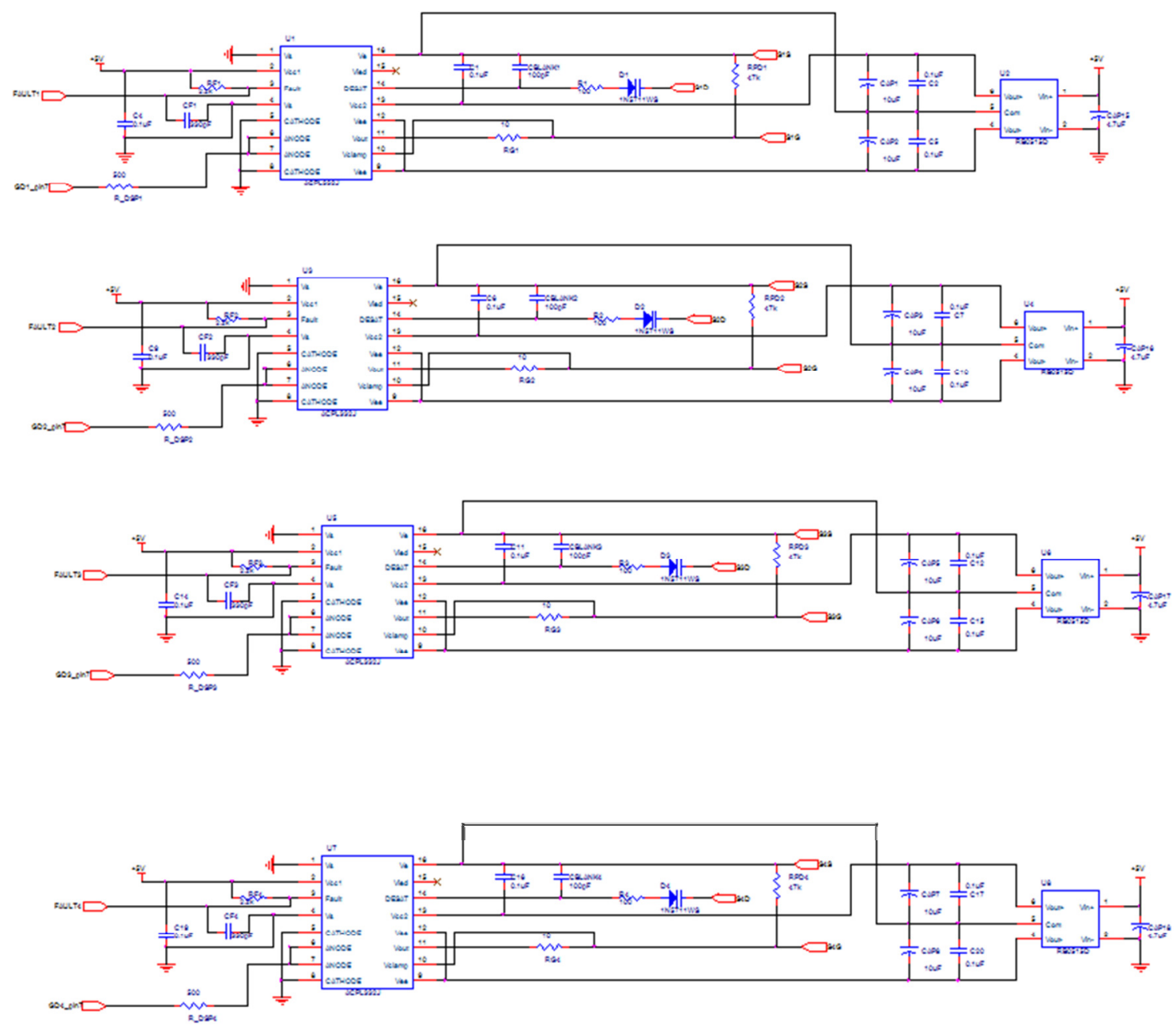


\section{B.2 Schematics of the H-Bridge Inverter Moidule}

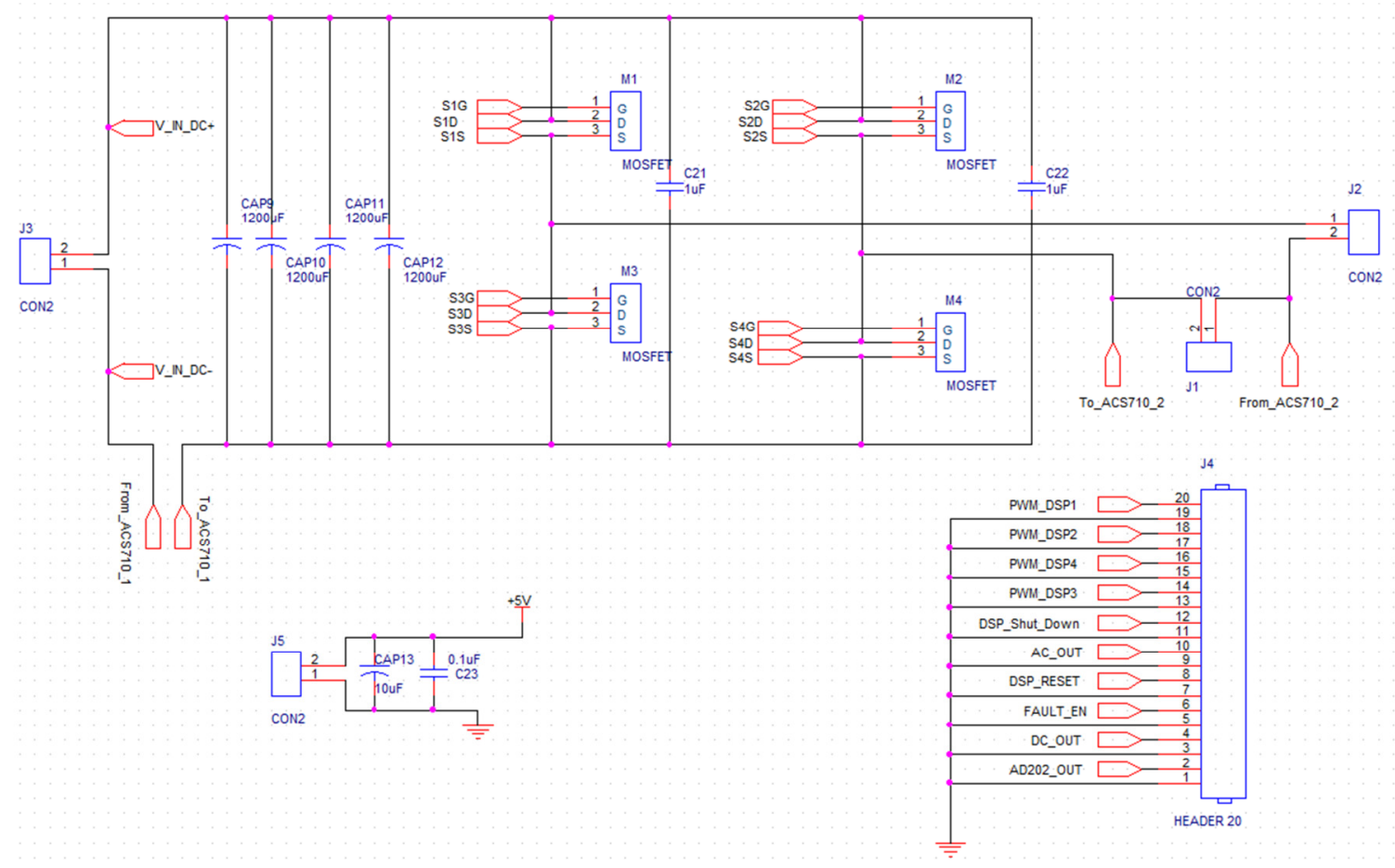




\section{B.3 Schematics of the Fault Protection and Detection Circuitry}

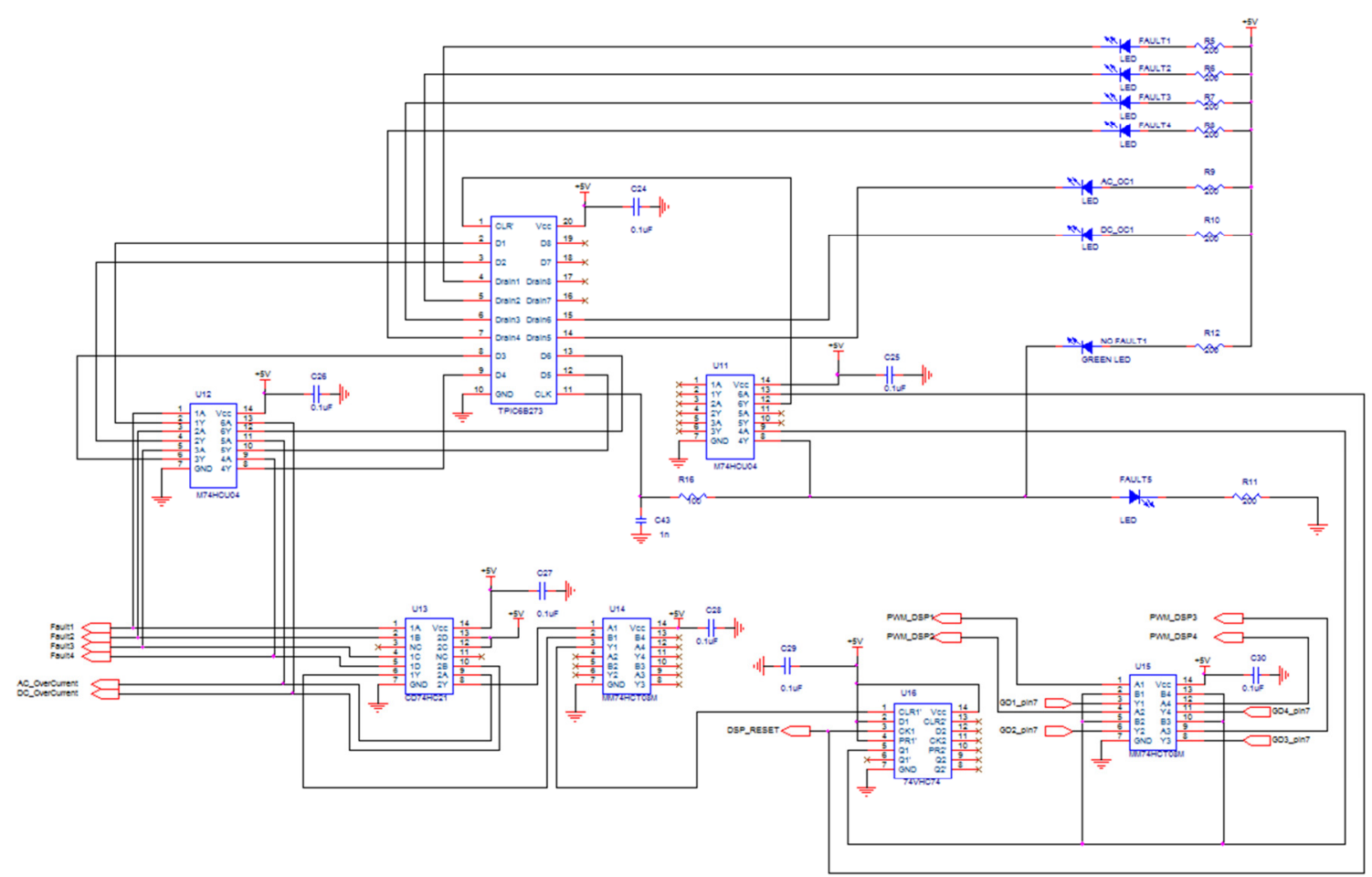




\section{B.4 Schematics of the Current Sensor Circuitry}

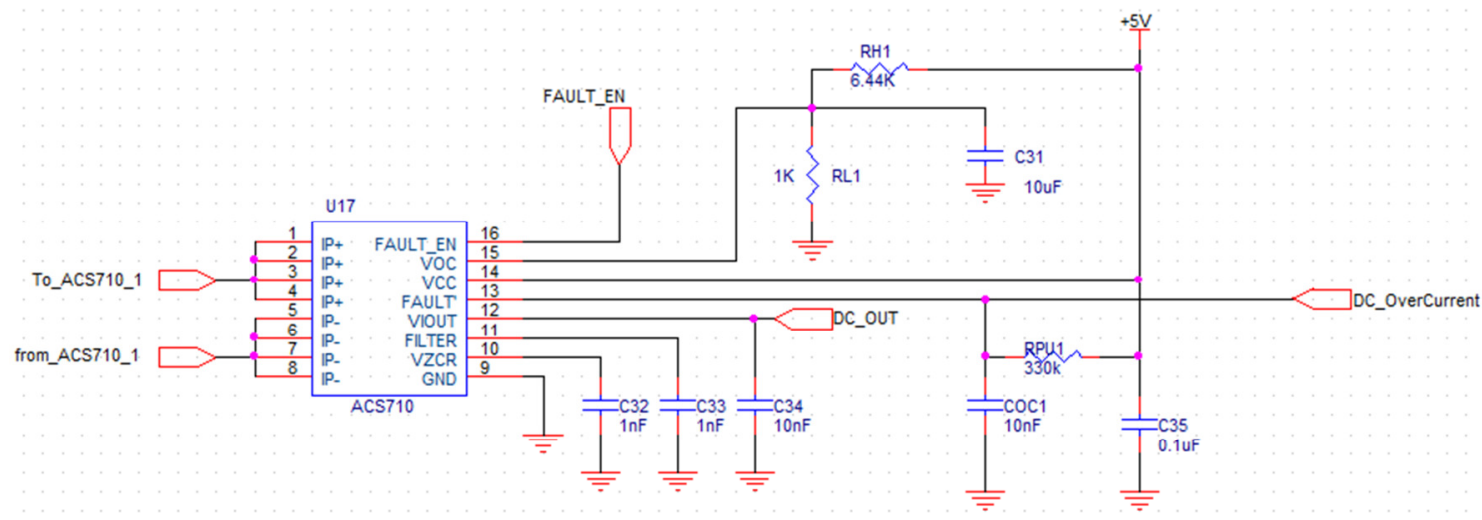

\section{B.5 Voltage Sensor Circuitry}

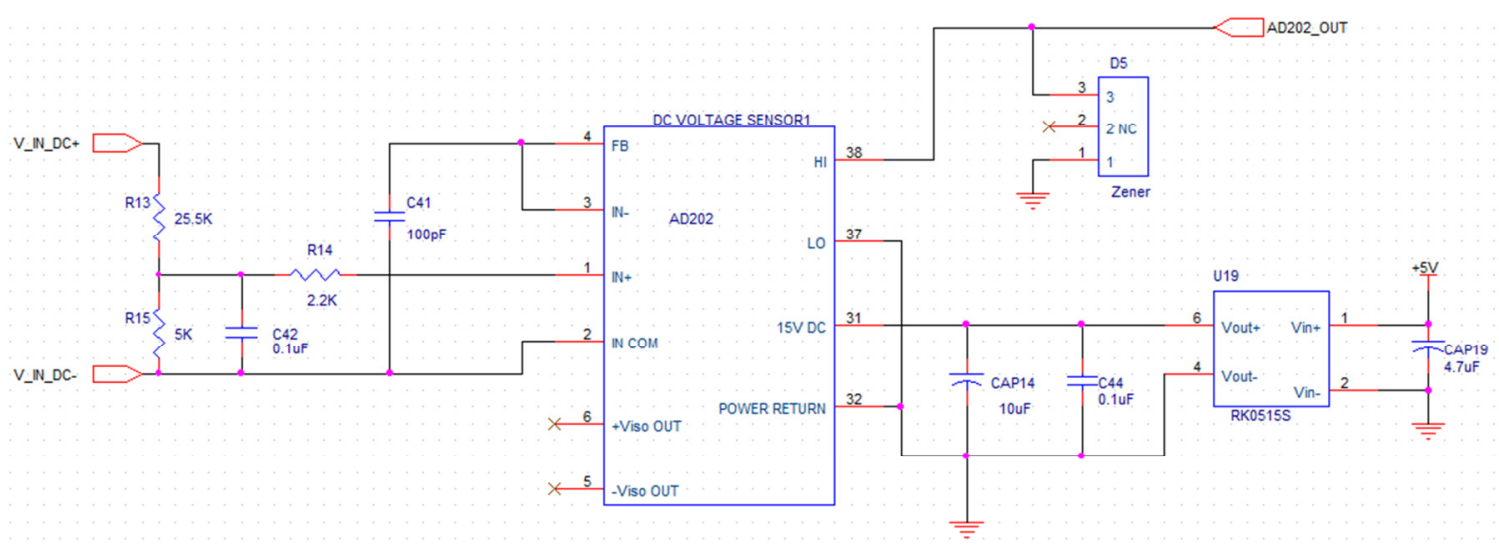


B.6 PCB Layouts

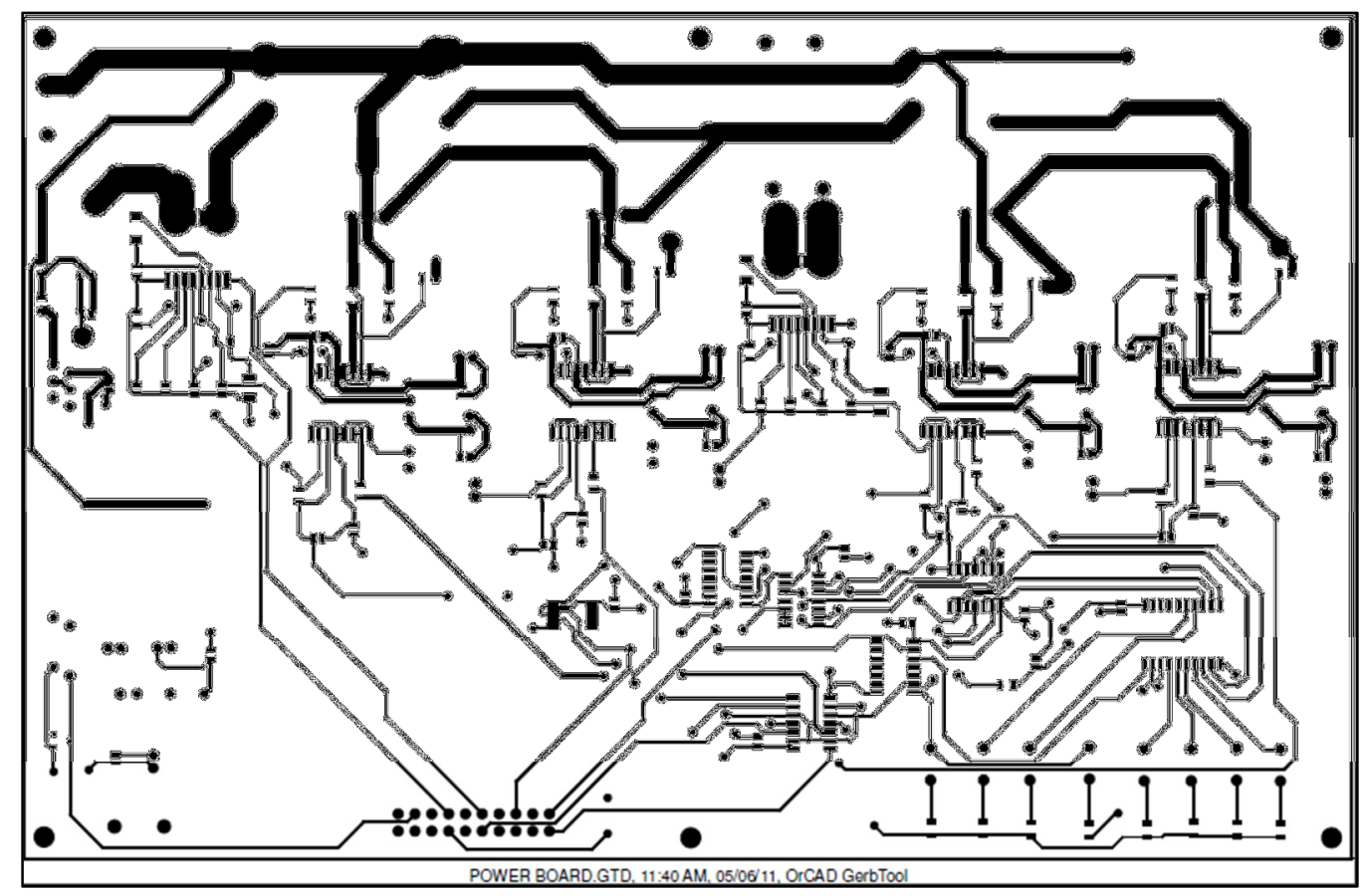

Top Layer

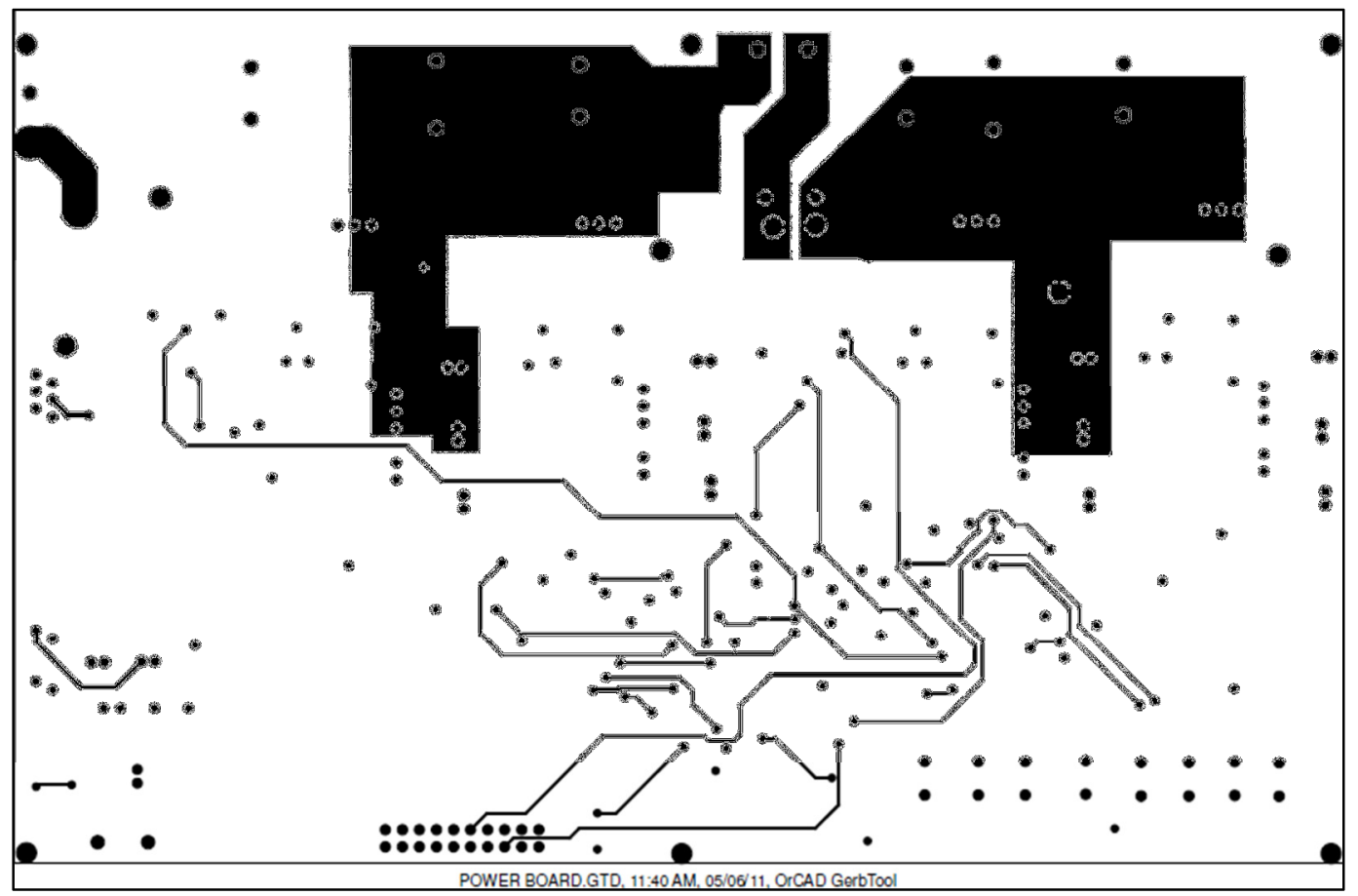

Inner 1 Layer 


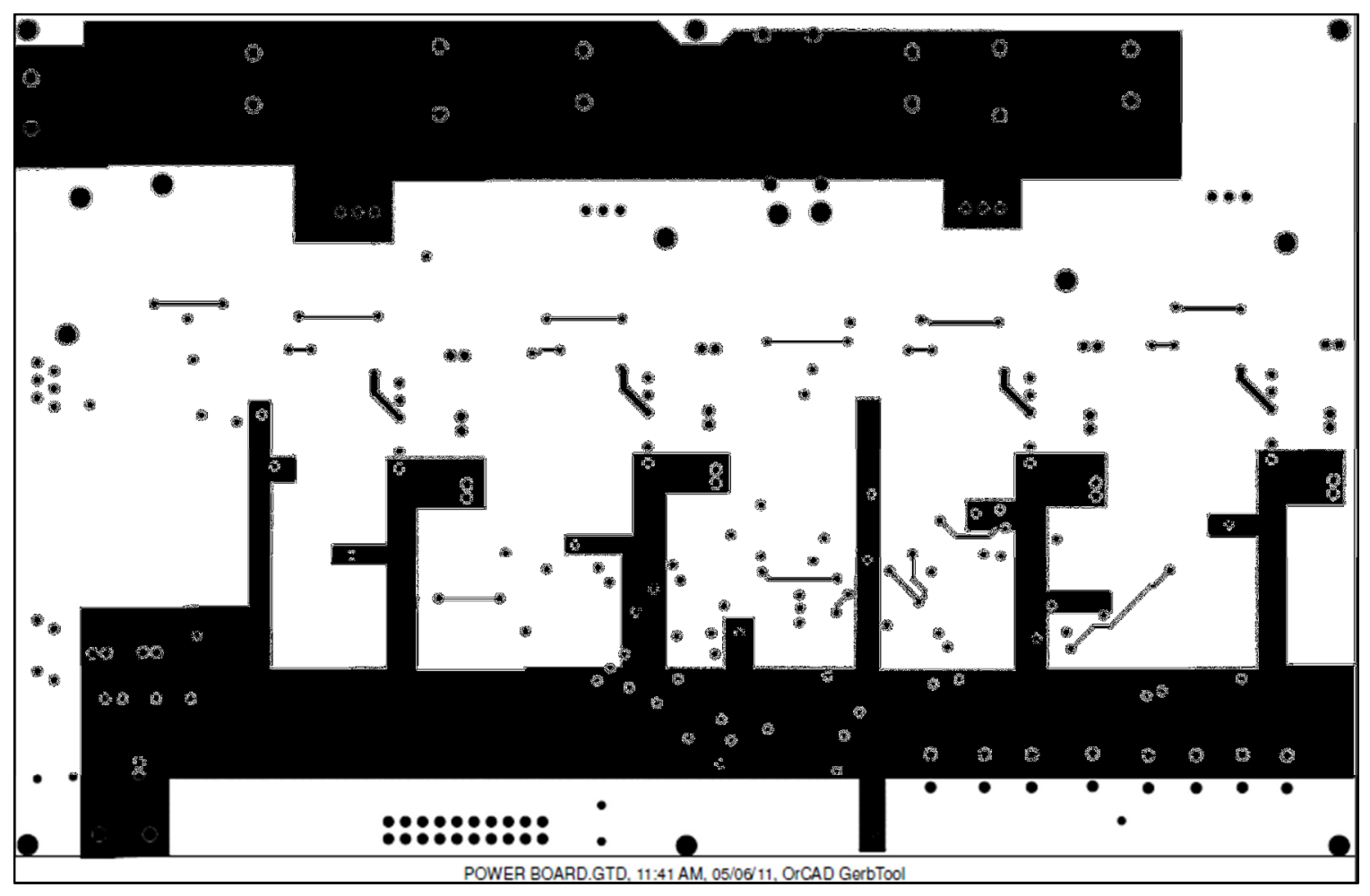

Inner 2 Layer

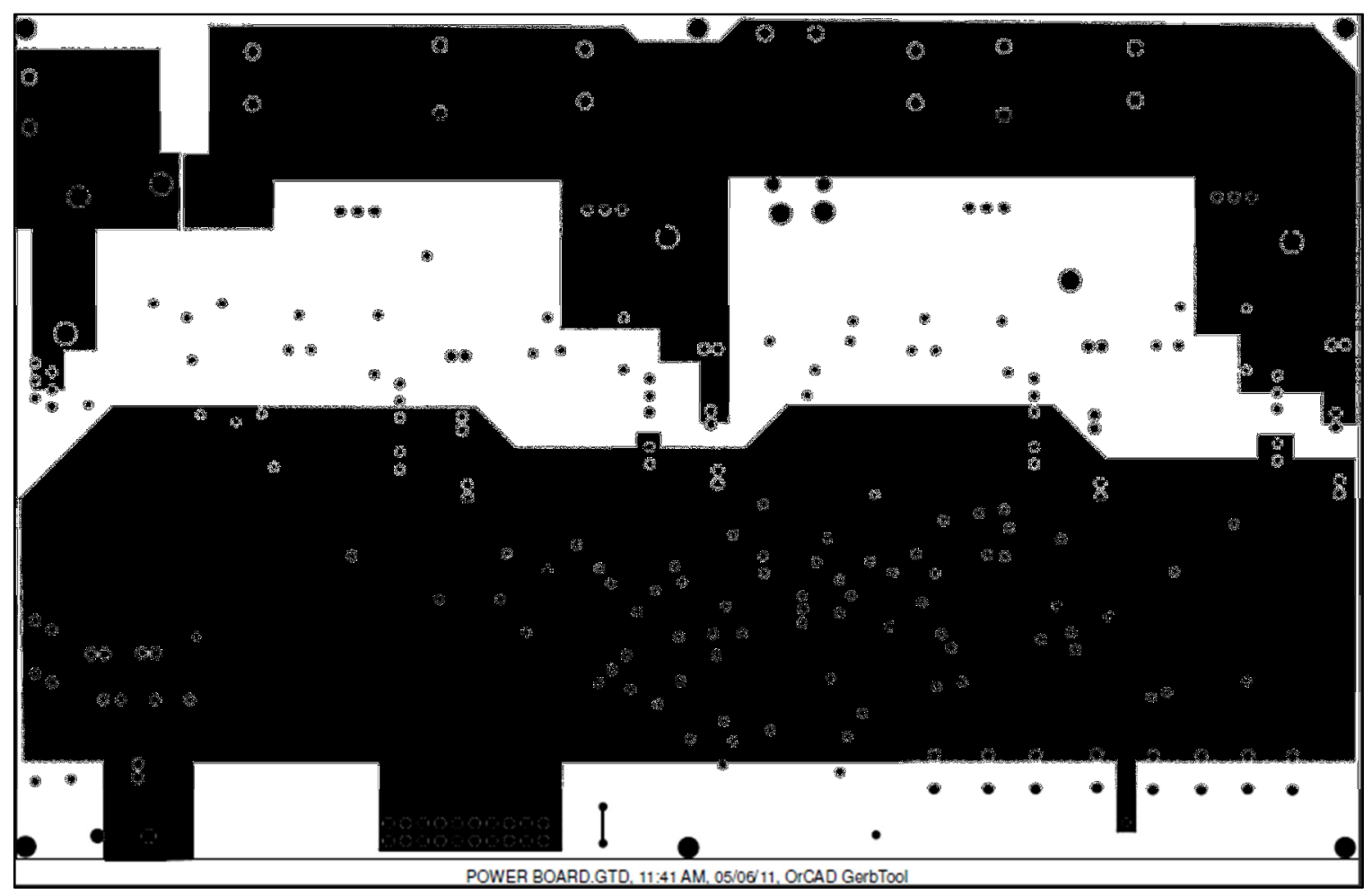

Bottom layer 